\title{
WestVirginiaUniversity
}

THE RESEARCH REPOSITORY @ WVU

Graduate Theses, Dissertations, and Problem Reports

2012

\section{Real-Time Load Frequency Control for an Isolated Microgrid System}

Moataz A. Elbaz

West Virginia University

Follow this and additional works at: https://researchrepository.wvu.edu/etd

\section{Recommended Citation}

Elbaz, Moataz A., "Real-Time Load Frequency Control for an Isolated Microgrid System" (2012). Graduate Theses, Dissertations, and Problem Reports. 3510.

https://researchrepository.wvu.edu/etd/3510

This Thesis is protected by copyright and/or related rights. It has been brought to you by the The Research Repository @ WVU with permission from the rights-holder(s). You are free to use this Thesis in any way that is permitted by the copyright and related rights legislation that applies to your use. For other uses you must obtain permission from the rights-holder(s) directly, unless additional rights are indicated by a Creative Commons license in the record and/ or on the work itself. This Thesis has been accepted for inclusion in WVU Graduate Theses, Dissertations, and Problem Reports collection by an authorized administrator of The Research Repository @ WVU. For more information, please contact researchrepository@mail.wvu.edu. 


\title{
Real-Time Load Frequency Control for an Isolated Microgrid System
}

\author{
Moataz A. Elbaz \\ Thesis submitted to \\ The College of Engineering and Mineral Resources \\ at West Virginia University \\ in partial fulfillment of the requirements \\ for the degree of \\ Master of Science \\ in \\ Electrical Engineering
}

Ali Feliachi, Ph.D., Chair

Muhammad Choudhry, Ph.D.

Sarika Solanki, Ph. D.

Department of Computer Science and Electrical Engineering

\author{
Morgantown, West Virginia \\ 2012
}

Keywords: Microgrid, Load Frequency Control, Energy Storage Systems, Model Predictive Control 


\title{
Abstract \\ Real-Time Load Frequency Control for an Isolated Microgrid system
}

\author{
By \\ Moataz A. Elbaz \\ Master of Science in Electrical Engineering \\ West Virginia University \\ Ali Feliachi, Ph.D., Chair
}

Microgrids are small power grids with distinct operation characteristics; they can operate either independently or connected to larger grids, and usually a significant proportion of their generation capacity is comprised from intermittent resources such as solar and wind power generations. Power grids, in general, must operate such that the power generation and power demand are balanced at all times. Such balance is attained by implementing a Load Frequency Control (LFC) mechanism. The goal of LFC in a microgrid system is to maintain the system's frequency within acceptable limits around nominal value under various conditions, such as fluctuating power demand and/or contingency situation such as unexpected loss of one or more of the system's generating units, in order to ensure system's stable operation. In case of small and isolated microgrid systems, however, the stability of the microgrid system is an issue of much greater significance as there are no means of connecting to primary grid power. The objective of this thesis is to design a Load Frequency Control (LFC) mechanism using Battery Storage System (BSS) and Diesel Generation (DG) units for an isolated microgrid system. The microgrid system under consideration is comprised from two DG units, a BSS unit, and two solar panels. The proposed LFC mechanism is implemented in a decentralized fashion. It was tested under different operation conditions; fluctuating power demand which represents the normal operation of power systems, and emergency situations where one of the system's generation units was lost in each case. Results show that the proposed control systems were robust and successful to regulate the system's frequency under all conditions. The microgrid model as well as the proposed control strategy is developed within the Simulink and SimPowerSystems environments. 


\section{Acknowledgements}

First of all, I would like to thank Allah for his great help, continuous guidance and support. This work would have been impossible without his help and support.

I would like to take an opportunity and express my gratitude to my adviser Professor Ali Feliachi for his guidance throughout this work. His help, support, creative ideas and suggestions made it more valuable.

I would also like to thank Professor Muhammad Choudhry and Dr. Sarika Solanki for serving on my examining committee.

Finally, my deepest gratitude goes to my parents and my elder brother Hosam for always being there for me. Their endless love and support lighted the way for me. 


\section{Contents}

1. Chapter 1: Introduction 1

1.1 What is a microgrid? .............................................. 1

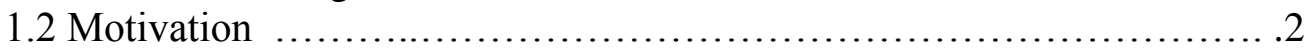

1.3 Problem Statement ................................................. 4

1.4 Thesis Outline..................................................... 4

2. Chapter 2: Literature Survey 5

2.1 Background on Energy Storage System........................... 5

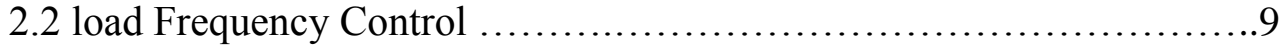

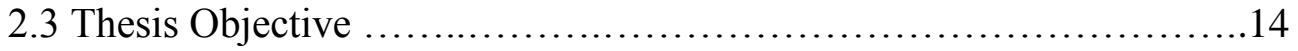

3. Chapter 3: System Modeling 15

3.1 Diesel Generator ................................................ 15

3.1.1 Modeling of Diesel Engine ................................... 15

3.2 Photovoltaic System ............................................... 19

3.2.1 Modeling of Photovoltaic System ..............................20

3.3 Battery Storage System .........................................26

3.3.1 Modeling of BSS ...........................................26

4. Chapter 4: Model Predictive Control 30

4.1 Background .....................................................30

4.2 Prediction Based on a Step Response ................................ 32

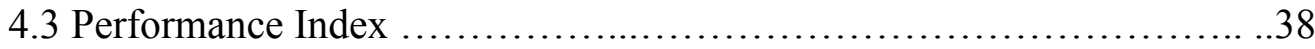

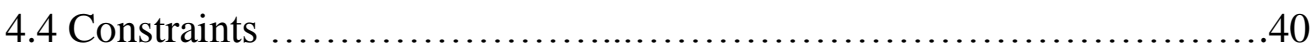

4.5 A MPC Algorithm................................................44 
5. Chapter 5: Control Design and Simulation Results

5.1 Control Design ..................................................... 46

5.1.1 Diesel Generators .............................................. 46

5.1.1.1 MPC Controllers Design .........................................49

5.1 .2 Grid-connected Battery System ….............................50

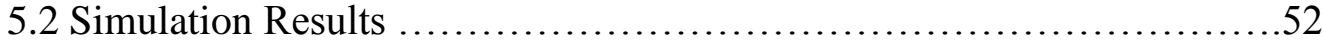

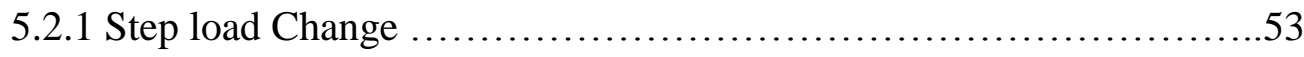

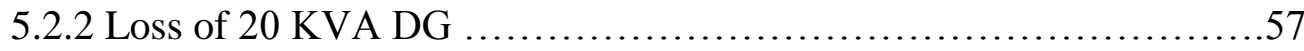

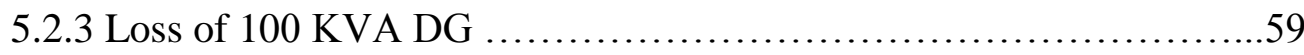

Conclusion $\quad 63$

References $\quad 65$

Appendix A: Simulink and SimPowerSystems

Models

69 


\section{Chapter 1}

\section{INTRODUCTION}

This chapter is an introductory chapter. It will start by defining microgrid system. Next the motivation for this work is presented. Then the problem statement, and finally the outline of this thesis and how it is organized.

\subsection{What is a microgrid?}

Generally, a microgrid is a small power grid. There is no agreement on an exact size or a specific structure for a microgrid. Chowdhury, et al in [1] define microgrids as smallscale, Low Voltage Combined Heat and Power (LVCHP) supply networks designed to supply electricity and heat loads to a small community, such as a housing estate or a suburban locality or an academic or public community such as a university, an industrial site, a trading estate or a municipal region. The microgrid could be a portion of an electric power distribution system that is located downstream of the distribution substation, or could be a small independent power grid of an island or a remote area which has limited or no access to primary grid power.

The microgrid concept provides a platform for incorporation of several Distributed Energy Resources (DERs), which include both Distributed Generation (DG) and Distributed Storage (DS) units [2], [3]. Distributed generation units encompass both dispatchable units such as micro gas turbines, diesel generators, and combined heat and power units, and non-dispatchable generation units; typically renewable energy resources such as solar and wind power generations. DG units bring several advantages from grid point of view such as deferring investments in generation, transmission or distribution facilities and reducing electrical losses, and from end user point of view such as increased level of supply reliability. One of the main advantages of renewable energy resources, such as solar and wind generations, is the reduction of environmental pollution and global warming since no gaseous emissions result from such generations. Figure 1 shows an example for microgrid system architecture. In the shown architecture, the microgrid encompasses different kinds of loads as well as different kinds of generations. 


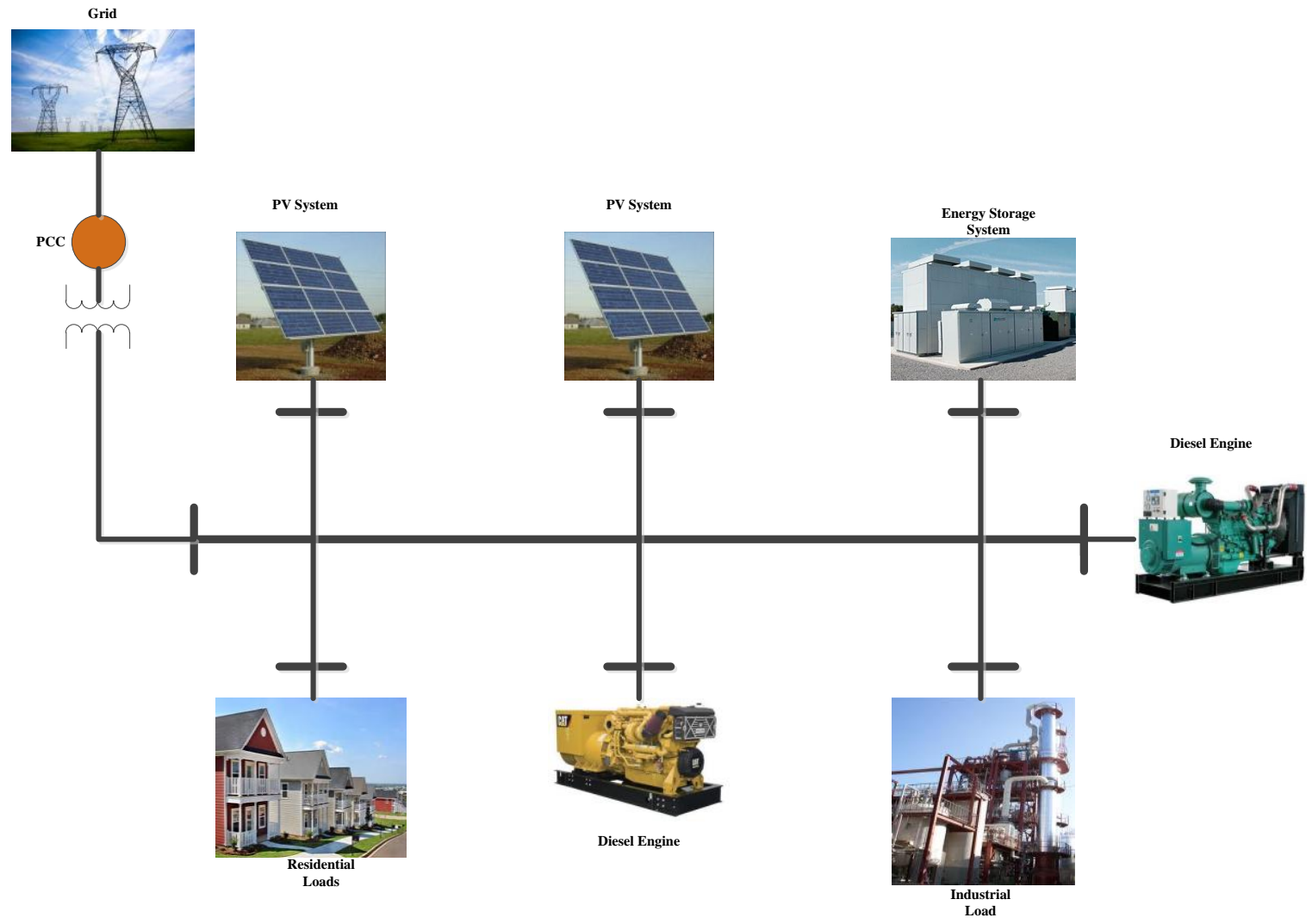

Figure 1.1 Example of a Microgrid system

\subsection{Motivation}

Although various advantages of microgrids arise from their capability of operating in grid connected mode as well as islanded operation, such as local reliability improvement and deferring investments in transmission or distribution facilities, and led to their proliferation over the last few years, it is very important to shed light on the fact that microgrids are not without flaws. These flaws are obvious when comparing microgrids to large power grids from operational point of view, and challenging especially when microgrids have no connection to primary power grids. The key differences between microgrids and conventional large scale power systems dictate the development of robust energy management and control algorithms appropriate for the microgrid system depending on its structure. 
The main differences according to [2] are that a microgrid may have:

- High proportion of intermittent or weather dependent resources e.g. solar, and wind power generations.

- Negligible internal inertia of its distributed generation units.

- Generators which have very distinct steady-state and dynamic characteristics compared to those of the conventional large generator units.

From the mentioned differences it is obvious that, depending on the structure of the microgrid system, generation might not be predictable with certainty since intermittent resources such as wind and solar power generation constitutes a considerable portion of the system's total generation. In some preceding studies the penetration level of renewable resources in the network was up to $20 \%$. Moreover, the power consumption in a power system is usually not level. An increase in the power consumption has the same effect on the system's frequency as a decrease in the power generation and vice versa. At all times, the system must be operated in such a way that there is a balance between generation and consumption. If this balance is violated, then the system's frequency will deviate from the nominal value $(60 \mathrm{~Hz}$ in US) which could result in system instability. Load Frequency Control (LFC) is implemented in order to maintain the balance between generation and consumption. The objective of LFC is to maintain the frequency at nominal value. Traditionally LFC uses Proportional-Integral (PI) type of controllers due to their simple structure and robust performance. Several techniques were proposed for tuning the gains of PI controllers. Heuristic approaches, such as Genetic Algorithm (GA), were commonly used in gain tuning where a search space is defined, and a population searches inside that space for the optimal solution. In such approaches, however, finding the solution is primarily dependent on how the search space is defined, the number of population and other factors, and there is no guarantee an optimal solution will be found. Other tuning approaches require extensive field measurements, and usually based on trial-and-error approach.

Model Predictive Control (MPC) is a control technique based on a system model, where an optimization procedure is performed in every sampling interval calculating an optimal control action. MPC has been proved as a powerful control technique in process industry over the last decade. One of the main reasons MPC gained high popularity is that it can handle constrains on control as well as system states and/or output variables. The next section of this chapter is a statement of the problem which this research is dedicated to address. Finally the chapter is concluded by describing the organization of this thesis. 


\subsection{Problem Statement}

In order to ensure a stable operation for a power system, it is crucial to have an automated and robust LFC mechanism to ensure a balance between power generation and consumption under all circumstances; fluctuating power demand which represents the normal operation of power systems, and emergency conditions when one or more of the system's generation units is suddenly lost, especially for isolated systems where there are no means of getting help from large grids. Attaining real-time matching between generation and consumption for small and isolated power systems comprised of small DG units and renewable energy sources subject to such circumstances is an issue of great significance. The increasing integration of ESSs, however and their excellent capability of providing LFC will sooner or later necessitate the contribution of ESSs in LFC. This thesis will focus on addressing the matching between generation and consumption in an isolated small power system using a battery storage system. The problem is to design robust control mechanism for the battery unit so that it will track frequency deviations and regulate system's frequency under the above mentioned operation conditions. The simulation model is developed in the Simpowersystems environment. It will be explained in detail in chapter 3. The objective of the thesis is presented in the last section of the next chapter.

\subsection{Thesis Outline}

Chapter 2 of this thesis is a literature survey; the chapter starts by a background on incorporating energy storage systems especially Battery Energy Storage Systems (BESS) in power grids. Next the chapter will discuss previous research on LFC in small isolated microgrids. Finally, the last section of this chapter will be the objective of this research. Chapter 3 describes the modeling of the different parts of the system in this study. Chapter 4 presents a simple example of MPC based on a step response as well as problem formulation Chapter 5 discusses the different case studies performed, and the results obtained, and finally the conclusion of this work. 


\section{Chapter 2}

\section{LITERATURE SURVEY}

In this chapter, a literature survey of preceding studies related to frequency regulation of small power systems is given. The chapter starts by a background on incorporating energy storage systems in power grids. Next the chapter will discuss previous research on LFC in small isolated microgrids. Finally, the last section of this chapter will be the objective of this research.

\subsection{Background on Energy Storage Systems}

The research and development efforts in energy storage technologies were actually triggered in the early 1970s due to the Arab oil embargoes, and the increasing implementation of nuclear power [4]. The United States considered the oil embargoes a national crisis, and alleviating the dependence on imported oil was vital. Since the power industry is one of the main consumers of fossil fuel, bulk energy storage technologies gained great considerations. The goal of implementing such technologies was to save on oil, and gradually displace oil-fired generations. Moreover, due to the increasing implementation of nuclear power generations, the predictions that nuclear power generating capacity would exceed the minimum utility power requirements, and the slow response when regulating the power generated from such stations, the solution was selfevident; to store energy at surplus times, and use it later for regulation purposes. The authors in [5] presented an estimation of the installed capacities of energy storage worldwide, and in United States in 2011. Figure 2.1 shows an estimation of installed capacities in the global grid. Figure 2.2 shows the installed capacities in the global grid excluding Pumped Hydro Storage. Figure 2.3 shows an estimation of installed capacities in U.S grid. Figure 2.4 shows installed capacities in U.S grid excluding Pumped Hydro Storage. 


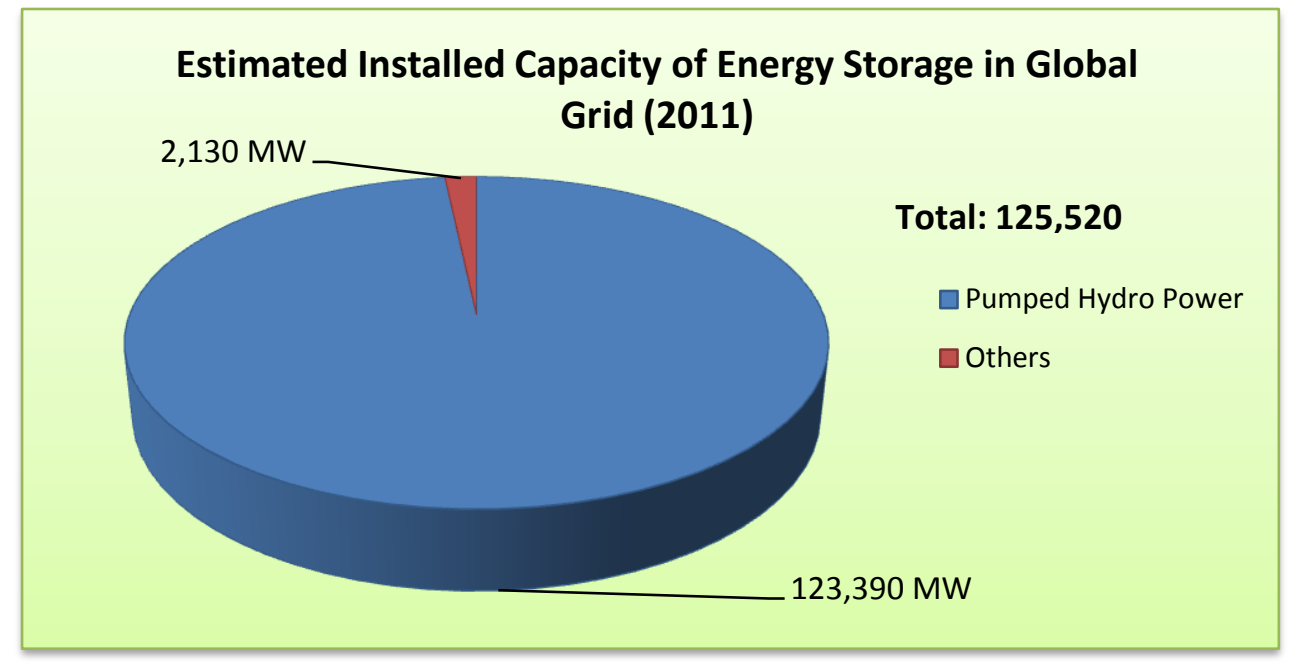

Figure 2.1 Installed Capacities of Energy Storage in Global Grid (2011)

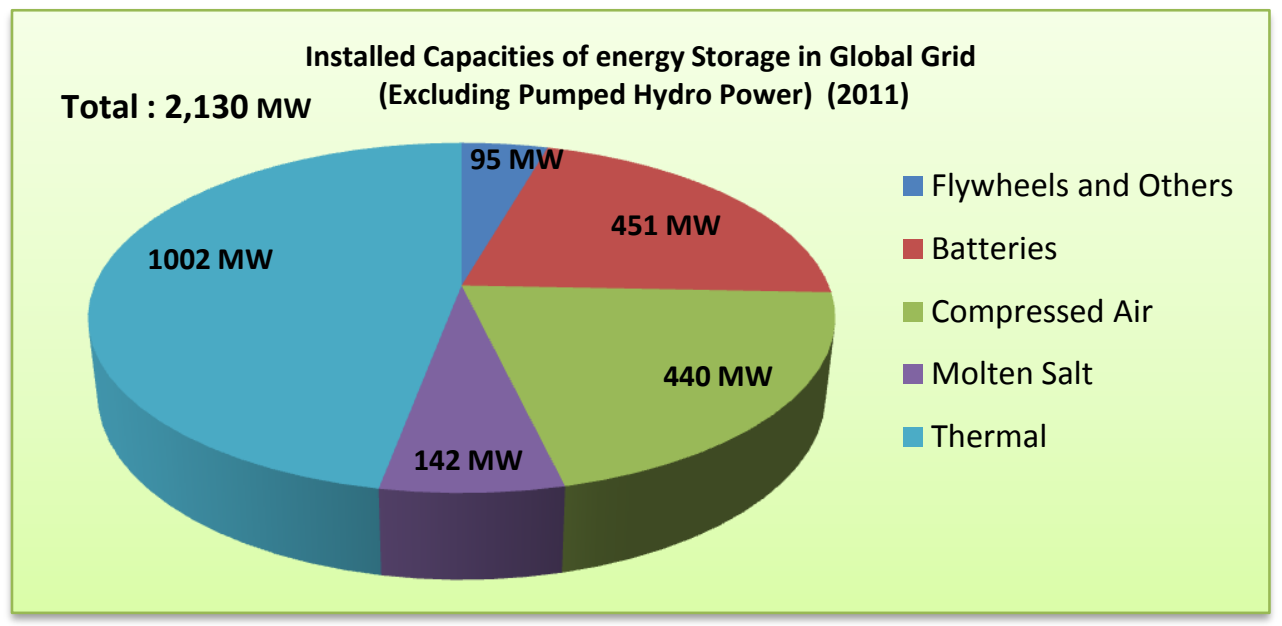

Figure 2.2 Installed Capacities of Energy Storage in Global Grid excluding Pumped Hydro Power (2011) 


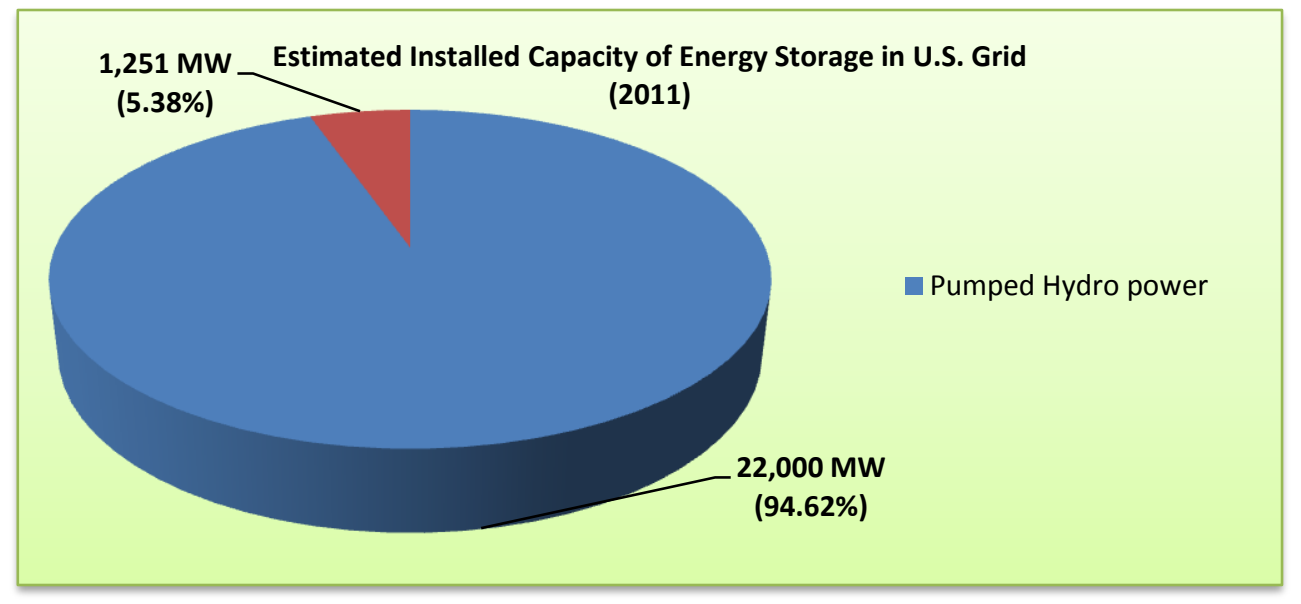

Figure 2.3 Installed Capacities of Energy storage in U.S grid (2011)

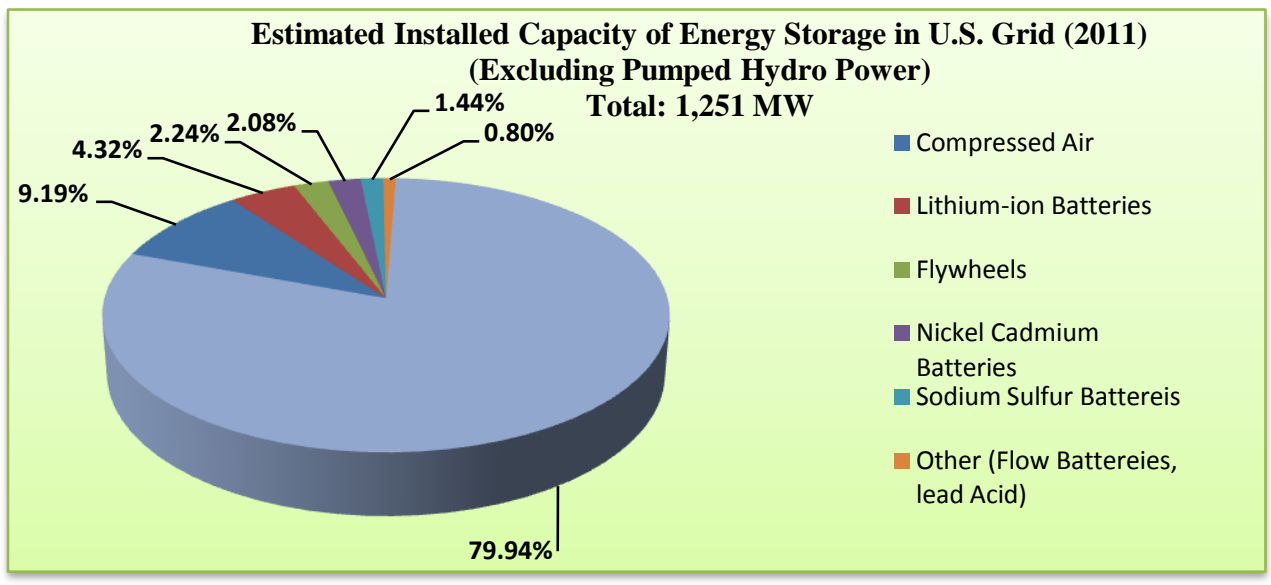

Figure 2.4 Installed Capacities of Energy Storage in U.S grid excluding Pumped Hydro Power (2011)

Integration of Energy Storage Systems (ESSs) in electric power systems provides several advantages from reliability, and security point of view. Several preceding studies pointed out the advantages of incorporating ESSs in power systems and especially small isolated power systems. In [6], Kottick et al studied the effects of a $30 \mathrm{MW}$ Battery Energy Storage System (BESS) on the frequency deviations of the Israeli island power system. They point out that ESSs, in general, impose benefits in peak shaving, and load leveling applications. In [7], Oudalov et al provided an overview of different energy storage technologies and their possible applications in power systems. The authors mentioned that energy storage technologies provide the means of a wide spectrum of power system applications, ranging from power quality to energy management. 
Nowadays, the electricity market deregulation has led to escalating penetration of discontinuous distributed power generations, such as solar and wind power, in the power grid. Such intermittent generations push towards the need for more storage capabilities. Furthermore, the perpetual load growth consequents a stressed and less secure power system operation. Hence, utilities and Transmission System Operators (TSOs) are now more interested in ESSs to provide economical as well as technical advantages such as: reliability improvement, providing stability, and congestion management [8]. It is projected that the implementation of ESSs will significantly increase over the next decade due to their various advantages, and technologies. The Electricity Storage Association commissioned a study in 2010 which depicted that distributed storage systems could reach an installed capacity of about $18 \mathrm{GW}$ by 2020 [5].

Among various energy storage technologies, BES technologies stand up as one of the most popular ways of storing energy. They are distinct by their availability, wide range of sizes, and not limited by topography like Pumped Hydro Storage as well as the capability of being integrated as a centralized facility or distributed facilities throughout the system which makes them ideal for different kinds of systems especially remote and isolated power systems. Furthermore, they are a modern cost-effective solution that can help both electric utilities and industrial and commercial businesses to meet the growing need of controlling peak energy usage, power quality and environmental problems [10]. In [9], Lasseter et al summarized the advantages of integrating a BESS in microgrid systems as follows:

- Allows time shifting between generation and energy consumption.

- Bi-directional power flow capabilities i.e. the ability to send and receive power.

- Can provide a certain amount of immediately available power to reduce the need to ramp generators up or down, which reduces the maintenance cost of generators as well as carbon emissions.

- Can act as an Uninterruptible Power Supply (UPS) system during grid faults, providing backup power while the microgrid is islanded from the main grid.

There is a tremendous amount of advantages in integrating BESSs in power grids. Several preceding studies investigated the benefits of BESS from technical as well as economical point of view. In [4] Cook et al provided an estimation of the potential dollar value of benefits, of BESSs integration, which might be obtained by a typical utility. The authors categorized these benefits into generation related, and transmission related benefits. The future of BESS lies in multitasking, where a singular modular and flexible unit can do peak shaving, load leveling, frequency control, and load management [8]. Figure 2.5 depicts the installed capacities of different BESS technologies in U.S. grid (2011) [5]. 


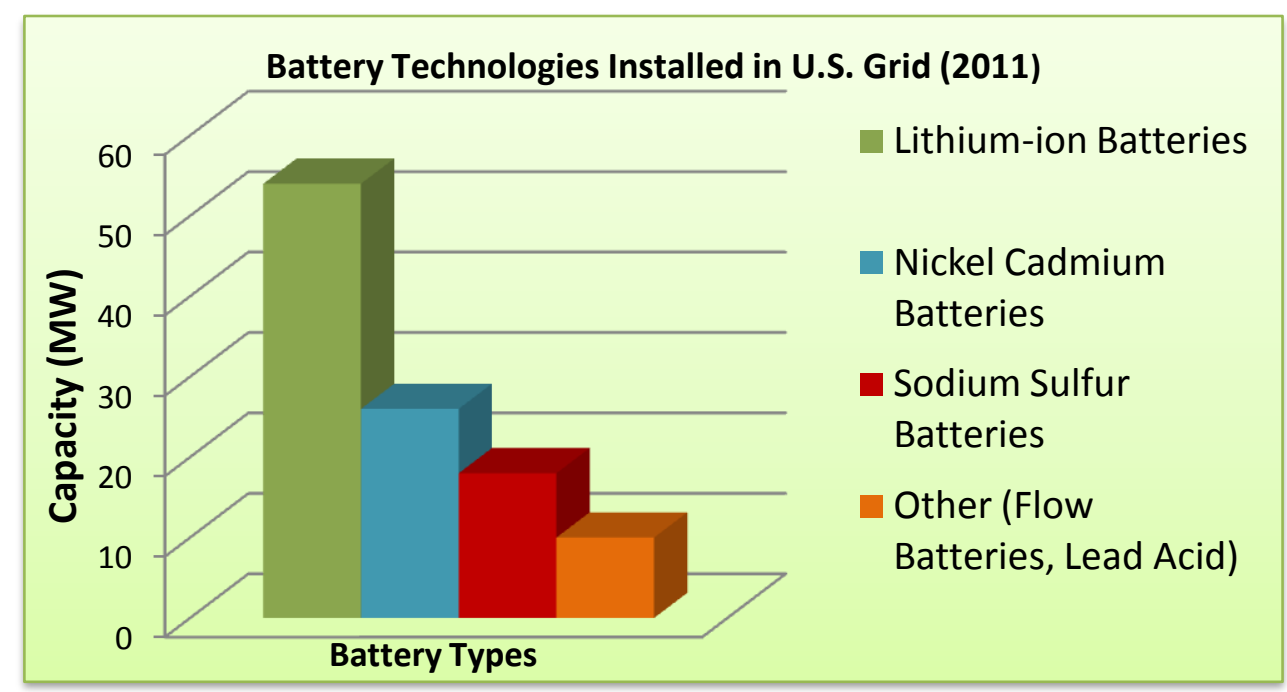

Figure 2.5 Installed Capacities of different BESS technologies in U.S. grid (2011)

\subsection{Load Frequency Control (LFC)}

In this section a survey of studies related to development of LFC, and power management techniques in micorgrid systems will be given.

Generally, when operating a power system, continuous changes in demand must be accompanied by adequate changes in generation to maintain the balance between generation and consumption. Such balance and maintaining the system's frequency at nominal value could be thought of as two faces for one coin. The grid's frequency will deviate from its nominal values whenever such balance violated. Since the load can change at any time or any event, such as a fault or a sudden loss of a generating unit, could happen unexpectedly it is crucial to have an automated and robust balancing mechanism to adjust the power generation. The need of such mechanism is more significant when the system is isolated, for example an island in the middle of an ocean, a small rural area, and has no means of connecting to primary grid power.

Several preceding studies presented different techniques of providing power management and/or LFC for small microgrids. Kottick et al in [6] and Mercier et al in [8] investigated the feasibility of using BESS as a spinning reserve for frequency control application in an isolated power system. In [6], the authors quantified the effects of a 30 MW BESS on frequency deviations in the Israeli island power system. According to the authors a series of measurements were conducted by the Israeli Electric Corporation including frequency and total generated power in order to determine the magnitude of the load disturbances, and performance parameters required from the BESS. Results depicted that frequency deviation was reduced dramatically when the BESS was discharged right 
after sudden load increase by $30 \mathrm{MW}$. In [8], the authors presented an operation as well as sizing methodology of a BESS. Simulations were performed on a load-frequency control model of the isolated network implemented in Simulink environment. According to the results, the frequency deviations without the BESS reached a peak value of 0.49 $\mathrm{Hz}$. After the incorporation of the BESS, the frequency deviation peak was reduced to $0.13 \mathrm{~Hz}$ i.e. frequency damping improved by almost a factor of 4 over a period of one month. Furthermore, the authors presented an optimization procedure for the BESS operation with the objective to maximize the operating benefit using the Net Present Value (NPV) as a performance index. The study focused primarily on the commercial aspect of BESS operation. Both [6] and [8] showed that the charge and discharge of BESS in accordance of the system load can significantly improve the frequency deviations. However, they did not present a coordination control mechanism which would coordinate the BESS and the generated power from other units. Watson and Kimball in [12], and Pappu et al in [13] proposed frequency regulation methodology in a microgrid system using solar power. The proposed methodology is based on tracking a fraction of the Maximum Power Point (MPP) of the Photovoltaic arrays (PV arrays). Hence, a power margin is kept as a reserve for regulation purposes. However, extracting a fraction of the MPP isn't the most efficient utilization of solar power. Furthermore, such technique for LFC is not adequate as intermittent sources are not always available by nature, and can change at any time unexpectedly. Thereby, all available output must be taken when it is available and either stored or transported over transmission lines where it can be used.

In [14] Brokish developed a load shedding technique for frequency regulation in a microgrid environment called FAPER (Frequency Adaptive Power and Energy Reschedules). This technique uses appliances, such as air conditioners and refrigerators, as energy storage units triggered by the grid frequency signal. According to the author energy consumption of such appliances could be shed off during peak hours, and they can maintain a temperature range during that period. However, the timing of shedding signal may not be appropriate with the appliance cycle. An air conditioner, for example, must be operated first for a certain time in order to be off for a certain time such that the temperature bounds specified by the customer are not violated. If the shedding signal coincides with the operation time of the appliance, then a strong possibility of customer inconvenience arises. Furthermore, these appliances are not a good candidate for energy storage and LFC application since they are not capable of bi-directional power flow i.e. they cannot send and receive power from the grid like BESSs. Thereby, they don't offer the same amount of benefits to the grid as BESSs offer and they are not adequate for LFC. In [15] Oudalov et al presented a methodology for sizing a BESS to provide a primary frequency reserve in UCTE (Union for the Coordination of Transmitting Electricity) system. The procedure was developed for a large interconnected power system encompassing a relatively small BESS compared to the total volume of the 
spinning reserve provided by conventional generation. Thus, the impact of the BESS on the system's frequency behavior was widely negligible. The grid's frequency was used as the system's input, and the BESS was considered in an open loop configuration. Explicitly, a given input frequency deviation resulted in small output power to absorb or to inject according to the p-f characteristics.

In [16], Kunisch et al demonstrated the operation of a BESS test facility which was settled in West Berlin after World War two. The authors discussed the problems confronted the supply system of Berlin (West) when it was operated as an isolated system in 1952 and the pushing need for integrating an ESS to address problems like LFC, peak load coverage, and voltage regulation. Investigations came to conclusion that BESS promises both operational and economical advantages for LFC and instantaneous reserve operation.

Papic in [17] developed a simulation model for lead acid battery to assess the feasibility of such technology for daily load leveling. The model was based on the performed battery measurements at constant discharging currents, which were taken from TAB Mezica, battery manufacturer, in Slovenia. The battery was used for spinning reserve and was able to level the amount of active power supplied by the generating unit. In [20] the Redox flow batteries were charged when the system frequency exceeded the nominal and discharged when the frequency dropped below the nominal value. The purpose of these two studies, however, was to test the feasibility of specific battery technologies in charge and discharge processes. Both, like [6] and [8], did not present a coordination control mechanism to coordinate between the system units.

In [18] Mendis et al developed a coordination strategy to coordinate the operation of a BESS and a dummy load with a doubly fed induction generator based wind turbine in a remote area power system to provide frequency and voltage regulation. Two case studies have been conducted: one is based on a simple small signal system model and the other considered the non-linearities in the system. In both cases the authors tested their algorithm at two main instances. Firstly, the wind power was reduced while the load was constant and finally the load was increased while the wind power was constant. Results depicted that the algorithm was able to keep the system's frequency and voltage almost unaffected by the wind power change. However, according to the algorithm, sometimes the surplus power generated from the wind turbine exceeds the battery charging limit. Hence the algorithm dissipated the surplus power in the dummy load.

The authors in [21] proposed hierarchical control architecture for microgrid isolated operation. A PI-based Microgrid Central Controller (MGCC) coordinates between PI-based Local Controllers (LCs) located at each of the micro sources. Frequency profiles when the proposed control architecture and traditional local control scenario (using local PI controller at each micro source without the MGCC) were compared. Results showed that the both cases were able to restore the system frequency at nominal value of $50 \mathrm{~Hz}$. However, from the results shown, the local control structure 
was able to restore to frequency to nominal value faster than the case when the proposed MGCC was used.

Mohamed in [22] and [23] proposed an optimization procedure to optimize the operation cost of microgrid system. The objective of the optimization was to minimize the gaseous emissions from the generating units as well as the operation and maintenance costs. IN [22] he focused primarily on the formulation of the system cost function while in [23] he explained different optimization algorithms he used to solve the problem. Both [22] and [23] were actually solving an economic problem not LFC. The driving force behind minimizing the gaseous emissions was due to the $\$ / \mathrm{Kg}$ charge imposed by the state on these emissions. Furthermore, the author in both studies focused primarily on the case when the microgrid system was connected to the main grid. Little attention was given to the case of the isolated operation.

Majumder [24] and proposed an angle droop control technique to share power amongst converter interfaced DGs in micorgrid. The proposed technique is based on changing the phase angles and the magnitudes of the converters output voltages to control the output real and reactive power from the DGs (figure 2.6). The average active and reactive power $\mathrm{P}$ and $\mathrm{Q}$ from the $\mathrm{DG}$ to the microgrid can be calculated as

$$
\begin{aligned}
& P=\frac{V * V t * \sin (\delta-\delta t)}{X f} \\
& Q=\frac{V^{2}-V * V t * \cos (\delta-\delta t)}{X f}
\end{aligned}
$$

Where:

$\mathrm{V}$ and $\delta$ are the converter output voltage magnitude and angle.

$\mathrm{V}_{\mathrm{t}}$ and $\delta_{\mathrm{t}}$ are the line filter output voltage magnitude and angle.

$\mathrm{X}_{\mathrm{f}}$ is the inductive reactance of the line filter. 


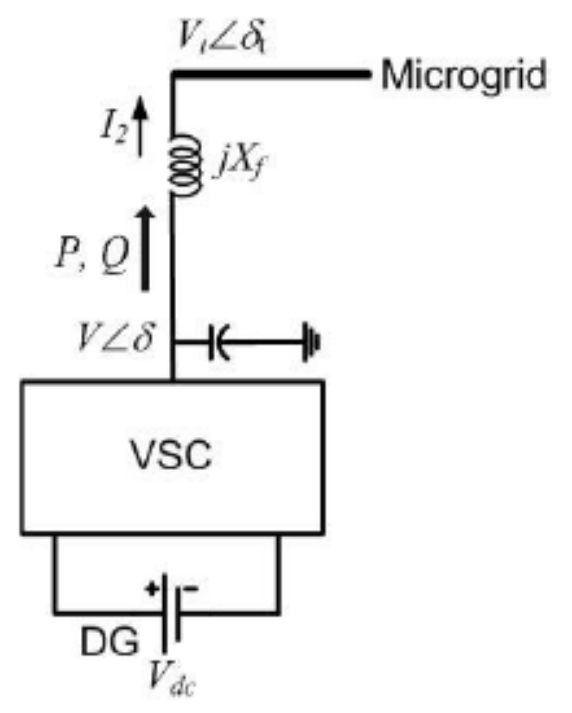

Figure 2.6: DG connection to Microgrid.

According to the proposed technique the amount of active and reactive power injected by the DG into the microgrid can be controlled by controlling the phase angle difference and the converter output voltage magnitude and hence establishing frequency and voltage control for the micorgrid system. Results depicted that the proposed technique was successful in providing frequency control for a simple microgrid system composed of two VSC DGs and a load. The frequency deviation in both DGs was limited between 0.05 and $-0.05 \mathrm{rad} / \mathrm{sec}$ during a constant load changing operation. The proposed technique could provide faster response compared to situation of using frequency-droop control in the VSC DGs. this is because the power electronic converters can change their output voltages magnitudes and angles much quicker than the rotating masses responding to changes in their governors set points. However, the capability of such technique is limited by the level of VSC DGs integrated in the system. Moreover from (2.1) it is obvious there is a strong coupling between $\mathrm{P}$ and $\mathrm{Q}$; changing the angle difference to change the real power output from the DG will impact both the active and reactive power flow, and similar situation for changing the voltage magnitude to control the reactive power which makes the proposed technique not appealing for complicated systems.

The proposed technique in [24] was much similar to what Karlis et al in [25] did. The authors in [25] first presented a simple software simulation for a small power system composed of Hydroelectric and Diesel generators, a PV system, and a Wind Turbine unit. Then a very similar technique to the one proposed in [24] was to change the angle and magnitude of the PV inverter's voltage. The situation is the same as for [12] and [13]. Changing the output power from the intermittent sources is not an adequate mechanism for LFC as their availability is not guaranteed by nature. Leitermann and Kirtley in [26] shed light on the option of providing LFC by sharing the system demand between the ESS and thermal generation units. The authors first discussed how some ESS 
technologies are well suited for LFC purpose in contrast to the traditional technique ramping up or down the output power from thermal generation units. The proposed LFC technique was to split the LFC signal between the ESS and thermal generation i.e. to dispatch the ESS and thermal generation to meet the system demand, and hence the balance between generation and demand achieved. The required rate from thermal generation and energy from ESS was obtained from the so-called ramp-rate-duration curve and load-duration curve. The fastest cycling portion of the LFC is assumed by the ESS due to its very fast capability of providing power or absorbing power from the grid. Hence this allows more steady operation and slower ramping rates for thermal generations which could significantly save on maintenance and equipment wear and tear. The authors, however, did not provide a control strategy on how the system is operated. This is emphasized when ESSs are used for LFC as they require special and sometimes complicated control algorithms for adequate operation. Moreover, usually load-duration curves and the so-called ramp-rate-duration curves are based on historical system operation to expect how the system will operate over the next period of time. The authors did not show how the system is handled after an unexpected event, such as loosing the ESS or a thermal unit.

The last section will discuss the objective of this thesis; first a description of the microgrid system model is provided, then the objective

\subsection{Thesis Objective}

The objective of this thesis is to propose a LFC mechanism for a battery storage unit and diesel generation units to regulate the frequency of a small isolated microgrid system. According to standard EN50160/2006 in [41] and [42], under normal operation conditions, the mean value of the fundamental frequency of an isolated system measured over 10 seconds must stay within range of $f^{s} \pm 2 \%$, where $f^{s}$ is the nominal frequency, in order to ensure stable system operation. The goal of the proposed LFC mechanism is to drive the system's frequency error $\left(\Delta f=f^{s}-f\right)$ to zero under different operation conditions mentioned in section 1.3 in the previous chapter. The microgrid system under consideration is shown in figure 1.1. 


\section{Chapter 3}

\section{SYSTEM MODELING}

This chapter will discuss the modeling of the different components of the microgrid system under consideration. The microgrid system under consideration is comprised of two diesel generators, two PV arrays, and a battery storage unit. First each component is completed individually. Then, the models are combined to form a complete model of an isolated microgrid system.

\subsection{Diesel Generator}

Diesel engines, innovated more than a century ago, were among the very popular and widespread distribution generation technologies. Their high efficiency and reliability led to their significant proliferation in almost every sector of the economy worldwide. Hence they are used on many scales, ranging from small generation units of $1 \mathrm{KW}$ to large tens of MW power plants. Because of sudden and random load changes, it is crucial that the diesel prime mover is equipped with a robust control mechanism to ensure stable operation and foster disturbance rejection [23].

\subsubsection{Modeling of Diesel Engine}

To simulate the complete dynamics of a diesel engine, a complex and high order model will be required. However, from control system and speed dynamics point of view, it is sufficient to use a much lower order model. The diesel engine model gives a description of the fuel consumption rate as a function of speed and mechanical power at the output of the engine, and is usually modeled by a simple first order model relating the fuel consumption (fuel rack position) to the engine mechanical power [23], [27], and [28]. The diesel engine model is basically composed of three parts; the governor system, the diesel combustion engine, and the flywheel.

Most studies on speed dynamics of internal combustion engines adopted the simplest model of diesel engine where the governor system is represented by a first-order 
phase lag transfer function, and the engine is represented by a time delay multiplied by a constant known as the engine torque constant.

Figures 3.1 and 3.2 show the mathematical representation of the governor system, and the engine model. The governor system takes the driving current signal (i), which controls the fuel rack position, and outputs the amount of fuel $(\Phi)$ to be injected in the combustion chamber. The governor (or the actuator system) transfer function is characterized by a gain $\mathrm{K}_{\mathrm{a}}$ and a time constant $\mathrm{T}_{\mathrm{a}}$ known as the actuator time constant.

$$
\Phi(s)=\frac{K_{a}}{\left(1+T_{a} s\right)} I(s)
$$

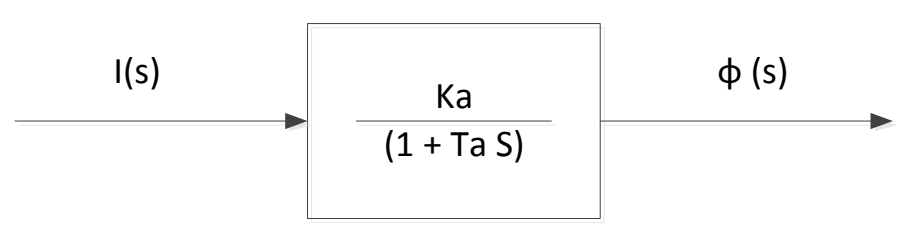

Figure 3.1: The transfer function of the actuator model

The combustion engine converts fuel flow $\Phi(s)$ into mechanical torque $T(s)$ after a time delay, known as the input dead time of the system, and engine torque constant $\mathrm{K}_{\mathrm{b}}$. This is represented by equation 3.2 and shown in figure 3.2

$$
T(s)=\Phi(s) K_{b} e^{-\tau s}
$$

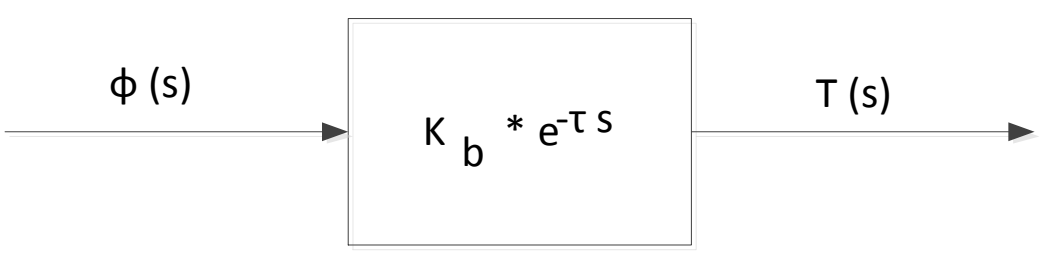

Figure 3.2: The engine model 
In real systems, the dead time comprises three parts [23], [27], and [28]:

i. Power stroke delay which is the time from the actuator signal change until fuel is injected to any cylinder.

ii. Combustion delay which is the time for fuel to burn in a cylinder and to produce a torque output.

iii. The time for a new torque level to produce a sufficient number of cylinders assignable to the prime-mover as a whole. This is an effect of the multi-cylinder nature of the prime-mover.

The flywheel part represents an approximation of the complex dynamic effects of the engine inertia, the loaded alternator, angular speed of flywheel $\omega_{\mathrm{m}}$, and the viscous friction coefficient $\rho$. The flywheel is modeled as an integrator with flywheel acceleration constant $\mathrm{J}$ which filters out a large portion of the disturbance and noise effects. Figure 3.3 shows the overall transfer function model of the diesel engine system. The control system senses the frequency error which the difference between the scheduled frequency $f^{s}$ (60 $\mathrm{Hz})$ and the measured frequency $(f)$, and generates the current signal I(s) which controls the fuel rack position.

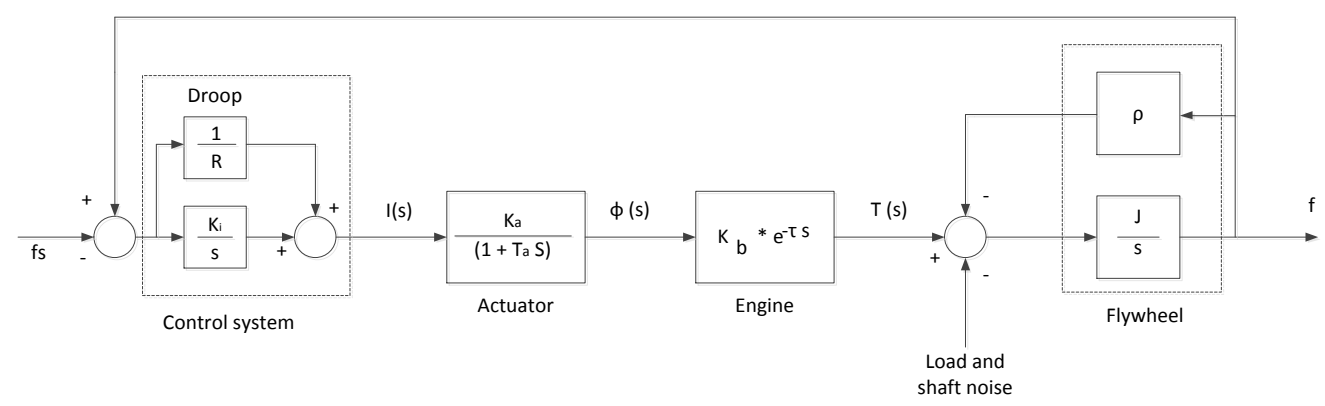

Figure 3.3: The block diagram of the diesel engine system 


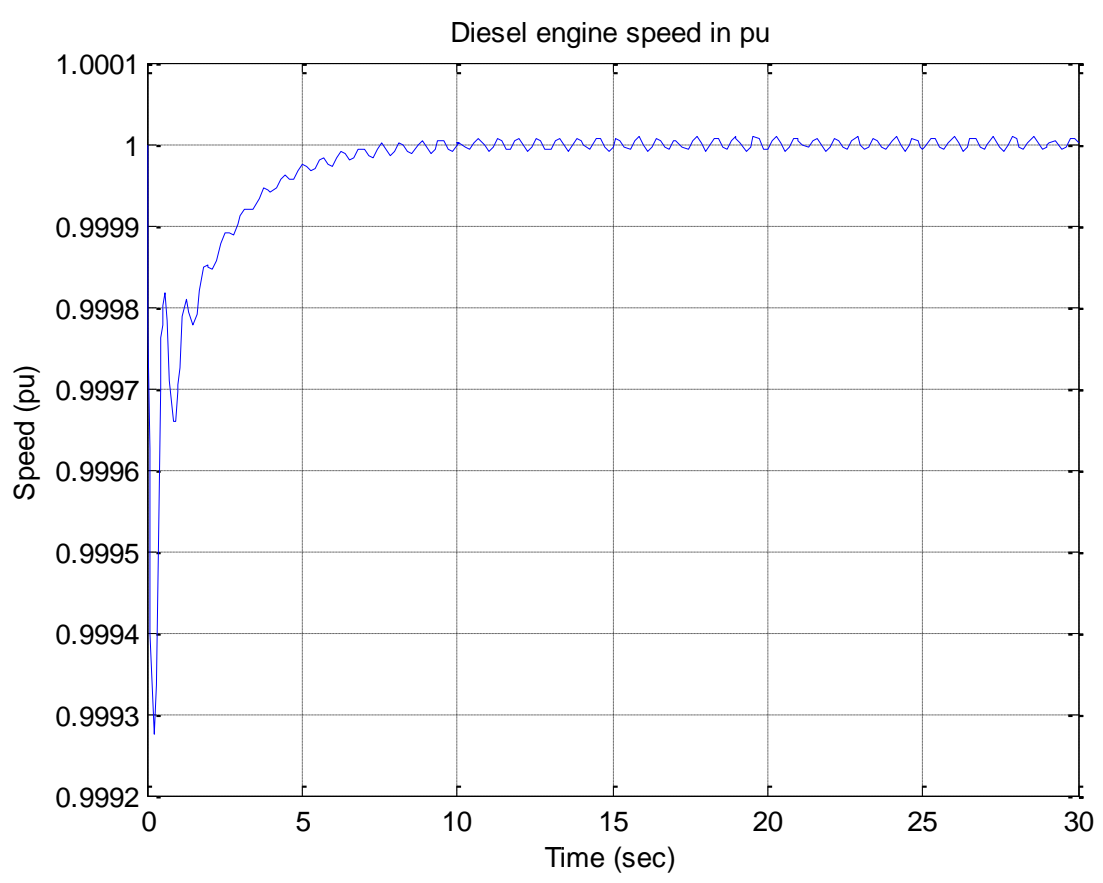

3.4: Diesel engine speed

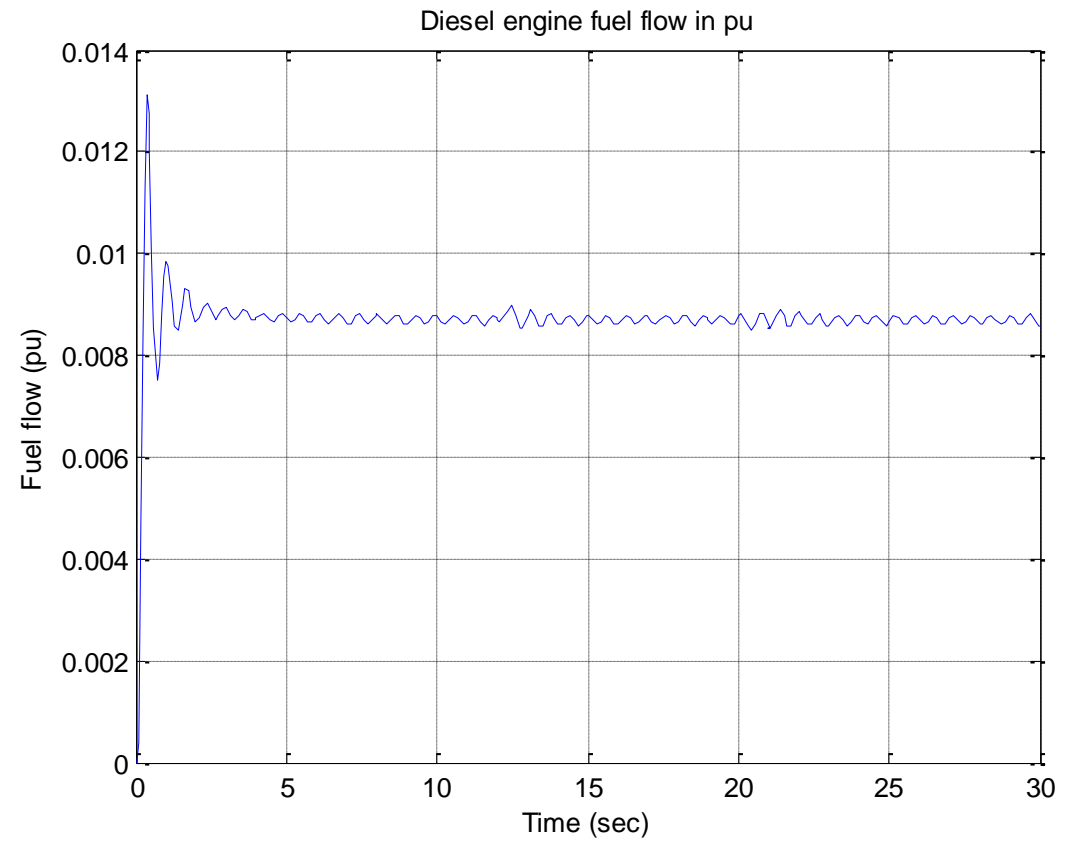

Figure 3.5: Diesel engine fuel flow 
The values of $K_{a}$ and $T_{a}$ can be considered constant over a short period of time. Gain $\mathrm{K}_{\mathrm{a}}$ is a parameter that determines the amount of the mechanical torque obtained per unit of fuel flow. Time constant $\mathrm{T}_{\mathrm{a}}$ depends on the temperature of oil flowing into the actuator. Figures 3.4and 3.5 show the per unit speed and fuel flow of the above diesel engine system over a 30 seconds time period.

\subsection{Photovoltaic System}

Photovoltaic (PV) systems are very popular among renewable energy technologies. Their wide spread is primarily due to their relatively small sizes and less fluctuations in generated power compared to wind generation. Their penetration level in the world grid is expected to significantly increase in the near future. The major advantages of PV power are summarized as follows [23], and [29]:

- Light weight, and hence more mobility.

- Less maintenance and noiseless due to absence of moving parts.

- Highly modular structure, hence the plant economy is almost not a function of size.

- Power output matches very well with peak load demands.

- High power capability per unit of weight.

Figure 3.6 shows the schematic diagram of a PV grid connected system. It typically consists of the following components:

- PV panel.

- Maximum Power Point Tracking (MPPT) controller.

- DC converter used to increase or decrease DC voltage.

- An AC inverter stage.

- An output filter to limit the harmonic current injected in the grid.

- A transformer to step up or step down the AC voltage to the grid level. 


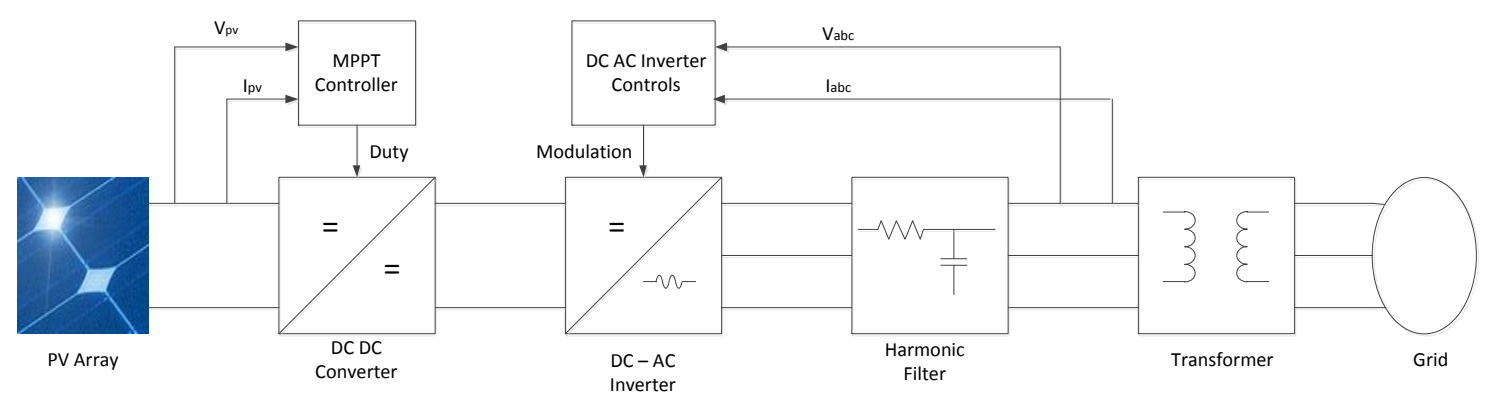

Figure 3.6: Schematic diagram of a grid connected PV system.

\subsubsection{Modeling of Photovoltaic System}

Solar cells are the building blocks of PV arrays. Basically a solar cell is comprised of p-n semiconductor junction that directly converts solar radiation into dc current using the photovoltaic effect. The two commonly used models for solar cells are the Single-Diode and the Double-Diode implementations [30]. The Single-Diode and the Double-Diode implementations of a solar cell are shown in figures 3.7 and 3.8. Both implementations consist of a light generated current source, series and parallel intrinsic resistances, and diodes representing the non-linear impedance of the p-n junction. Details on solar cell implementations are available in [30], and [31]. The mathematical models of the Single-Diode and Double-Diode implementations are the current-voltage relationship in equation 3.7 and equation 3.8.

$$
I=I p h-I s\left(e^{\frac{V+I * R s}{N * V t}}-1\right)-(V+I * R s) / R p
$$

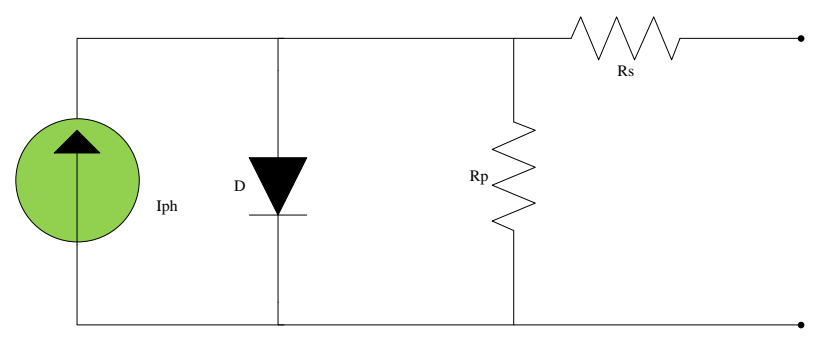

Figure 3.7: Single-Diode implementation of solar cell 
Where:

$\mathrm{I}_{\mathrm{ph}}$ is the solar induced current.

$\mathrm{I}_{\mathrm{S}}$ is the diode saturation current.

$\mathrm{N}$ is the quality factor (diode emission coefficient).

$\mathrm{V}_{\mathrm{t}}$ is the thermal voltage, KT/q, where $\mathrm{K}$ is the Boltzmann constant.

$\mathrm{T}$ is the device operating temperature.

$\mathrm{q}$ is the elementary charge on an electron.

$\mathrm{V}$ is the voltage across the solar cell electrical ports.

I is the output current from the solar cell ports.

$R_{S}$ is the series resistance.

$R_{p}$ is the parallel resistance.

$I=I p h-I s *\left(e^{\frac{(V+I * R s)}{N * V t}}-1\right)-I s 2 *\left(e^{\frac{(V+I * R s)}{N 2 * V t}}-1\right)-(V+I * R s) / R p$

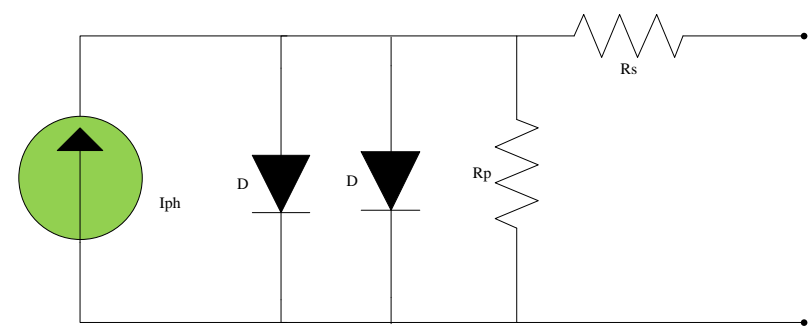

Figure 3.8: Double-Diode implementation of solar cell.

Where:

$\mathrm{I}_{\mathrm{s} 2}$ is the saturation current of the saturation current.

$\mathrm{N}_{2}$ is the quality factor of the second diode.

In this thesis, the Single-Diode implementation is considered. The ideal values for $R_{s}$ and $R_{p}$ are assumed i.e. $R_{s}$ is assumed equal to zero, and $R_{p}$ assumed infinity since parameter extraction procedure is out of the scope of this thesis. Table 3.1 illustrates the parameters values at Standard Test Conditions (STC) for a single cell [31]. 
Table 3.1: Parameters values for a single solar cell

\begin{tabular}{|c|c|}
\hline Parameter & Value \\
\hline Maximum Power Point (Watts) & 3.4592 \\
\hline Voltage @ MPP (Volt) & 0.5 \\
\hline Current @ MPP (Amp) & 6.9184 \\
\hline Series Resistance, $\mathrm{R}_{\mathrm{s}}(\mathrm{Ohms})$ & 0 \\
\hline Parallel Resistance, $\mathrm{R}_{\mathrm{p}}(\mathrm{Ohms})$ & infinity \\
\hline Quality Factor, N & 1.5 \\
\hline Solar generated current @ STC, $\mathrm{I}_{\text {pho }}(\mathrm{Amp})$ & 7.34 \\
\hline Irradiance, $\mathrm{I}_{\mathrm{rr}}\left(\mathrm{W} / \mathrm{m}^{2}\right)$ & 1000 \\
\hline Temperature, $\mathrm{T}\left({ }^{\circ} \mathrm{C}\right)$ & 25 \\
\hline
\end{tabular}

In order to simulate a PV panel with a specific power rating using the model of a single cell, the parameter series resistance $\mathrm{R}_{\mathrm{s}}$, parallel resistance $\mathrm{R}_{\mathrm{p}}$, quality factor $\mathrm{N}$, and solar induced current $\mathrm{I}_{\mathrm{ph}}$ need to scaled accordingly with the number of series cells in each string and the number strings connected in parallel inside the panel.

The PV panels used in this thesis are $14.8 \mathrm{KW}$ each. Each panel is assumed to have 10 strings connected in parallel; each string is comprised 6 modules connected in series. Each module is comprised of 60 cells. Thus, both the solar generated current Iph, and parallel resistance $R_{p}$ need to be scaled by 10 and both series resistance $R_{s}$ and quality factor $\mathrm{N}$ need to be scaled by 360 . Figures 3.9 , and 3.10 show the power-voltage and the current-voltage characteristics of the $14.8 \mathrm{KW}$ PV panel at constant temperature of $25{ }^{\circ} \mathrm{C}$ while the irradiance (Irr) is changing. Figure 3.11 shows the power-voltage characteristics at constant irradiance of $1000 \mathrm{~W} / \mathrm{m}^{2}$ while the temperature is changing. 


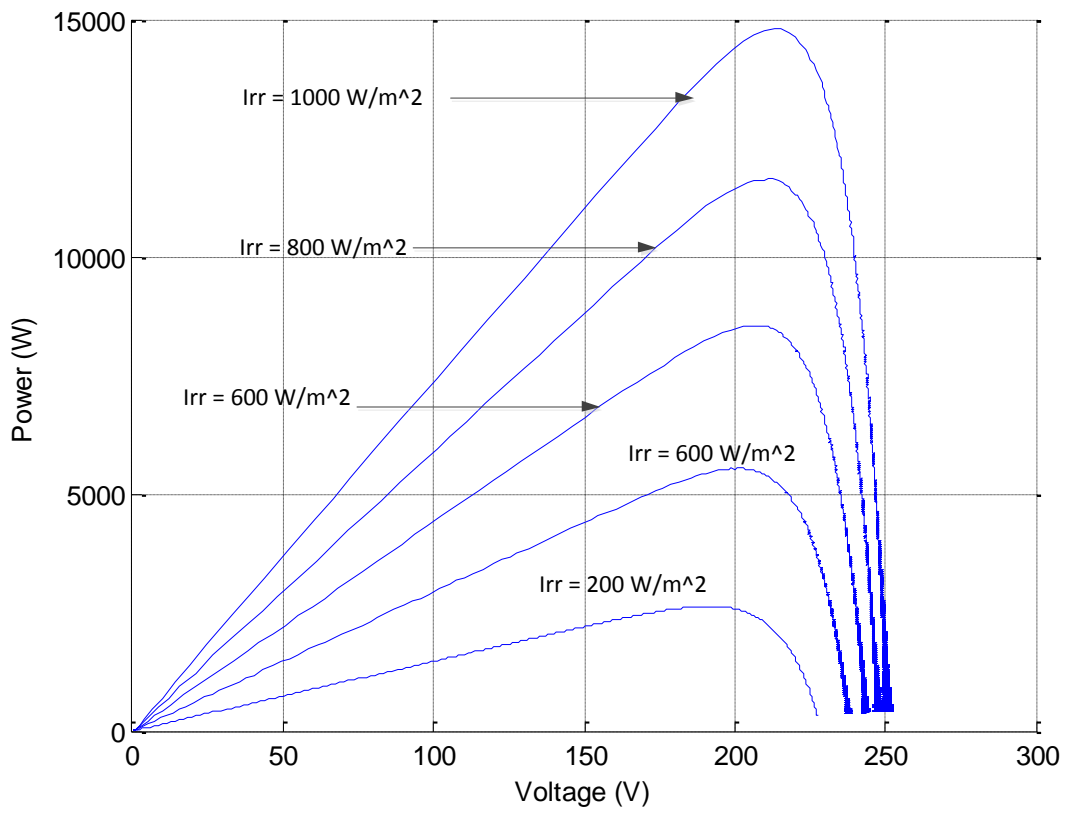

Figure 3.9: P-V characteristics at $25^{\circ} \mathrm{C}$ and changing irradiance

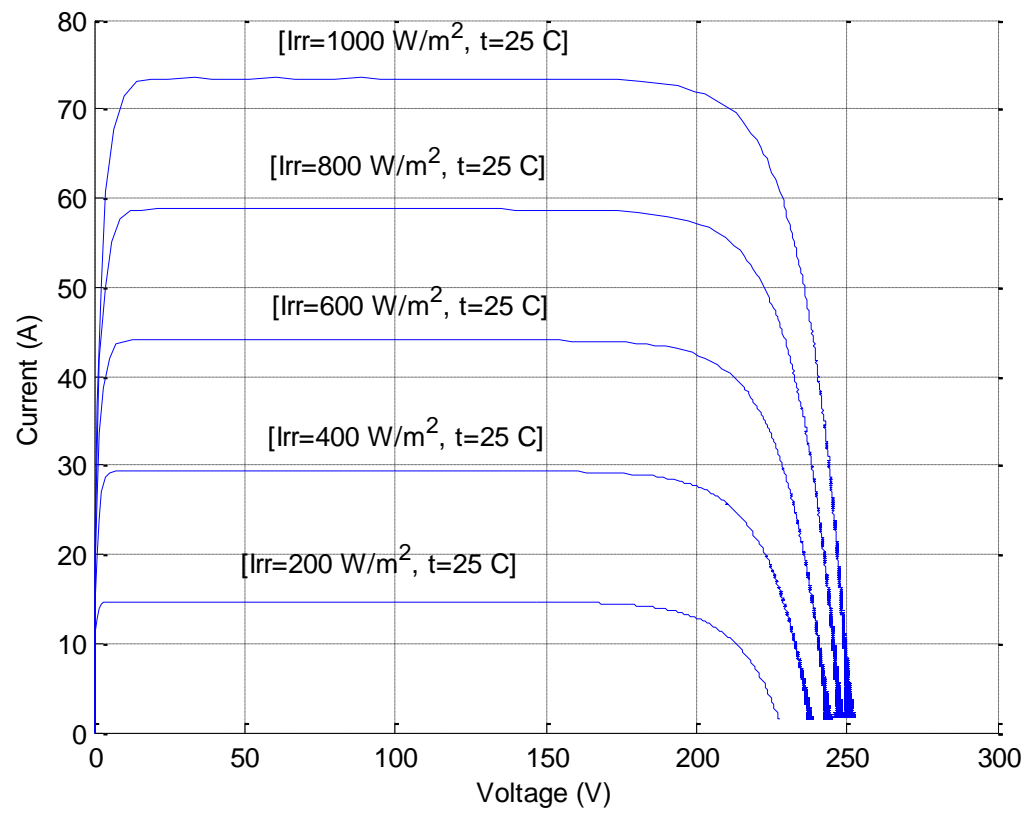

Figure 3.10: I-V characteristics at $25^{\circ} \mathrm{C}$ and changing irradiance 


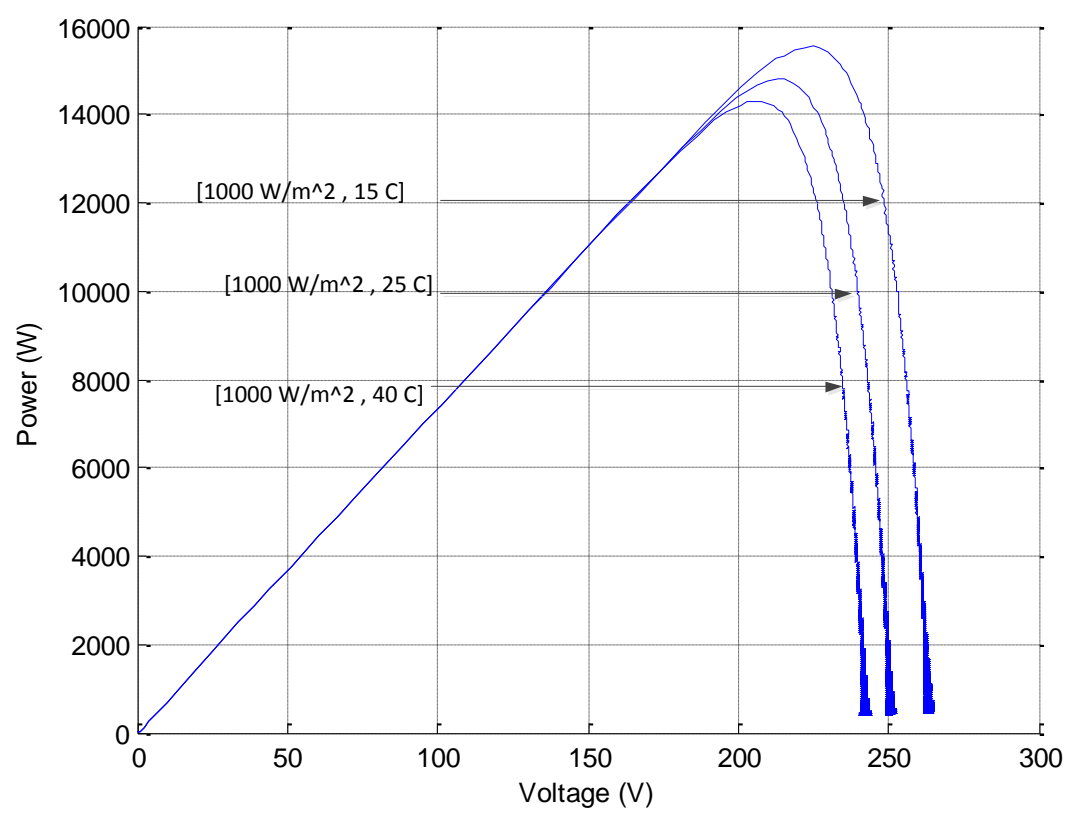

Figure 3.11: P-V characteristics at $1000 \mathrm{~W} / \mathrm{m}^{2}$ and changing temp.

From these figures, figure 3.9 shows that the open-circuit voltage of the panel is 250 Volt, when the irradiance Irr $=1000 \mathrm{~W} / \mathrm{m}^{2}$, which corresponds to the STC. As the voltage decreases and at short circuit $(\mathrm{V}=0)$ no power is produced. At open-circuit and short-circuit, no power is produced. From figures 3.9 and 3.11, there is a point at which the power produced reaches a peak known as the Maximum Power Point (MPP). Also it is observable that the power produced from the PV panel is not significantly function of the temperature as of the irradiance level. The goal is try to operate as close as possible to the MPP in order to extract the maximum amount of power from the PV system. To achieve such goal, a Maximum Power Point Tracking (MPPT) control technique needs to be implemented. There are several MPPT algorithms known such as Incremental conductance (IC), Perturb and Observe (PO), Hill Climbing (HC), etc. A good comparison between the different MPPT techniques is available in [32]. Here, the IC algorithm was implemented as it is more robust compared to PO and $\mathrm{HC}$ algorithms, and yet easy to implement. The major advantage of the IC technique is that it can track the MPP while the atmospheric conditions are changing, unlike PO and HC which track the MPP only if the irradiance level is constant. Figure 3.12 shows a changing irradiance level. The irradiance is initially $1000 \mathrm{~W} / \mathrm{m}^{2}$ for four seconds. Then it drops to $800 \mathrm{~W} / \mathrm{m}^{2}$ for three seconds, and after seven seconds from simulation time it goes back to its initial value. Figure 3.13 shows the power produced from the PV panel injected into the microgrid. From figures 3.9, 3.12 and 3.13, it is clear that the MPPT controller was successful to track the MPP under changing irradiance conditions. 
The amounts of power produced at both values of irradiance in figure 3.13 are identical with the MPP values in figure 3.9 under the same irradiance conditions.

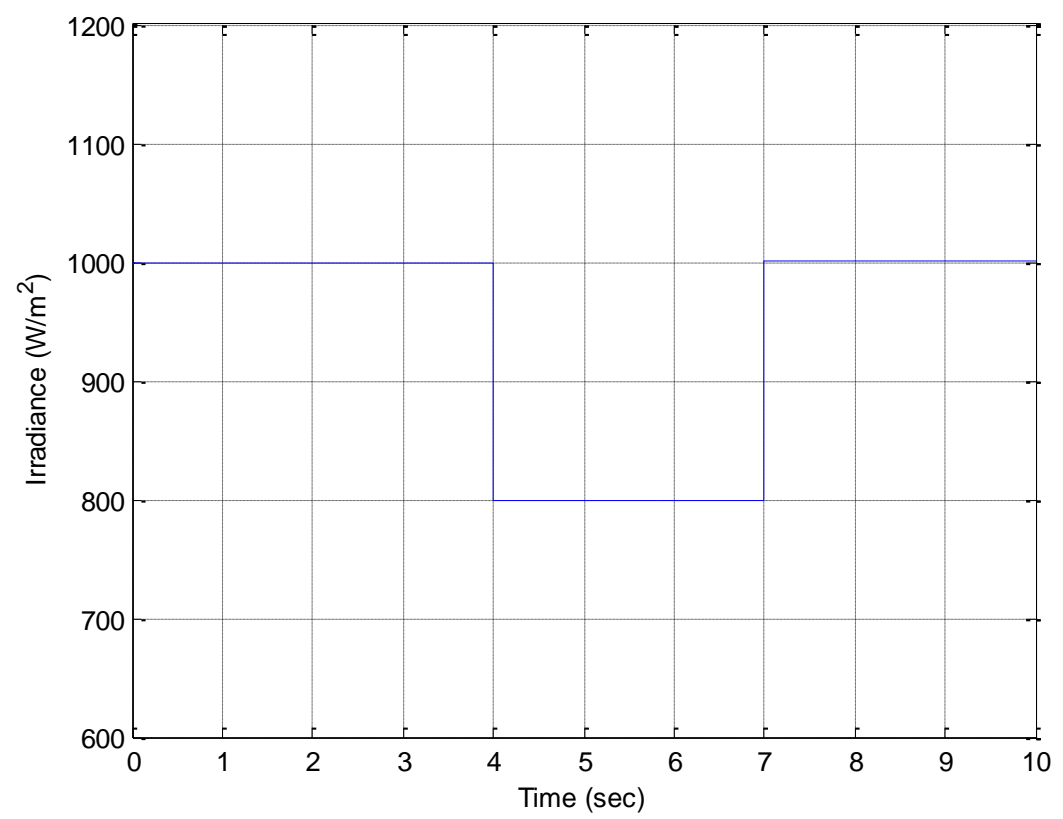

Figure 3.12: Changing irradiance conditions

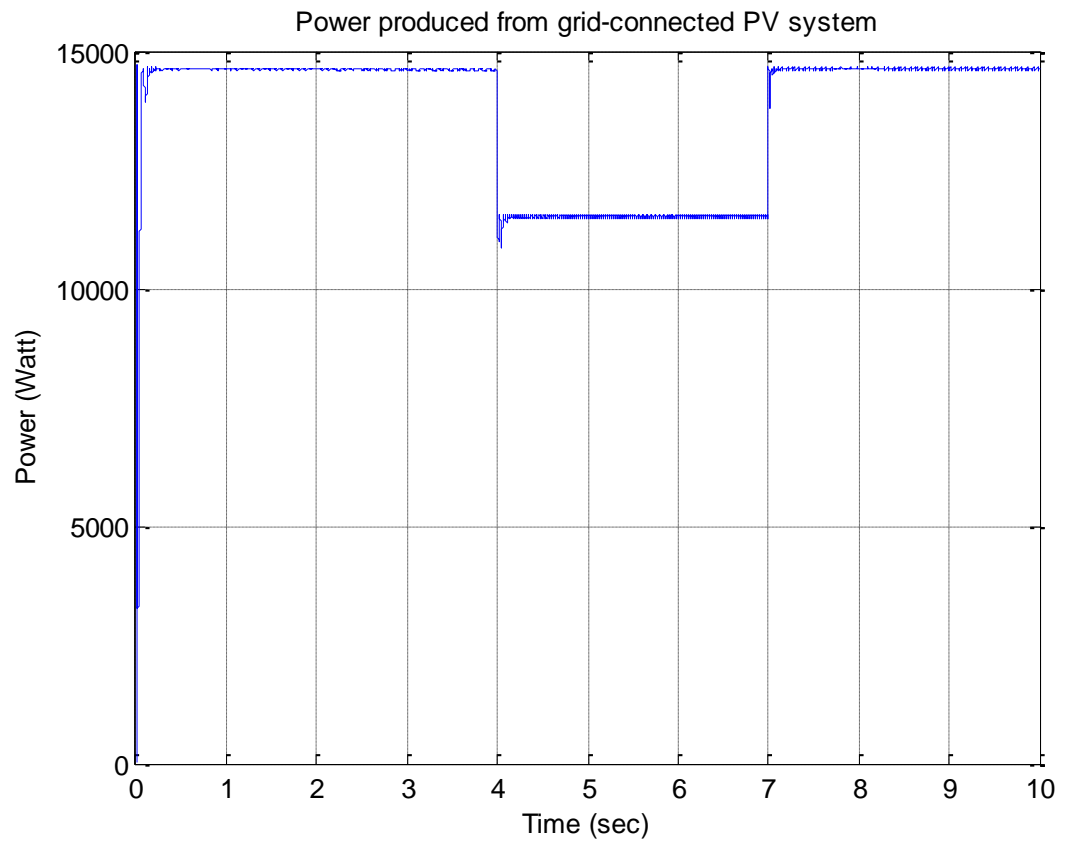

Figure 3.13: Power produced from PV panel 


\subsection{Battery Storage Systems}

Battery Storage Systems (BSS) integration in power grids is increasing worldwide. Their popularity is due to their wide ranges of sizes, not limited by topography, and the capability of being integrated as one facility or as distributed sources which make them ideal for virtually any kind of system. As the penetration level of BSSs increases, along with their bi-directional power flow capabilities, they will have to contribute in the load frequency control service.

The last part of this chapter is dedicated to discuss the modeling of the modeling of the BSS used in this thesis.

\subsubsection{Modeling of the BSS}

There are several models for BSS proposed for simulating the charging and discharging behavior for a BSS [33], [34], and [35]. Generally, a battery is modeled by a set of nonlinear equations representing the battery current as a function of the internal resistances and capacitances of the battery as well as the State of Charge (SOC). In [33], the authors proposed a battery model as a set of algebraic equations representing the nonlinear relationship between the SOC of the battery and each of the internal resistances and capacitances of the battery. The authors in [34] presented a review of different models for a BSS, and proposed a dynamic model which accounts for nonlinear characteristics such as dependence of capacity on storage time, and temperature. The authors in [35], however, compared their model with real manufacturer data and showed good accuracy for their model. Hence, the model in [35] was selected for this thesis. Figure 3.14 illustrate the battery model in [35].

Lithium Ion (LI) battery technology is amongst the very popular battery storage technologies. Its applications are very wide starting from hybrid electric vehicles, portable electronics, and grid storage applications. They are also environmental friendly compared to other battery technologies such as the Nickel-Metal-Hydride. Hence, the battery unit in this work is selected to be LI. 


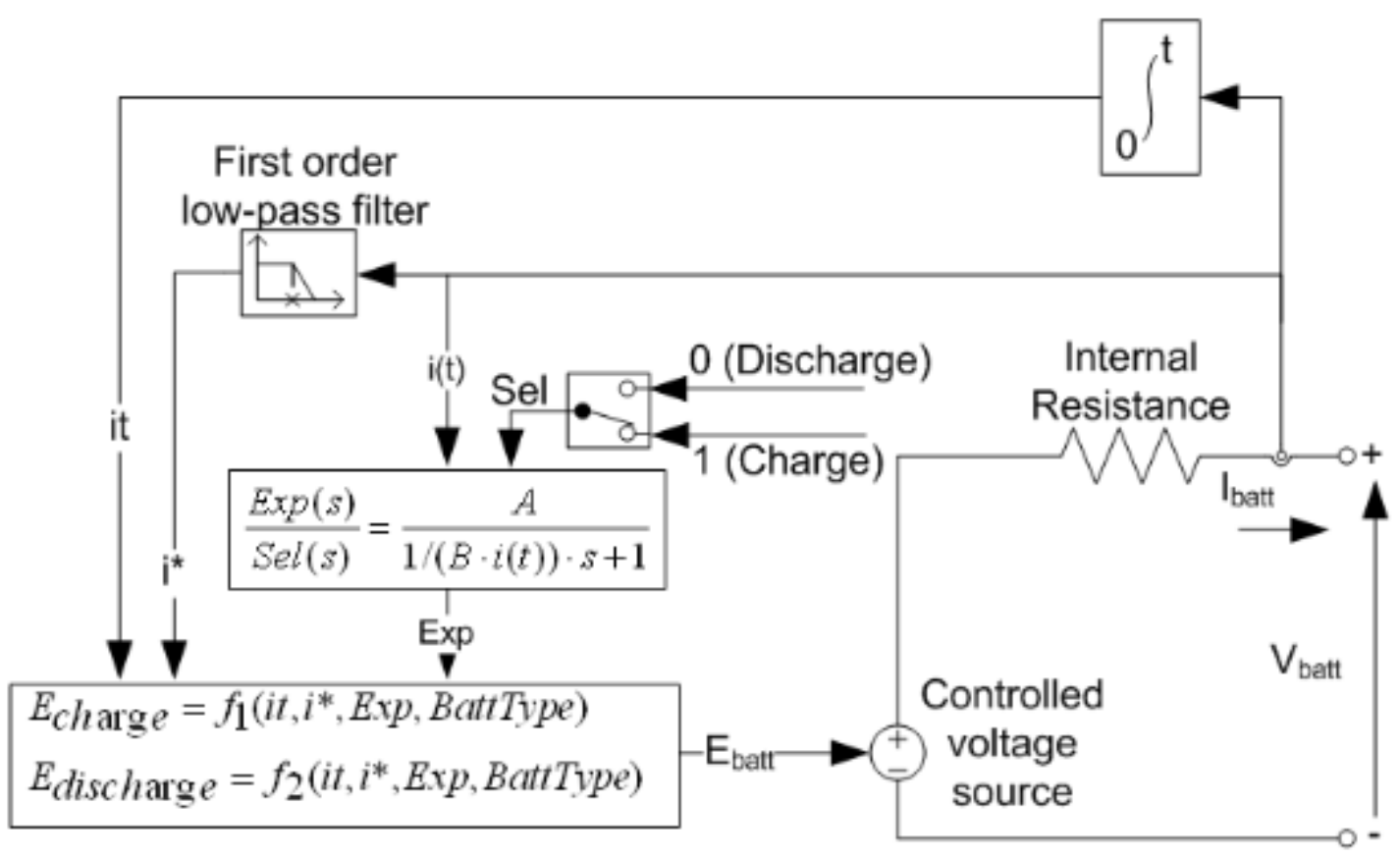

Figure 3.14: Schematic diagram of battery model

From [35], the charge and the discharge characteristics of LI battery are given by equation (3.9) and (3.10).

$$
\begin{aligned}
\mathrm{E}_{\text {charge }}\left(\mathrm{it}, \mathrm{i}^{*}, \mathrm{i}\right) & =\mathrm{E}_{0}-K \frac{Q}{i t+0.1 Q} i^{*}-K \frac{Q}{Q-i t}+\mathrm{A} \exp (-\mathrm{B} * \mathrm{it}) \\
\mathrm{E}_{\text {discharge }}\left(\mathrm{it}, \mathrm{i}^{*}, \mathrm{i}\right) & =\mathrm{E}_{0}-K \frac{Q}{Q-i t} i^{*}-K \frac{Q}{Q-i t} i t+\operatorname{Aexp}(-\mathrm{B} * \mathrm{it})
\end{aligned}
$$


Where:
$\mathrm{E}_{0}$ is constant voltage $(\mathrm{V})$
$\mathrm{i}^{*}$ is low frequency current dynamics $(\mathrm{A})$
$\mathrm{i}$ is battery current (A)
it is extracted capacity (Ah)
$\mathrm{Q}$ is maximum battery capacity (Ah)
A is exponential voltage $(\mathrm{V})$
$\mathrm{B}$ is exponential capacity $(\mathrm{Ah})^{-1}$
$\mathrm{K}$ is polarization constant $(\mathrm{Ah})^{-1}$ or polarization resistance (ohms)

From figure 3.14 and equations 3.9 and 3.10, the battery is modeled as a controlled voltage source, and a resistance connected in series with the voltage source. The value of the controlled voltage source is dependent on the mode of operation (charge or discharge). Equations 3.9 and 3.10 represent the charge and the discharge voltages as nonlinear functions in the above parameters.

The discharge characteristics of $30 \mathrm{Kwh}$ of LI battery is shown in figure 3.15. The first curve is composed of three sections; the first section represents the exponential voltage drop when the battery is charged. The second section represents the charge that can be extracted from the battery until the voltage drops below the battery nominal voltage (10 volts). Finally, the third section represents the total discharge of the battery, when the voltage drops rapidly. 

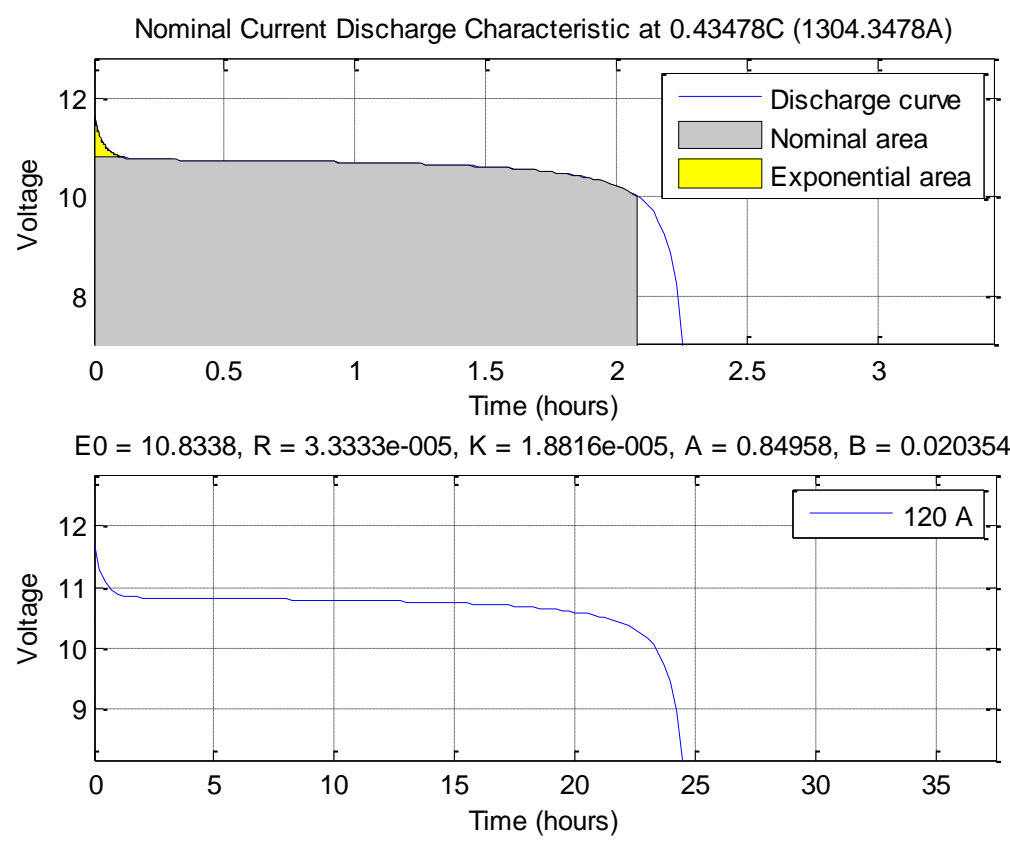

Figure 3.15: Discharge characteristics of $30 \mathrm{Kwh} 10$ Volts lithium ion battery.

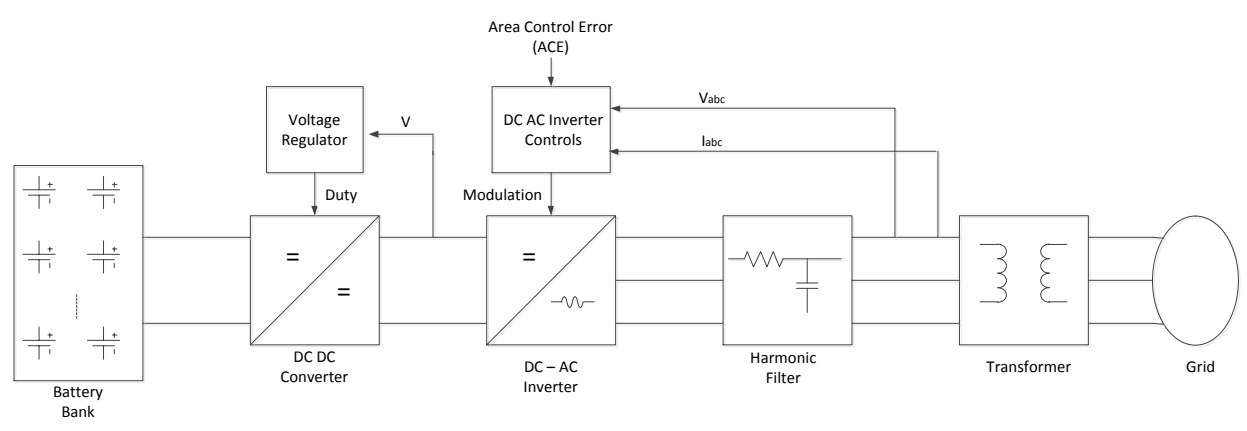

Figure 3.16: Schematic diagram of grid-connected battery system.

In this thesis, it is intended to operate the battery in grid-connected mode. The grid-connected battery system is not much different from the PV system in figure 3.6. Figure 3.16 illustrates the schematic diagram of a grid-connected battery system. The main differences between the PV and the battery system lie in the controls. The controls implemented in the battery system must maintain the voltage of the DC-DC converter at a desired level, and respond to a power signal to inject or absorb certain amount of power in order to provide regulation service. The next chapter is dedicated to discuss the controls developed for the battery unit as well as the diesel generators. 


\section{Chapter 4}

\section{MODEL PREDICTIVE CONTROL}

The purpose of this chapter is to give the basis of MPC controllers design. The chapter will start by a background on MPC mechanism. Next, a mathematical formulation of an MPC algorithm based on a step response system model [36] will be presented. Finally, the general procedure of MPC algorithm will be provided [37].

\subsection{Background}

Model Predictive Control (MPC) is a widely-used and very popular control mechanism in process control industries, such as chemical, electrical, automotive, oil etc. One can define MPC as a model-based control mechanism well-tailored for Multiple Input Multiple Output (MIMO) systems. Typically a model predictive controller is comprised of two main parts; a model of the system or the process under control used to predict the behavior of the system over a certain period of time known as the prediction horizon, and an optimizer used to compute an optimal sequence of control actions to maintain the system output as close as possible to a desired trajectory. The time period in which the control signals are imposed on the system is known by the control horizon and it is usually shorter than the prediction horizon. The procedure of the MPC algorithm is repeated in each sampling interval with the prediction horizon shifted by one sampling interval forward. The system output response is maintained as close as possible to a desired trajectory by minimization of a performance index at each sampling interval. The MPC algorithm will be illustrated in the last section of this chapter. The general MPC scheme is illustrated in figure 4.1. The feedback compensates for modeling mismatch and rejects disturbance. 


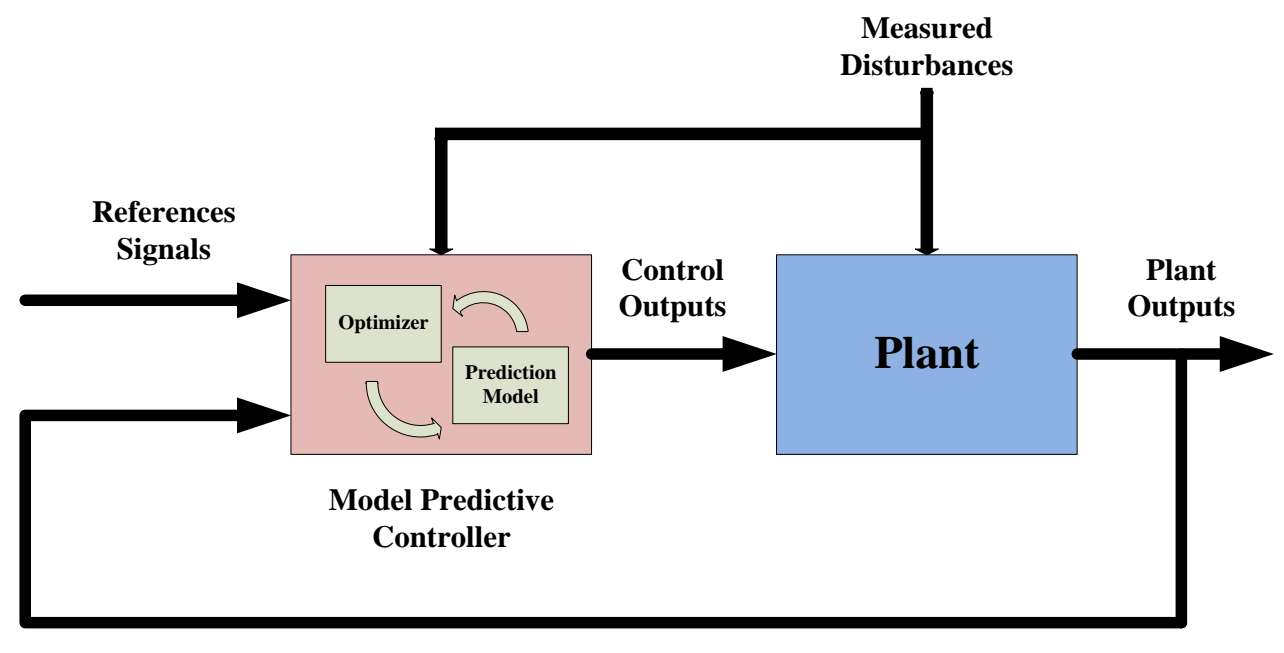

Figure 4.1: General MPC scheme

In MPC technique, constraints, such as rate limits and/or upper and lower bounds, on plant inputs and outputs are explicitly handled. Figure 4.2 shows example of system's response controlled by MPC technique. In the example shown, both the system's input and output are maintained between upper and lower bounds. Also the prediction and the control horizon are illustrated. The prediction horizon is the finite time period over which the system's future behavior is predicted. The control horizon is clearly shorter than the prediction horizon. It is the time horizon during which the calculated control moves are imposed on the system. In order to explain more MPC algorithm, the next section will present a mathematical formulation for MPC algorithm based on step response of Single Input Single Output (SISO) system. With small modifications, the presented formulation could be standing for MIMO systems as well. 

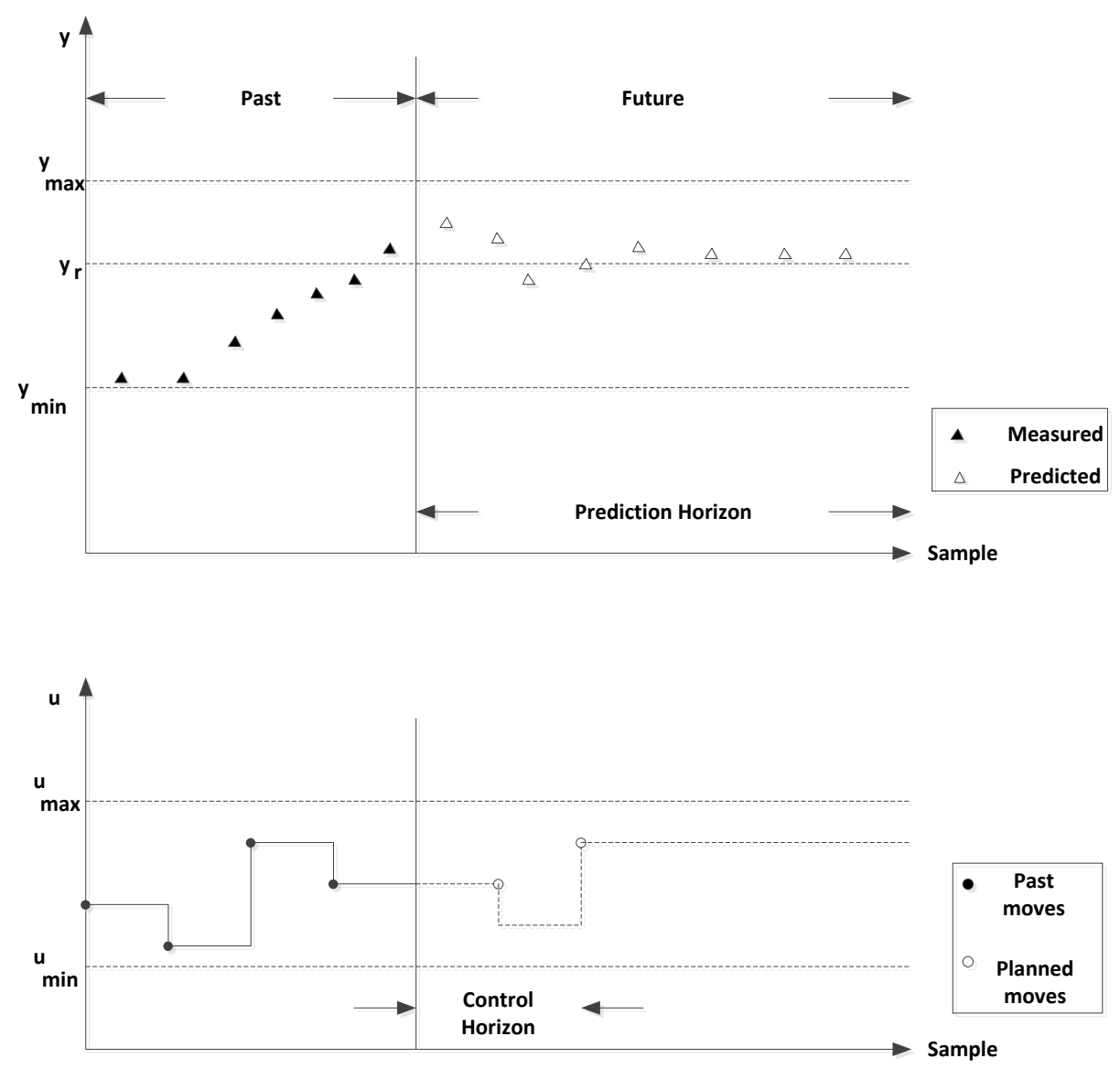

Figure 4.2: MPC controlled system's response

\subsection{Prediction based on a step response}

The standard state space representation of a Linear Time Invariant (LTI) system is given by:

$$
\begin{gathered}
X^{o}(t)=A_{c} \cdot x(t)+B_{c^{u}} \cdot u(t)+B_{c^{d}} \cdot d(t) \\
y(t)=C \cdot x(t)
\end{gathered}
$$


Where

$\mathrm{x}(\mathrm{t})$ is the state vector.

$\mathrm{u}(\mathrm{t})$ and $\mathrm{y}(\mathrm{t})$ are the input and output vectors.

$\mathrm{d}(\mathrm{t})$ is the disturbance vector.
$\mathrm{A}_{\mathrm{c}}, \mathrm{B}_{\mathrm{c}}{ }^{\mathrm{u}}, \mathrm{B}_{\mathrm{c}}{ }^{\mathrm{d}}$, and $\mathrm{C}$ are the system, input, disturbance, and output matrices.
$\mathrm{c}$ is an index that stands for continuous.

The discrete time state space representation of the above system will be:

$$
\begin{aligned}
& x(k+1)=A_{d} \cdot x(k)+B_{d}^{u} \cdot u(k)+B_{d}^{d} \cdot d(k) \\
& y(k)=C \cdot x(k)
\end{aligned}
$$

Where

$$
\begin{gathered}
A_{d}=e^{A c \cdot \Delta t} \\
B_{d^{u}}=\int_{0}^{\Delta t} e^{A c \cdot \zeta} d \zeta \cdot B_{c}^{u} \\
B_{d^{d}}=\int_{0}^{\Delta t} e^{A c \cdot \zeta} d \zeta \cdot B_{c}^{d}
\end{gathered}
$$

$\mathrm{d}$ is an index that stands for discrete.

Assume a unit step input $\mathrm{u}=\left[\begin{array}{llll}1 & 1 & 1 & \ldots 1\end{array}\right]$ is applied to the system (4.2) at rest, Not considering the effects of disturbance, i.e. $\mathrm{d}(\mathrm{k})=0, \mathrm{k}=1,2, \ldots$, the system's output will be the step response of the system on the unit step input $y=\left[\begin{array}{lll}0 & s_{1} & s_{2} \ldots . \\ s_{p}\end{array}\right]$ where $s_{1}, s_{2}, \ldots . s_{p}$ are the step response coefficients at sampling time $\mathrm{k}=1,2, \ldots, \mathrm{p}$. (figure 4.3). 

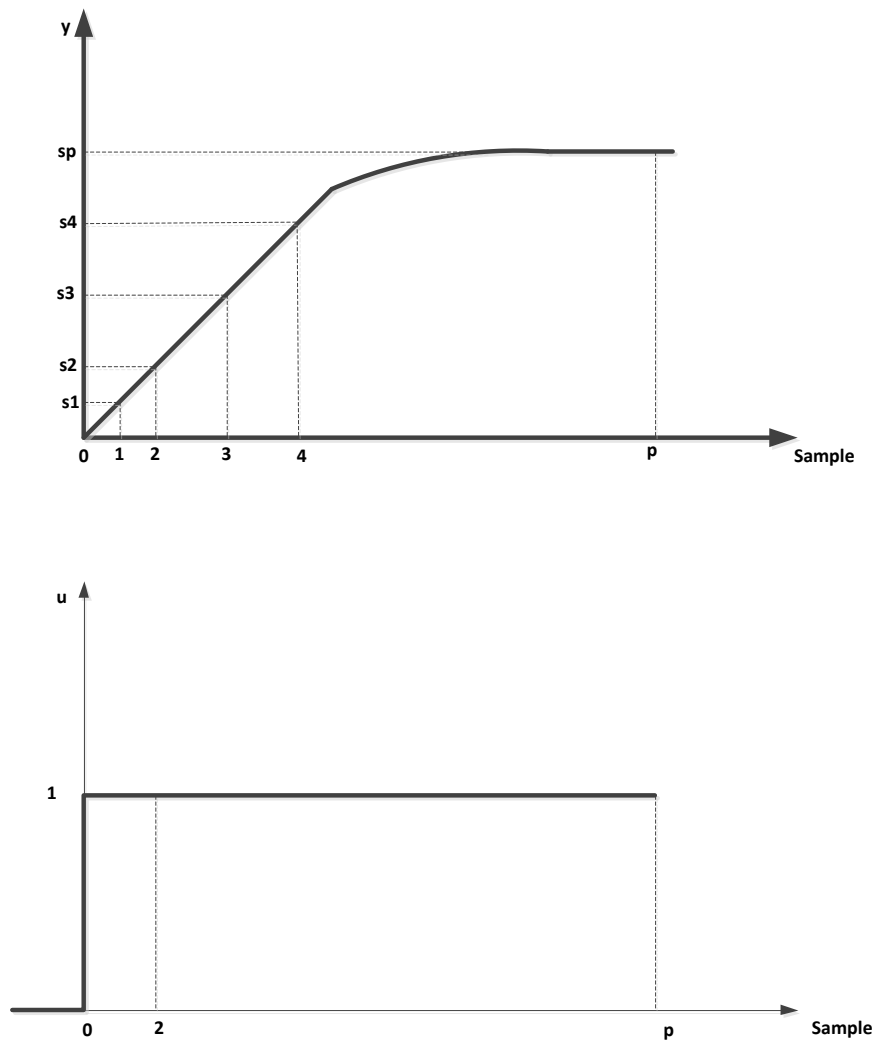

Figure 4.3: Step response on a unit step

The step response coefficients can be calculated as:

$$
S_{p}=C \cdot A_{d}^{p} X(0)+\sum_{i=1}^{p} C \cdot A_{d}^{i-1} \cdot B_{d}
$$

and for zero state response as:

$$
S_{p}=\sum_{i=1}^{p} C \cdot A_{d}^{i-1} \cdot B_{d}
$$


For linear systems, if the step input is shifted such that $u=\left[\begin{array}{lllll}0 & 1 & 1 & \ldots & 1\end{array}\right]$, the output will be a shifted step response $y=\left[\begin{array}{lllll}0 & 0 & s_{1} & s_{2} & \ldots . \\ s_{p}\end{array}\right]$, and if the step input is scaled such

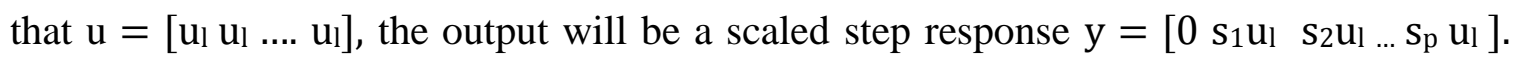
Assuming an arbitrary input $\mathrm{u}=\left[\mathrm{u}_{0} \mathrm{u}_{1} \ldots . . \mathrm{u}_{\mathrm{p}-1}\right]$ applied to the system at rest $\left(\mathrm{y}_{0}=0\right)$, the output based on the step response coefficients is:

$$
\begin{gathered}
y_{1}=s_{1} u_{0} \\
y_{2}=s_{2} u_{0}+s_{1}\left(u_{1}-u_{0}\right) \\
y_{3}=s_{3} u_{0}+s_{2}\left(u_{1}-u_{0}\right)+s_{1}\left(u_{2}-u_{1}\right) \\
\vdots \\
y_{p}=s_{p} u_{0}+s_{p-1}\left(u_{1}-u_{0}\right)+\ldots+s_{1}\left(u_{p-1}-u_{p-2}\right)
\end{gathered}
$$

Defining the change in input $\Delta \mathrm{u}_{\mathrm{i}}=\mathrm{u}_{\mathrm{i}}-\mathrm{u}_{\mathrm{i}-1,1} \mathrm{i}=1,2, \ldots$, and making an assumption that the first input was also an input change $\left(\mathrm{u}_{0}=\Delta \mathrm{u}_{0}\right)$, the output at sampling time $\mathrm{k}$ is given with:

$$
y_{k}=\sum_{i=1}^{k} s_{k-i+1} \Delta u_{i-1}
$$

Based on equation (4.6), system's step response model, a prediction of the system's output could be made at the sampling time k over the prediction horizon $\mathrm{p}$ :

$$
\begin{aligned}
& y^{\wedge}(\mathrm{k}+1 \mid \mathrm{k})=y^{\wedge}(\mathrm{k}+1 \mid \mathrm{k}-1)+s_{1} \Delta u(k \mid k)+w(k+1 \mid k) \\
& y^{\wedge}(\mathrm{k}+2 \mid \mathrm{k})=y^{\wedge}(\mathrm{k}+2 \mid \mathrm{k}-1)+s_{2} \Delta u(k \mid k)+s 1 \Delta u(k+1 \mid k)+w(k+2 \mid k) \\
& \vdots \\
& \begin{array}{c}
y^{\wedge}(k+p \mid k)= \\
y^{\wedge}(k+p \mid k-1)+s_{p} \Delta u(k \mid k)+s_{p-1} \Delta u(k+1 \mid k)+\cdots+ \\
s_{1} \Delta u(k+p-1 \mid k)+w(k+p \mid k)
\end{array}
\end{aligned}
$$


Where

- $*(\mathrm{k}+\mathrm{i} \mid \mathrm{k})$ is a prediction at sampling time $\mathrm{k}+\mathrm{i}$ based on information available at sampling time $\mathrm{k}$,

- $\quad *(\mathrm{k}+\mathrm{j} \mid \mathrm{k}-1)$ is a prediction at sampling time $\mathrm{k}+\mathrm{j}$ based on information available at sampling time $\mathrm{k}-1$,

- $\quad \mathrm{w}(* \mid *)$ represents effects of the disturbance on output prediction.

Assuming that the unmeasured disturbance will not change in the future, one can derive an estimate of it over the prediction horizon $\mathrm{p}$ as a difference between the "real" measured output $\mathrm{ym}_{\mathrm{m}}(\mathrm{k})$ and the predicted output made in the previous step $y^{\wedge}(\mathrm{k} \mid \mathrm{k}-$ 1) as:

$$
w(k \mid k)=w(k+1 \mid k)=\ldots=w(k+p \mid k) \approx y_{m}(\mathrm{k})-y^{\wedge}(k \mid k-1)
$$

Since the control variable $\mathrm{u}$ is considered only over the control horizon $\mathrm{m}$, and the control horizon $\mathrm{m}$ is shorter than the prediction horizon $\mathrm{p}(\mathrm{m}<\mathrm{p})$, therefore, the input changes are set to zero for all inputs after the control horizon:

$$
\Delta u(k+m \mid k)=\Delta u(k+m+1 \mid k)=\cdots=\Delta u(k+p-1 \mid k)=0
$$

With the assumptions in (4.8) and (4.9), equation (4.7) can be written as:

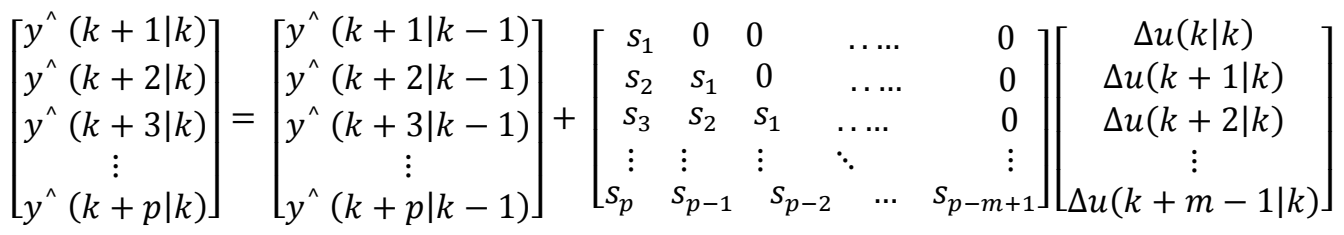

$$
\begin{aligned}
& +\left[\begin{array}{c}
y_{m}(k)-y^{\wedge}(k \mid k-1) \\
y_{m}(k)-y^{\wedge}(k \mid k-1) \\
y_{m}(k)-y^{\wedge}(k \mid k-1) \\
\vdots \\
y_{m}(k)-y^{\wedge}(k \mid k-1)
\end{array}\right]
\end{aligned}
$$


Where $y^{\wedge}(k+p \mid k-1)$ is the $\mathrm{p}+1$ element of the output prediction at sampling time $\mathrm{k}-1$, just outside the prediction horizon. Since it is assumed that the system has settled after $\mathrm{p}$ steps, there is no change in output after prediction horizon has expired. For that reason, it can be adopted that $y^{\wedge}(k+p \mid k-1)=y^{\wedge}(k+p-1 \mid k-1)$ as the output prediction in $\mathrm{p}+1$ step.

Adopting the new notation that:

$$
\begin{aligned}
& Y^{\wedge}(k+1 \mid k)_{p x 1}=\left[y^{\wedge}(k+1 \mid k) y^{\wedge}(k+2 \mid k) \quad \ldots y^{\wedge}(k+p \mid k)\right]^{T} \\
& Y^{\wedge}(k \mid k-1)_{p x 1}=\left[y^{\wedge}(k \mid k-1) y^{\wedge}(k+1 \mid k-1) \quad \ldots y^{\wedge}(k+p-1 \mid k-1)\right]^{T} \\
& \Delta U(k \mid k)_{m x 1}=\left[\begin{array}{llll}
\Delta u(k \mid k) \Delta u(k+1 \mid k) & \ldots \Delta u(k+m-1 \mid k)
\end{array}\right]^{T} \\
& S_{p x m}=\left[\begin{array}{cccc}
s_{1} & 0 & \ldots & 0 \\
s_{2} & s_{1} & \ldots & 0 \\
\vdots & \vdots & \ddots & \vdots \\
s_{p} & s_{p-1} & \ldots & s_{p-m+1}
\end{array}\right] \\
& P_{p x 1}=\left[\begin{array}{llll}
1 & 1 & \ldots & 1
\end{array}\right]^{T}
\end{aligned}
$$

and defining the "shifting" matrix $\mathrm{M}$ as:

$$
M_{p x p}=\left[\begin{array}{ccccc}
0 & 1 & 0 & \ldots & 0 \\
0 & 0 & 1 & \ldots & 0 \\
\vdots & \vdots & \vdots & \ddots & \vdots \\
0 & 0 & 0 & 0 & 1 \\
0 & 0 & 0 & 0 & 1
\end{array}\right]
$$

The prediction equation (4.10) written in a matrix form becomes:

$$
Y^{\wedge}(k+1 \mid k)=M \cdot Y^{\wedge}(k \mid k-1)+S \cdot \Delta U(k \mid k)+P \cdot\left(y_{m}(k)-y^{\wedge}(k \mid k-1)\right)
$$




\subsection{Performance index}

The performance index is chosen in a quadratic form:

$$
J=\sum_{i=1}^{p} q_{i}\left(y^{\wedge}(k+i \mid k)-y_{r}(k+i \mid k)\right)^{2}+\sum_{j=1}^{m} r_{j}(\Delta u(k+j-1 \mid k))^{2}
$$

Minimized with respect to the sequence of input increments

$$
\Delta u(k \mid k), \ldots, \Delta u(k+m-1 \mid k): \min _{\Delta u(k \mid k), \ldots, \Delta u(k+m-1 \mid k)}^{J}
$$

Where $q_{i}$ and $r_{j}$ are nonnegative weighting coefficients.

In such criterion, the weighted sum of the square of predicted output deviations $y^{\wedge}(k+i \mid k)$ from the desired trajectory $y_{r}(k+i \mid k)$ is penalized, and an optimal sequence of control input changes $\Delta u(k \mid k)$ is calculated. Both $q_{i}$ and $r_{j}$ represent a contribution of their corresponding element in the performance index i.e. the larger the weight the more penalties for the corresponding element.

Equation (4.13) can be written in matrix form as:

$$
\begin{aligned}
\min _{\Delta U(k \mid k)} J & \\
& =\min _{\Delta U(k \mid K)}\left\{[ Y ^ { \wedge } ( k + 1 | k ) - Y _ { r } ( k + 1 | k ) ] ^ { T } Q \left[Y^{\wedge}(k+1 \mid k)\right.\right. \\
& \left.\left.-Y_{r}(k+1 \mid k)\right]+\left[[\Delta U(k \mid k)]^{T} R[\Delta U(k \mid k)]\right]\right\}
\end{aligned}
$$

Where

$$
Q_{p x p}=\left[\begin{array}{cccc}
q_{1} & 0 & \ldots & 0 \\
0 & q_{2} & \ldots & 0 \\
\vdots & \vdots & \ddots & \vdots \\
0 & 0 & \ldots & q_{p}
\end{array}\right] \quad \text { And } \quad R_{m x m}=\left[\begin{array}{cccc}
r_{1} & 0 & \ldots & 0 \\
0 & r_{2} & \ldots & 0 \\
\vdots & \vdots & \ddots & \vdots \\
0 & 0 & \ldots & r_{m}
\end{array}\right]
$$


If $Y^{\wedge}(k+1 \mid k)$ is substituted in equation (4.14) with (4.11) then:

$$
J=[E(k)+S \cdot \Delta U(k \mid k)]^{T} Q[E(k)+S \cdot \Delta U(k \mid k)]+\Delta U(k \mid k)^{T} \cdot R \cdot \Delta U(k \mid k)
$$

Where the term $\mathrm{E}(\mathrm{k})$ :

$$
E(k)=M \cdot Y^{\wedge}(k \mid k-1)+P \cdot\left(y_{m}(k)-y^{\wedge}(k \mid k-1)\right)-Y_{r}(k+1 \mid k)
$$

is the error vector whose elements are the mismatch between the output prediction and the reference trajectory, assuming that all future changes in the system input $\Delta U(k \mid k)$ are set to zero.

If equation (4.15) is expanded, one will get:

$$
\begin{aligned}
J=E(k)^{T} Q E & (k)+E(k)^{T} Q S \Delta U(k \mid k)+\Delta U(k \mid k)^{T} S^{T} Q E(k) \\
& +\Delta U(k \mid k)^{T} S^{T} Q S \Delta U(k \mid k)+\Delta U(k \mid k)^{T} R \Delta U(k \mid k)
\end{aligned}
$$

And with $E(k)^{T} Q S \Delta U(k \mid k)=\Delta U(k \mid k)^{T} S^{T} Q E(k)$, one can write:

$$
J=E(k)^{T} Q E(k)+2 E(k)^{T} Q S \Delta U(k \mid k)+\Delta U(k \mid k)^{T}\left[S^{T} Q S+R\right] \Delta U(k \mid k)
$$

Note that, in equation (4.18), $E(k)^{T} Q E(k)$ does not depend on the change of control input sequence $\Delta U(k \mid k)$ (equation (4.16)) and it is constant during the optimization procedure within the sample $\mathrm{k}$, hence, it can be excluded from the optimization procedure. Therefore, the performance index given with equation (4.14) can be written as a quadratic programming $(\mathrm{QP})$ problem:

$$
\min _{\Delta U(k \mid k)} J=\min _{\Delta U(k \mid k)} \frac{1}{2} \Delta U(k \mid k)^{T} H \Delta U(k \mid k)+f(k)^{T} \Delta U(k \mid k)
$$

With

$$
\begin{aligned}
& H=2\left[S^{T} Q S+R\right] \\
& f(k)=2 S^{T} Q E(k)
\end{aligned}
$$




\subsection{Constraints}

Almost all control problems require constraints on the system variables. The constraints can be imposed on the manipulated as well as the state and/or output variables. They can be expressed as a variable saturation, variable rate change, or to keep the variable with certain bounds.

Including constraints imposed on the system, the performance index (4.13) becomes:

$$
\begin{gathered}
\min _{\Delta u(k \mid k), \ldots, \Delta u(k+m-1)} J \\
=\min _{\Delta u(k \mid k), \ldots, \Delta u(k+m-1)} \sum_{i=1}^{p} q_{i}\left(y^{\wedge}(k+i \mid k)\right. \\
\left.-y_{r}(k+i \mid k)\right)^{2}+\sum_{j=1}^{m} r_{j}(\Delta u(k+j-1 \mid k))^{2} \\
\text { subject to }\left\{\begin{array}{c}
y_{i}^{\text {min }} \leq y^{\wedge}(k+i \mid k) \leq y_{i}^{\max } \\
u_{j-1}^{\text {min }} \leq u(k+j-1 \mid k) \leq u_{j-1}^{\max } \\
\Delta u_{j-1}^{\text {min }} \leq \Delta u(k+j-1 \mid k) \leq \Delta u_{j-1}^{\max }
\end{array}\right.
\end{gathered}
$$

Where $y_{i}^{\min }, y_{i}^{\max }, u_{j-1}^{\min }, u_{j-1}^{\max }, \Delta u_{j-1}^{\min }, \Delta u_{j-1}^{\max }$ are the lower/upper bounds to be enforced. The input and input-change constraints are treated as hard constraints, while the output constraints are considered as soft.

The output constraints in matrix form can be written as:

$$
Y_{\min } \leq Y^{\wedge}(k+1 \mid k) \leq Y_{\max }
$$

Where

$$
\begin{aligned}
Y_{\text {min }} & =\left[\begin{array}{lllll}
y_{1}^{\min } & y_{2}^{\text {min }} & y_{3}^{\text {min }} & \ldots & y_{p}^{\text {min }}
\end{array}\right]^{T} \\
Y_{\text {max }} & =\left[\begin{array}{lllll}
y_{1}^{\max } & y_{2}^{\max } & y_{3}^{\max } & \ldots & y_{p}^{\max }
\end{array}\right]^{T}
\end{aligned}
$$


Substituting $Y^{\wedge}(k+1 \mid k)$ in (4.22) with equation (4.11),

$$
Y_{\min } \leq M \cdot Y^{\wedge}(k \mid k-1)+S \cdot \Delta U(k \mid k)+P \cdot\left(y_{m}(k)-y^{\wedge}(k \mid k-1)\right) \leq Y_{\max }
$$

The output constraints can be expressed as a function of $\Delta U(k \mid k)$ as:

$$
\begin{gathered}
S . \Delta U(k \mid k) \leq Y_{\max }-M \cdot Y^{\wedge}(k \mid k-1)-P \cdot\left(y_{m}(k)-y^{\wedge}(k \mid k-1)\right) \\
-S . \Delta U(k \mid k) \leq-Y_{\min }+M \cdot Y^{\wedge}(k \mid k-1)+P \cdot\left(y_{m}(k)-y^{\wedge}(k \mid k-1)\right)
\end{gathered}
$$

Saturation constraints on the input variable can be expressed as:

$$
U_{\min } \leq U(k \mid k) \leq U_{\max }
$$

Where

$$
\begin{gathered}
U_{\text {min }}=\left[\begin{array}{llll}
u_{0}^{\min } & u_{1}^{\min } & \ldots & u_{m-1}^{\min }
\end{array}\right]^{T} \\
U_{\max }=\left[\begin{array}{llll}
u_{0}^{\max } & u_{1}^{\max } & \ldots & u_{m-1}^{\max }
\end{array}\right]^{T} \\
U(k \mid k)=\left[\begin{array}{llll}
u(k \mid k) u(k+1 \mid k) & \ldots & u(k+m-1 \mid k)
\end{array}\right]^{T}
\end{gathered}
$$

One can calculate the elements of $U(k \mid k)$ as:

$$
\begin{gathered}
u(k \mid k)=u(k-1)+\Delta u(k \mid k) \\
u(k+1 \mid k)=u(k-1)+\Delta u(k \mid k)+\Delta u(k+1 \mid k) \\
\vdots \\
u(k+m-1 \mid k)=u(k-1)+\Delta u(k \mid k)+\ldots+\Delta u(k+m-1 \mid k)
\end{gathered}
$$

Or in matrix form:

$$
U(k \mid k)=1_{m x 1} \cdot u(k-1)+L \cdot \Delta U(k \mid k)
$$


Where $\mathrm{u}(\mathrm{k}-1)$ is the input calculated in the previous step, and

$$
\begin{gathered}
1_{m x 1}=\left[\begin{array}{cccc}
1 & 1 & \ldots & 1
\end{array}\right]^{T} \\
L_{m x m}=\left[\begin{array}{cccc}
1 & 0 & \ldots & 0 \\
1 & 1 & \ldots & 0 \\
\vdots & \vdots & \ddots & \vdots \\
1 & 1 & \ldots & 1
\end{array}\right]
\end{gathered}
$$

Substituting (4.27) into (4.26)

$$
U_{\min } \leq 1_{m x 1} \cdot u(k-1)+L \cdot \Delta U(k \mid k) \leq U_{\max }
$$

The constraints can be expressed as a function of $\Delta U(k \mid k)$ as:

$$
\begin{gathered}
L . \Delta U(k \mid k) \leq U_{\max }-1_{m x 1} \cdot u(k-1) \\
-L . \Delta U(k \mid k) \leq-U_{\min }+1_{m x 1} \cdot u(k-1)
\end{gathered}
$$

Or:

$$
\left[\begin{array}{c}
L \\
-L
\end{array}\right] \Delta U(k \mid k) \leq\left[\begin{array}{c}
U_{\max }-1_{m x 1} \cdot u(k-1) \\
-U_{\min }+1_{m x 1} \cdot u(k-1)
\end{array}\right]
$$

Rate constraints on the input variable can be expressed as:

$$
\Delta U_{\min } \leq I_{\operatorname{mxm}} \cdot \Delta U(k \mid k) \Delta U_{\max }
$$

Where

$$
\begin{aligned}
\Delta U_{\min } & =\left[\begin{array}{lll}
\Delta u_{0}^{\min } \Delta u_{1}^{\min } & \ldots & \Delta u_{m-1}^{\min }
\end{array}\right]^{T} \\
\Delta U_{\max } & =\left[\begin{array}{llll}
\Delta u_{0}^{\max } \Delta u_{1}^{\max } & \ldots & \Delta u_{m-1}^{\max }
\end{array}\right]^{T}
\end{aligned}
$$


Rate constraints (4.31) can be also written as:

$$
\begin{gathered}
I_{m x m} \cdot \Delta U(k \mid k) \leq \Delta U_{\max } \\
-I_{m x m} \cdot \Delta U(k \mid k) \leq-\Delta U_{\min }
\end{gathered}
$$

Or in matrix form as:

$$
\left[\begin{array}{c}
I_{m x m} \\
-I_{m x m}
\end{array}\right] \Delta U(k \mid k) \leq\left[\begin{array}{c}
\Delta U_{\max } \\
-\Delta U_{\min }
\end{array}\right]
$$

Including the constraints derived with equations (4.24), (4.30), and (4.33) into (4.19), the constrained optimization problem (4.21) becomes:

$$
\min _{\Delta U(k \mid k)} J=\min _{\Delta U(k \mid k)} \frac{1}{2} \Delta U(k \mid k)^{T} H \Delta U(k \mid k)+f^{T} \Delta U(k \mid k)
$$

Subject to

$$
A \cdot \Delta U(k \mid k) \leq b
$$

Where

$$
A=\left[\begin{array}{c}
S \\
-S \\
L \\
-L \\
I_{m x m} \\
-I_{m x m}
\end{array}\right] ; b=\left[\begin{array}{c}
Y_{\max }-M \cdot Y^{\wedge}(k \mid k-1)-P \cdot\left(y_{m}(k)-y^{\wedge}(K \mid K-1)\right) \\
-Y_{\min }+M \cdot Y^{\wedge}(k \mid k-1)+P \cdot\left(y_{m}(k)-y^{\wedge}(K \mid K-1)\right) \\
U_{\max }-1_{\operatorname{mx}} u(k-1) \\
-U_{\min }+1_{\operatorname{mx}} u(k-1) \\
\Delta U_{\max } \\
-\Delta U_{\min }
\end{array}\right]
$$




\subsection{A MPC Algorithm}

A MPC algorithm for a constrained problem is:

1. Initialization: Choose sampling interval $\Delta \mathrm{t}$, prediction and control horizon $\mathrm{p}$ and $\mathrm{m}$, and set $\mathrm{k}=0$. Compute the step response coefficient matrix $\mathrm{S}$. Initialize weighting coefficients matrices $\mathrm{Q}$ and $\mathrm{R}$, reference trajectory $\mathrm{Y}_{\mathrm{r}}$ and control input $\mathrm{u}(0)$. Compute matrix $\mathrm{H}$ equation (4.20) and initialize the QP constraints matrix A, equation (4.35). Obtain current measurements $\mathrm{y}_{\mathrm{m}}(0)$ and $\Delta \mathrm{U}(0)$ :

$$
\begin{gathered}
\mathrm{Y}^{\wedge}(0)_{\mathrm{px} 1}=\left[\begin{array}{llll}
\mathrm{y}_{\mathrm{m}}(0) & \mathrm{y}_{\mathrm{m}}(0) & \ldots & \mathrm{y}_{\mathrm{m}}(0)
\end{array}\right]^{\mathrm{T}} \\
\Delta \mathrm{U}(0)_{\mathrm{mx} 1}=\left[\begin{array}{llll}
0 & 0 & \ldots & 0
\end{array}\right]^{\mathrm{T}}
\end{gathered}
$$

2. Obtain measurements $y_{m}(k)$.

3. Update the reference $Y_{r}(k+1 \mid k)$ and constraints $A$. Compute the error vector $E(k)$, equation (4.16), QP gradient vector $\mathrm{f}(\mathrm{k})$, equation (4.20) and $\mathrm{QP}$ constraint matrix b, equation (4.35).

$$
\begin{gathered}
\mathrm{E}(\mathrm{k})=\mathrm{M}^{*} \mathrm{Y}^{\wedge}(\mathrm{k} \mid \mathrm{k}-1)+\mathrm{P}^{*}\left(\mathrm{y}_{\mathrm{m}}(\mathrm{k})-\mathrm{y}^{\wedge}(\mathrm{k} \mid \mathrm{k}-1)\right)-\mathrm{Y}_{\mathrm{r}}(\mathrm{k}+1 \mid \mathrm{k}) \\
\mathrm{f}(\mathrm{k})=2 \mathrm{~S}^{\mathrm{T}} \mathrm{QE}(\mathrm{k}) \\
\mathrm{b}=\left[\begin{array}{c}
Y_{\max }-\mathrm{M} * \mathrm{Y}^{\wedge}(\mathrm{k} \mid \mathrm{k}-1)-\mathrm{P} *\left(y_{m}(\mathrm{k})-y^{\wedge}(k \mid k-1)\right) \\
-Y_{\min }+\mathrm{M} * \mathrm{Y}^{\wedge}(\mathrm{k} \mid \mathrm{k}-1)+\mathrm{P} *\left(y_{m}(\mathrm{k})-\mathrm{y}^{\wedge}(K \mid k-1)\right) \\
U_{\max }-1_{p x 1} * u(k-1) \\
-U_{\min }+1_{p x 1} * u(k-1) \\
\Delta U_{\max } \\
-\Delta U_{\min }
\end{array}\right]
\end{gathered}
$$


4. Solve the constrained QP problem, equation (4.34)

$$
\Delta \mathrm{U}(\mathrm{k} \mid \mathrm{k})=\mathrm{QP} \_ \text {solver }(\mathrm{H}, \mathrm{f}, \mathrm{A}, \mathrm{b})
$$

and implement the first element $\Delta \mathrm{u}(\mathrm{k} \mid \mathrm{k})$ on the plant:

$$
\mathrm{u}(\mathrm{k})=\mathrm{u}(\mathrm{k}-1)+\Delta \mathrm{u}(\mathrm{k} \mid \mathrm{k})
$$

5. Compute the output prediction $\mathrm{Y}^{\wedge}(\mathrm{k}+1 \mid \mathrm{k})$, equation (4.11):

$$
\mathrm{Y}^{\wedge}(\mathrm{k}+1 \mid \mathrm{k})=\mathrm{M}^{*} \mathrm{Y}^{\wedge}(\mathrm{k} \mid \mathrm{k}-1)+\mathrm{S}^{*} \Delta \mathrm{U}(\mathrm{k} \mid \mathrm{k})+\mathrm{P}^{*}\left(\mathrm{y}_{\mathrm{m}}(\mathrm{k})-\mathrm{y}^{\wedge}(\mathrm{k} \mid \mathrm{k}-1)\right)
$$

Set $\mathrm{k}=\mathrm{k}+1$ and wait for the next sampling time. Go to step 2 and repeat. 


\section{Chapter 5}

\section{CONTROL DESIGN AND SIMULATION RESULTS}

This chapter is dedicated to present the controls developed for the battery unit and the diesel generation units for load frequency control implementation in the microgrid system shown in figure 1.1, and discussing the results obtained for different scenarios. The integral of the squared frequency error is taken as performance index in this study.

\subsection{Control Design}

The control objective is to minimize a performance index $(\mathrm{J})$ associated with the frequency error $\left(\Delta f=f-f^{s}\right)$, and defined by:

$$
\text { Minimize } J=\int_{0}^{t_{f}}|\Delta f|^{2} d t
$$

The objective is to minimize $(\mathrm{J})$ under both normal operation conditions, where the power demand fluctuates, and contingency situations, where one of the system's generation units is suddenly lost. As a result, three control loops are proposed; one control loop on each of the two diesel units and a control loop to charge or discharge the battery storage unit to regulate the frequency error $\Delta f$ (i.e. to minimize the performance index $\mathbf{J}$ ).

\subsubsection{Diesel Generators}

The objective of the control system presented in figure 3.3 is to drive the frequency error $\left(\Delta f=f-f^{s}\right)$ to zero where $f^{s}$ is the scheduled frequency of $60 \mathrm{~Hz}$, and $f$ is the measured frequency. Hence, the corresponding diesel unit contributes in regulating the system's frequency error $\Delta f$ by minimizing the performance index $\mathrm{J}$. 
In this thesis, two types of control systems were designed for the diesel units; Proportional Integral (PI) controllers, and MPC controllers to regulate the frequency error. According to standard EN50160/2006 [41] and [42], under normal operating conditions, the mean value of the frequency of an isolated system measured over 10 seconds must stay within range $f^{s} \pm 2 \%$. The developed controls must comply with such standard to ensure stable system operation. The configuration presented in figure 3.3 is a PI controller, where the proportional gain is equal to the reciprocal of the speed droop $\mathrm{R}$, and the integral gain is a design parameter. Usually the value of $\mathrm{R}$ ranges from 4 to 5 percent $(0.04-0.05)$. It was assumed to be $4 \%$ for both generators. The microgrid system in figure 1.1 was simulated for time $t=15$ seconds with sampling time $\mathrm{T}_{\mathrm{s}}=0.0001$ seconds, and the microgrid frequency is shown in figure 5.1. The parameters (gains) of the PI controllers are given in table 5.1.

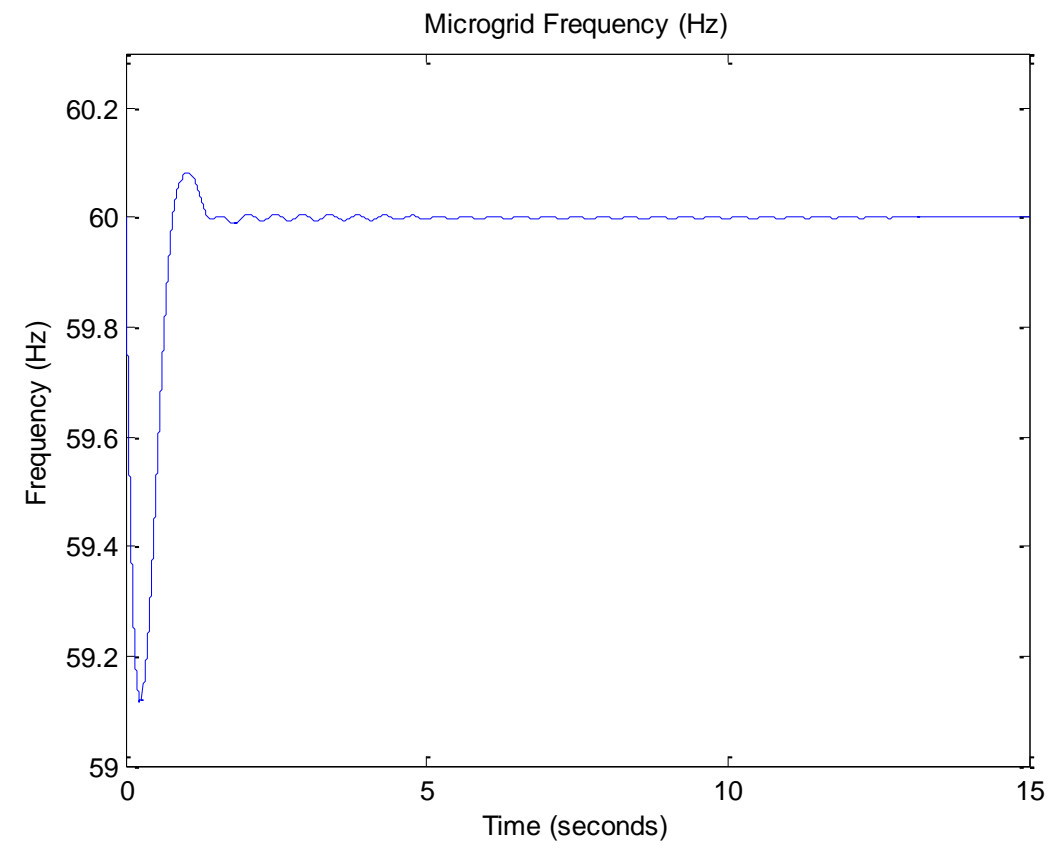

Figure 5.1: Microgrid frequency. 
Table 5.1: PI Gains

\begin{tabular}{|c|c|}
\hline Gains & Values \\
\hline $\mathrm{K}_{\mathrm{p}}$ & 25 \\
\hline $\mathrm{K}_{\mathrm{i}}$ & 100 \\
\hline
\end{tabular}

The power produced from each of the PV systems is shown in figure 5.2. The next section will present the design of MPC controllers for the diesel generators. Then the controls developed for the battery unit will be presented.

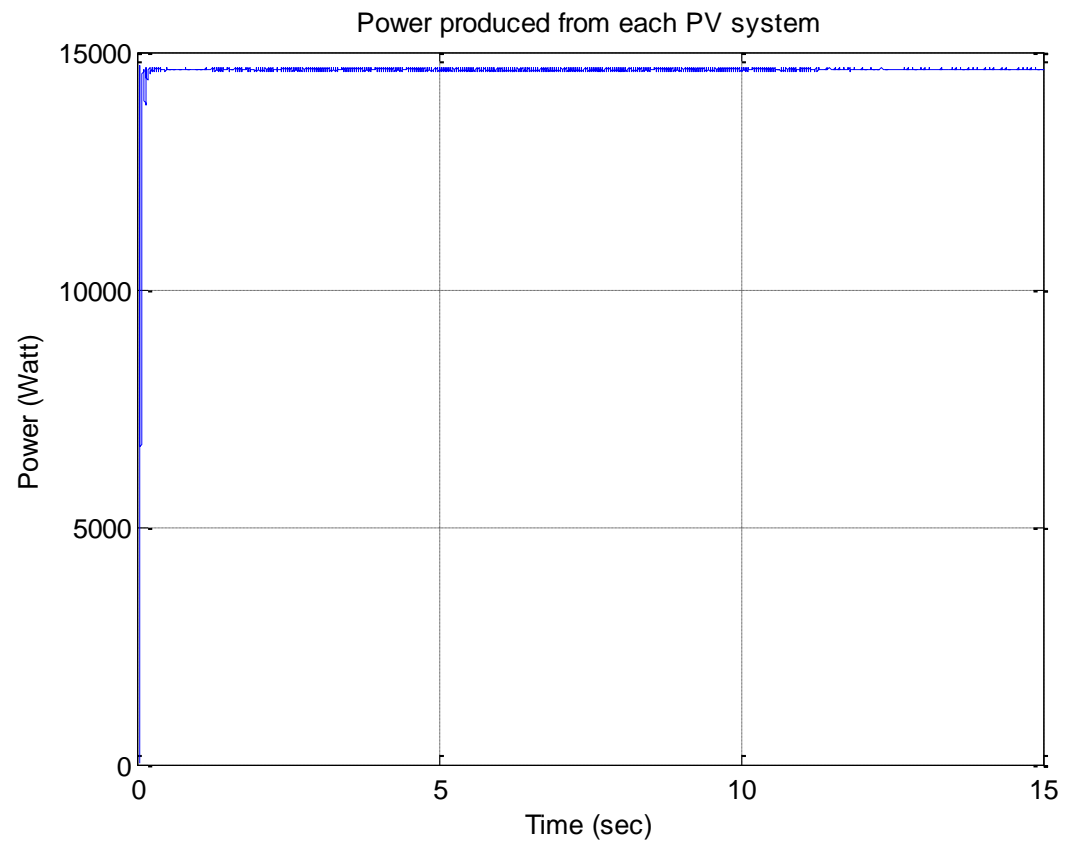

Figure 5.2: PV power produced from each panel. 


\subsubsection{MPC Controllers Design}

The basis for MPC controller design is given in chapter 4. It is vital to choose a proper sampling time $\mathrm{T}_{\mathrm{s}}$ as well as a prediction horizon $\mathrm{p}$ and a control horizon $\mathrm{m}$, since the amount of computations carried out by the optimization procedure depends on those parameters. A too-short sampling time and long prediction and control horizons would result in a very high computational burden. Also, an unacceptable control performance would result from a too long sampling time. In our case, the sampling time Ts is restricted as to comprise between the amount of memory consumed by the simulation, so that the simulation will not crash, and the ability of the solver to capture the dynamics of the simulation.

From figure 5.1 it can be considered that the system come to rest before time $t=10$ seconds and the speeds oscillations can be considered settled after 5 seconds.

This means that a prediction horizon of 10 seconds ( $\mathrm{p}=10$ seconds), control horizon of 5 seconds ( $\mathrm{m}=5$ seconds), and a sampling time $\mathrm{Ts}=0.0001$ seconds are appropriate to achieve good control performance with manageable amount of computations in real-time.

Constraints in the system are defined with the physical characteristics of the system [37]. They can be expressed in a form of bounds on the system output ( $\Delta \mathrm{f}^{\mathrm{min}}$ and $\Delta \mathrm{f}^{\mathrm{max}}$ ), saturation of the generator set point (input signal to the governor), or limits on the set point rate of change.

The frequency error $\Delta f$ is taken as the system output, and it is measured in every sampling time. If, at any instant, the total generation in the system is equal to the demand and the losses, then the frequency error will be zero. Hence, the control objective is to keep $\Delta f$ equal to zero, and therefore the system frequency will be kept at the nominal value of $60 \mathrm{~Hz}$. Therefore, the reference trajectory for the MPC controllers is set to zero all the time.

After choosing the prediction and control horizons ( $\mathrm{p}$ and $\mathrm{m}$ ), sampling time $\mathrm{T}_{\mathrm{s}}$, defining the system constraints and the reference trajectories, the MPC controllers are designed using the Model Predictive Control Toolbox in MATLAB. The procedure of the design process is made easy using the graphical user interface of the tool in [38]. Figure 5.3 compares the frequency with PI and MPC controllers implemented. It is visible that when MPC controllers are implemented, the frequency experienced a significant improvement in overshoot as well as the steady state oscillations.

In the case of PI controllers, the frequency dropped to about $59.1 \mathrm{~Hz}$ at about time $\mathrm{t}=$ 0.2 seconds. Then, the overshoot reached a value of $60.08 \mathrm{~Hz}$ at about time $\mathrm{t}=1$ seconds. 
In the case of MPC controllers, the frequency dropped to about $59.5 \mathrm{~Hz}$, and the overshoot reached about $60.02 \mathrm{~Hz}$ at about time $\mathrm{t}=0.7$ seconds.

It is clear that the overshoots improved by almost a factor of 4 when MPC controllers were implemented compared to the case of PI controllers. Also, it is noticeable that both transient and steady state speed oscillations significantly improved.

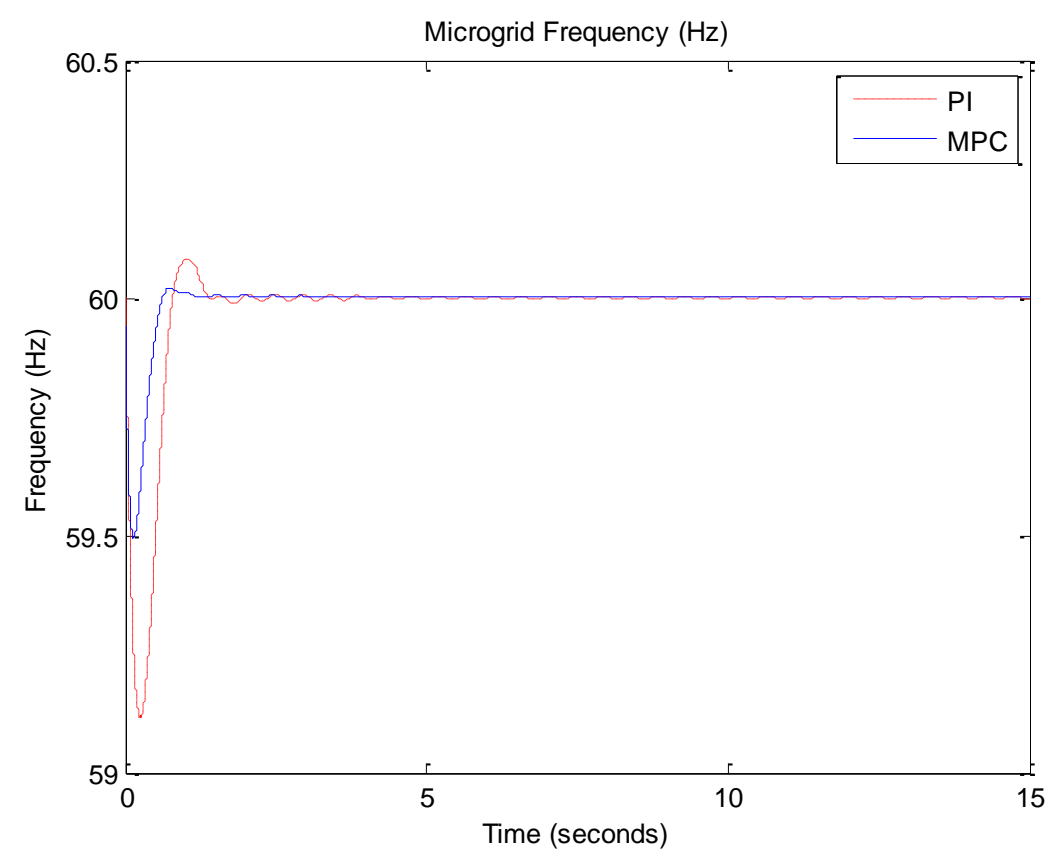

Figure 5.3: Microgrid frequency with PI and MPC controls.

\subsubsection{Grid-connected Battery System}

In order for the battery to contribute in load frequency control application, it is crucial that the battery unit respond to the frequency error signal, and inject or absorb certain amount of power in real-time in order to contribute in regulating the frequency error $\Delta f$. Such requirement is attained by measuring the system's frequency error $\Delta f$, and generating appropriate modulation signal that will control the power flow of the battery system inverter. 
It is important to note that the control capability of the energy storage systems, in general, for balancing between generation and consumption may be limited by its available system capacity.

Therefore the output of the battery unit should be brought back to zero as soon as possible, in normal operation conditions, to secure the maximum reserve. Figure 5.4 is a block diagram that illustrates the structure of the battery inverter control system for LFC purposes. The frequency error $\Delta f$ as well as the inverter output three phase voltages and currents are measured and input to the control system, and a sinusoidal three phase modulation signal is produced which controls the power flow from the battery system inverter. The frequency error $\Delta f$ signal is input to a PI controller that outputs the d-axis current command signal $I_{\text {dref. }}$. The output three phase currents from the battery unit $I_{a b c}$ are measured in p.u, and they are feedback to the control system. Since it is very difficult to implement controls directly on sinusoidal signals, it is required to transform the three phase sinusoidal currents to direct-quadrature (dqo) frame. The $I_{d}$ controller regulates the active power produced or absorbed by the battery system by driving the system direct current $I_{d}$ to the desired reference direct current $I_{d r e f}$. The $I_{q}$ controller regulates the inverter reactive power. The reference q-axis current signal is set to zero to attain unity power factor.

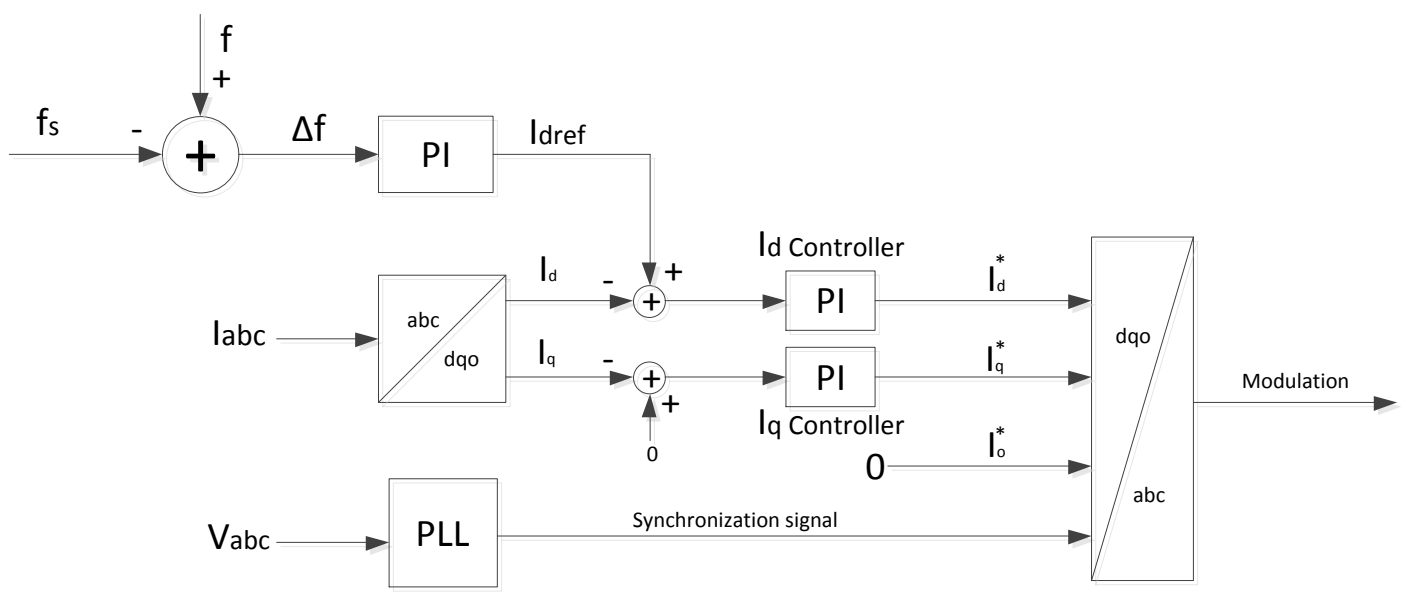

Figure 5.4: Block diagram of battery system inverter controls. 
In order to generate the modulation signal, which is input to the inverter, a sinusoidal synchronization signal is needed. Since the battery system will be connected to the grid, it is crucial to be synchronized with the grid.

The synchronization is obtained using a Phase Locked Loop (PLL) controller. The microgrid three phase voltages is measured in p.u, and fed to the PLL controller which generates the required synchronization signal. The $I_{d}$ and $I_{q}$ controllers are designed using the Frequency Response Estimation (FRE) technique in [39] and [40]. The gains of the $\mathrm{I}_{\mathrm{d}}$ and $\mathrm{I}_{\mathrm{q}}$ controllers are given in table 5.2.

Table 5.2: $I_{d}$ and $I_{q}$ controllers gains

\begin{tabular}{|c|c|c|}
\hline Controller & Gains & Values \\
\hline \multirow{2}{*}{ Id Controller } & $\mathrm{Kp}$ & 20 \\
\cline { 2 - 3 } & $\mathrm{Ki}$ & 180 \\
\hline \multirow{2}{*}{ Iq Controller } & $\mathrm{Kp}$ & 0.594 \\
\cline { 2 - 3 } & $\mathrm{Ki}$ & 233.83 \\
\hline
\end{tabular}

\subsection{Simulation Results}

Performance of the proposed controllers is tested on three different scenarios:

- Step load change.

- Loss of the $20 \mathrm{KVA}$ DG.

- Loss of the $100 \mathrm{KVA}$ DG.

The reasons for proposed scenarios are to:

1. Show the controllers' performance during microgrid system normal operation.

2. Test the robustness of the controllers in an unexpected situation such as losing suddenly any of the two generator units. 


\subsubsection{Step Load Change}

A step change in power demand is shown in figure 5.5. The change is a sudden increase in the demand by about $4.4 \mathrm{KW}$ at time $\mathrm{t}=5$ seconds. Fluctuations in power demand are common in power system operation, and the purpose of this scenario is to check the behavior of the proposed controllers under normal operating conditions.

Change in the battery system power is visible due to the battery system tracking and following frequency deviations caused by the load change. However, it is important to note that the change in power demand is not supplied sole by the battery system. It is shared amongst generation units. Figure 5.6 shows the current reference signal Idref and the BSS power. Figure 5.7 shows the power generated from the DGs. Figure 5.8 shows the changes in the power generated from each of the DGs. Figure 5.9 shows the power demand change and total changes in DGs generations and BSS power. Figure 5.10 shows the microgrid frequency and the ACE, which is defined in this study as the frequency error $(\Delta f)$. It is clear that frequency and ACE fluctuations are very small and within acceptable limits. Figure 5.11 compares the system's frequency and ACE when the secondary control loops of the DGs were disabled. From figure 5.11 clearly the integral term is responsible for restoring the system frequency back to scheduled value of $60 \mathrm{~Hz}$.

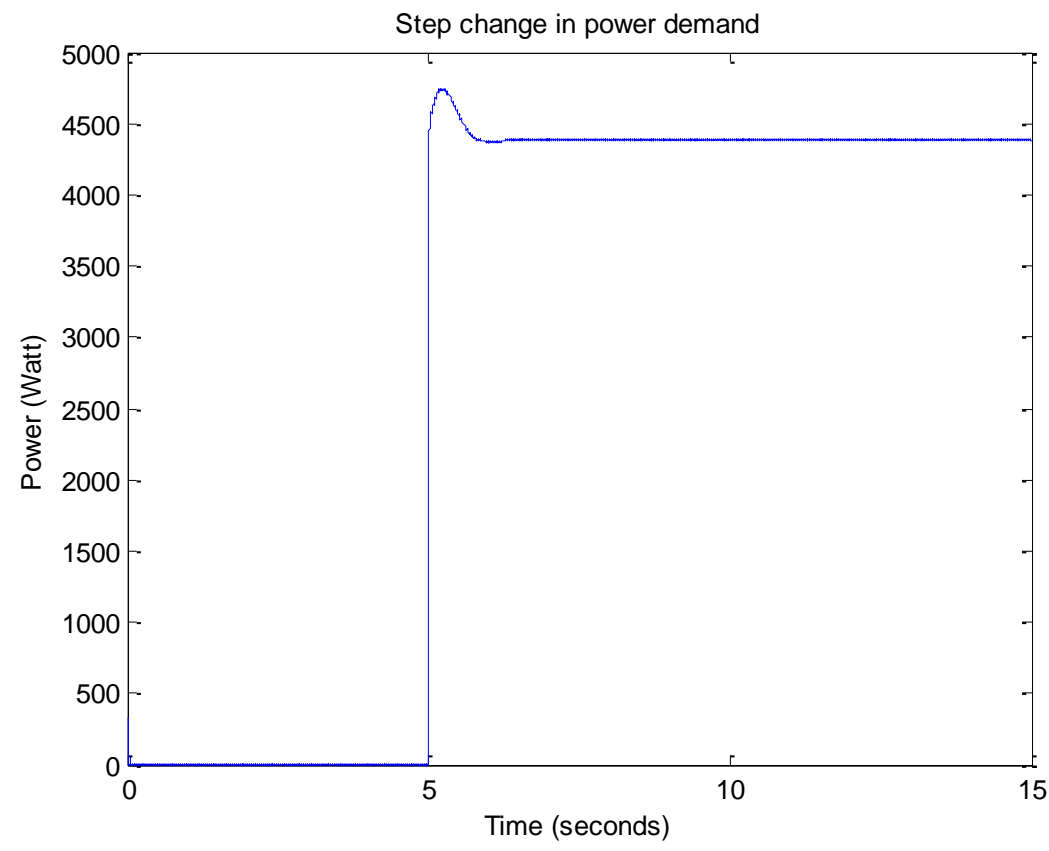

Figure 5.5: Step change in power demand. 

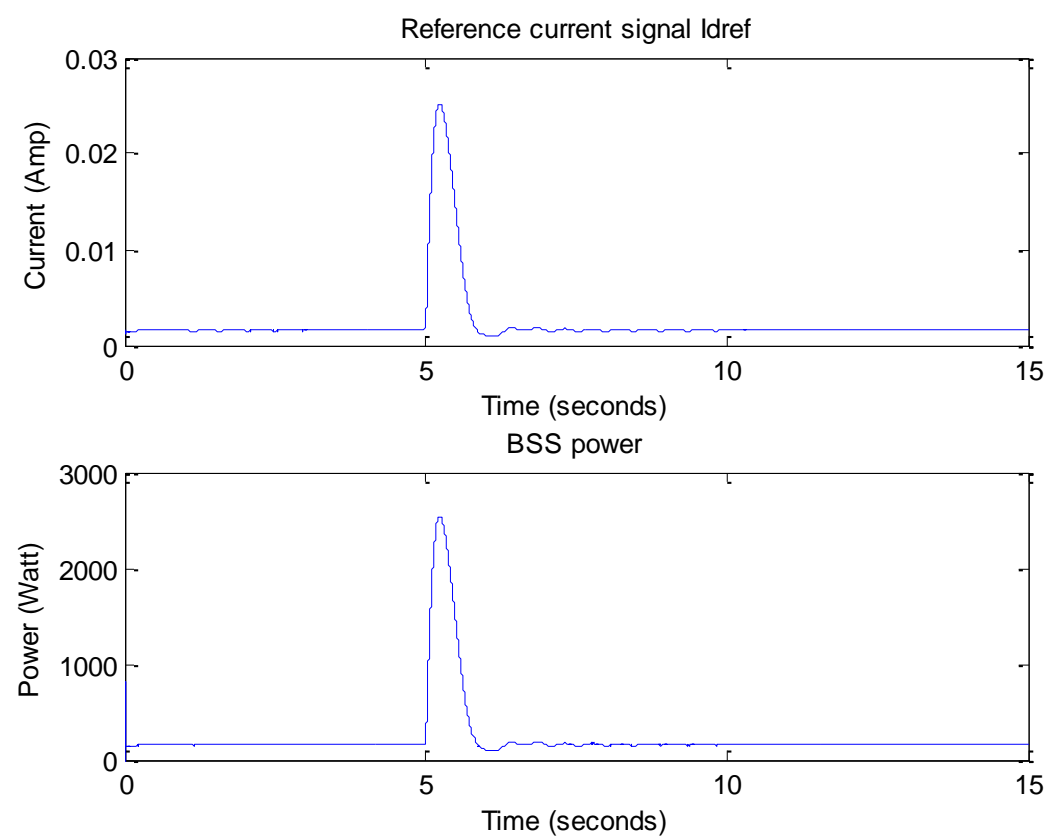

Figure 5.6: Power from BSS.
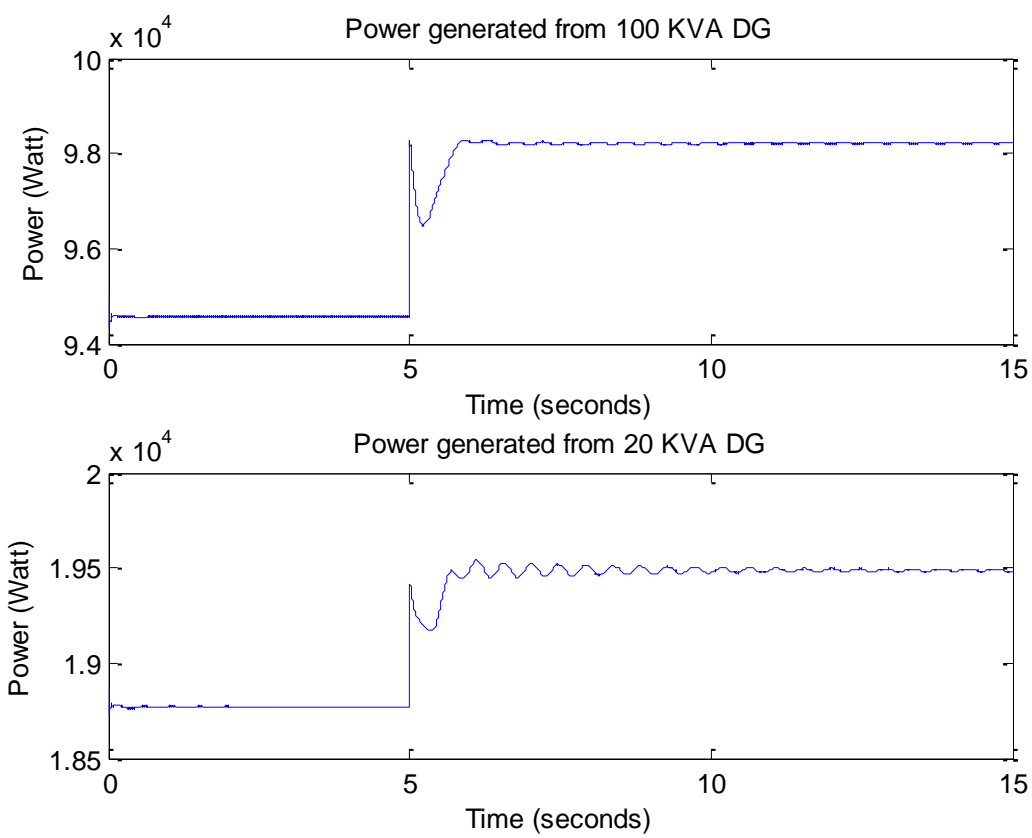

Figure 5.7: Power generated from diesel generators. 

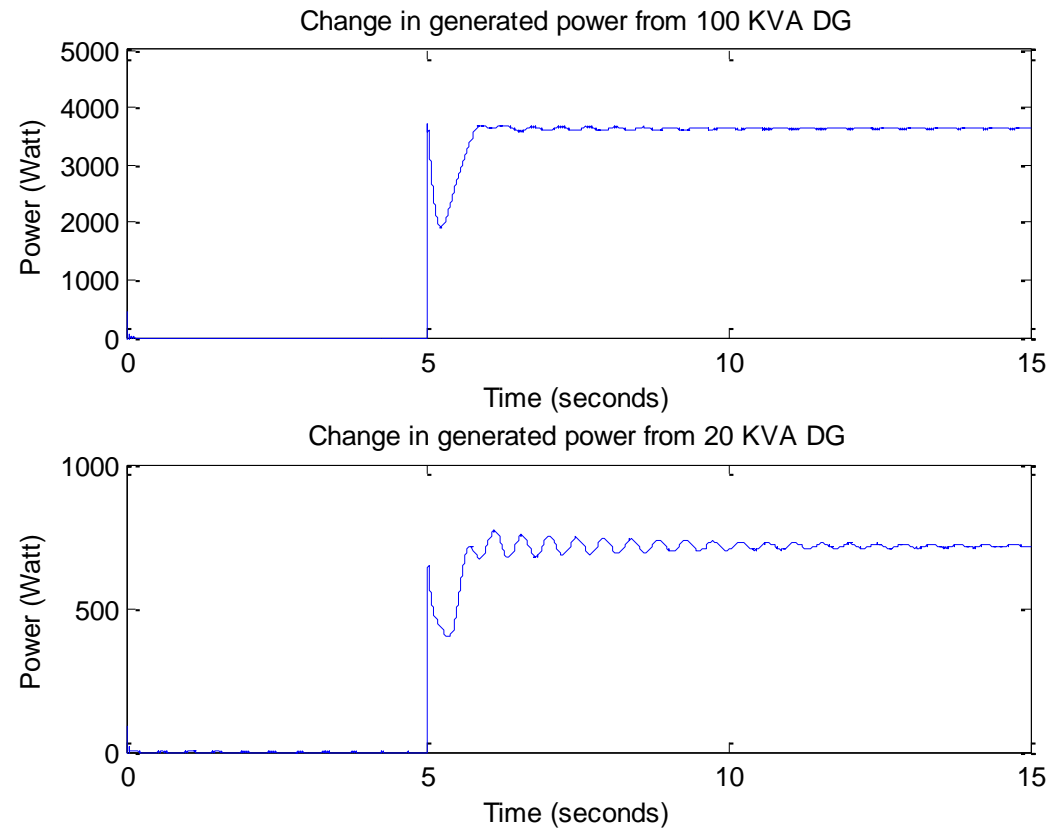

Figure 5.8: Changes in generated power from DGs.

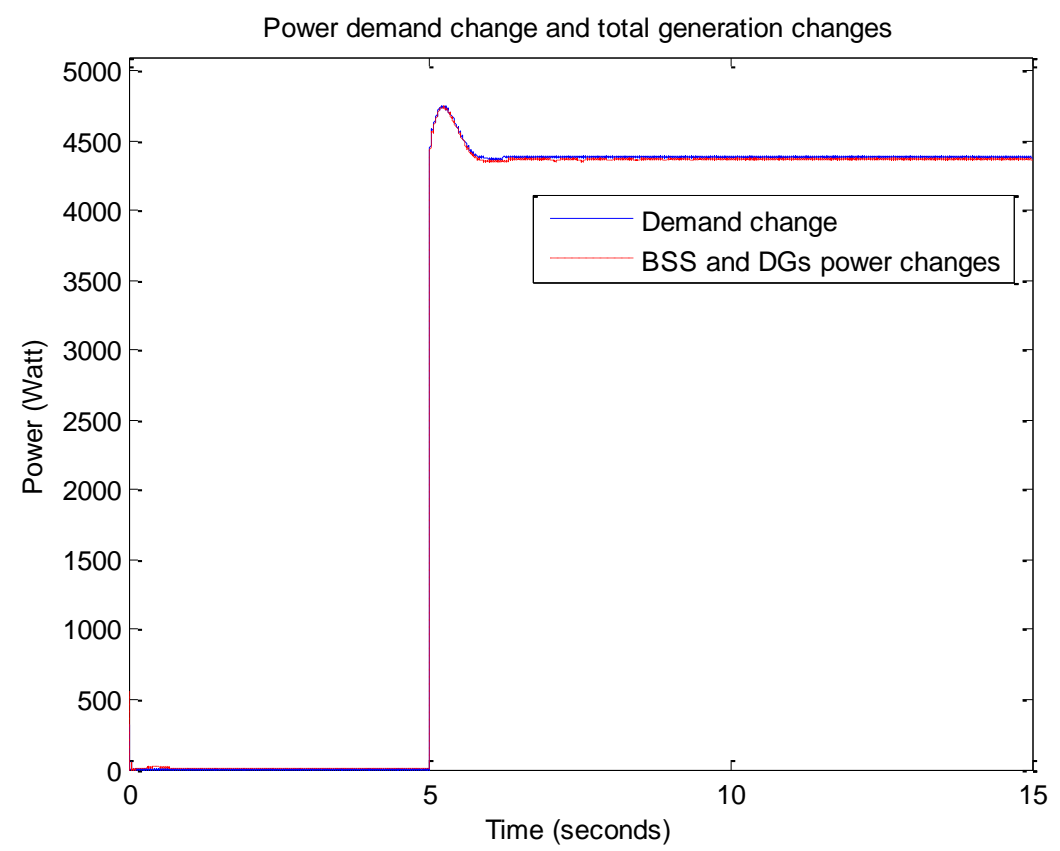

Figure 5.9: Power demand change and total generation changes. 

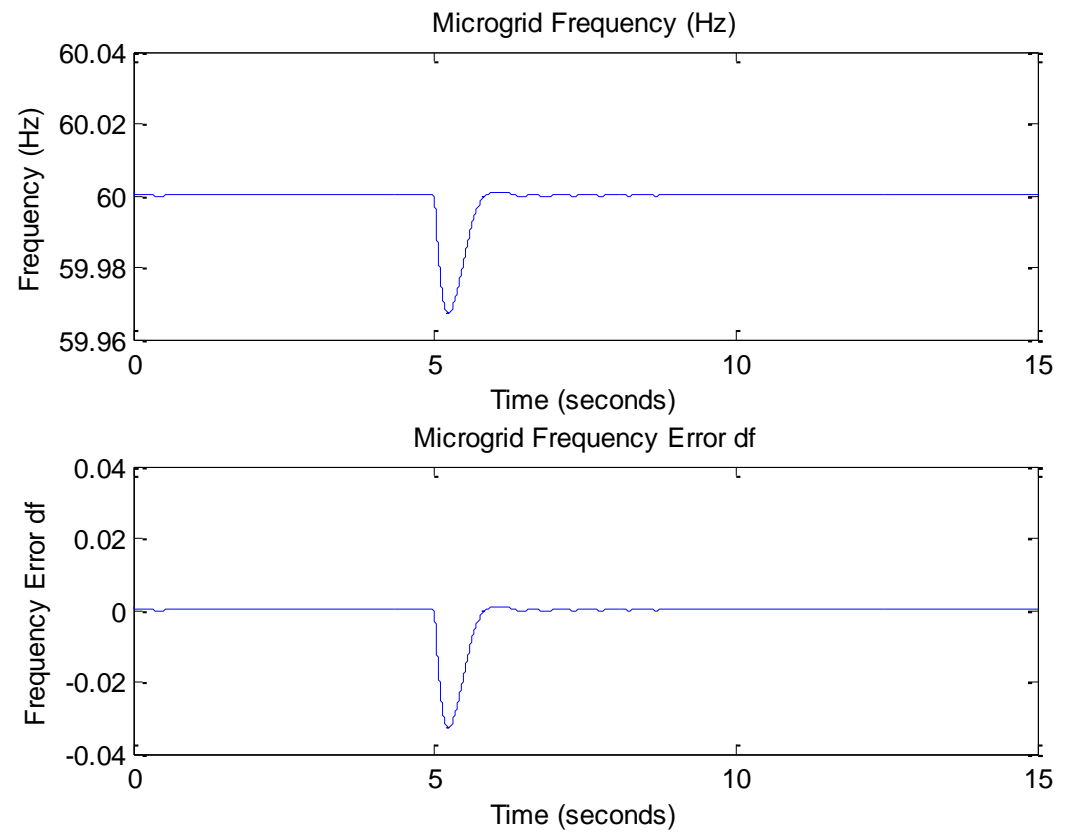

Figure 5.10: Microgrid Frequency and $\operatorname{ACE}(\Delta f)$.
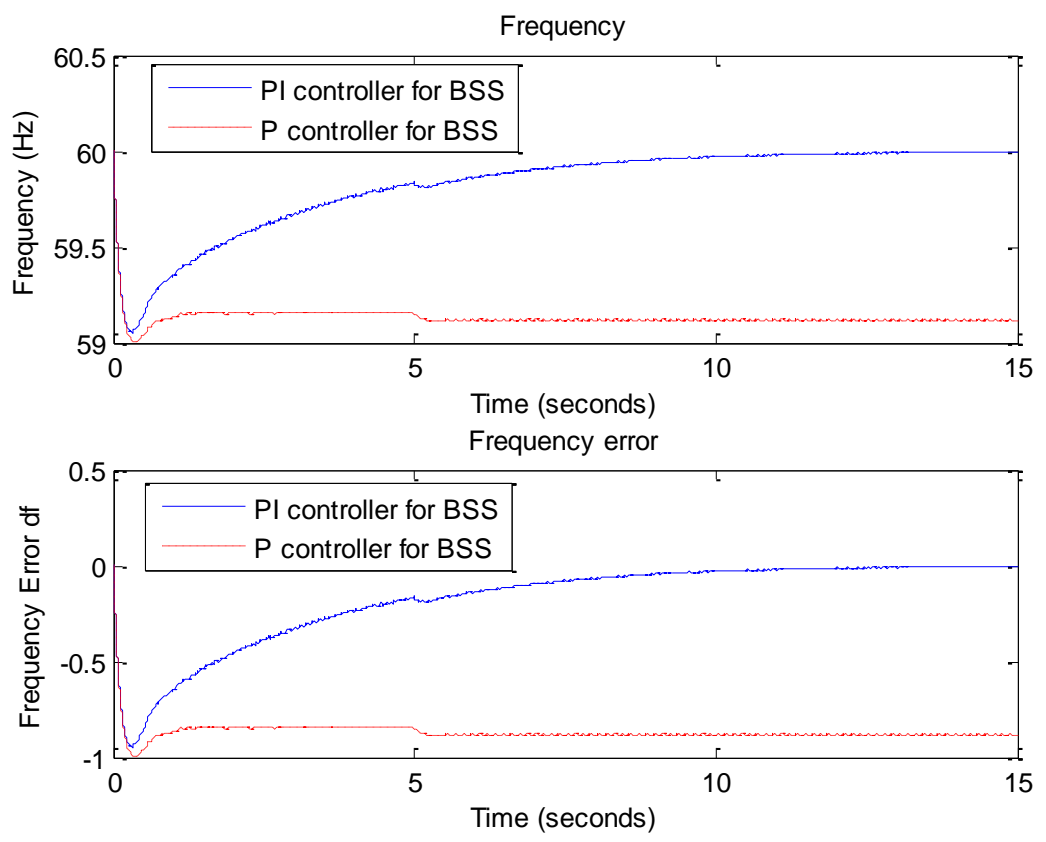

Figure 5.11: Microgrid Frequency and $\operatorname{ACE}(\Delta f)$ when P and PI controller used in BSS control system. 


\subsubsection{Loss of 20 KVA Diesel Generator}

In this scenario the circuit breaker connecting the $20 \mathrm{KVA}$ diesel generator to the microgrid will tripp at time $t=10.2$ seconds. The purpose of this scenario is to see how the battery unit will respond when the smaller DG is lost. Figure 5.12 shows the power produced from the battery system and the power generated from diesel generators. From figure 5.12 it is clear that the battery system power settled at zero till the occurrence of the fault while the power generated from the $100 \mathrm{KVA}$ generator was almost $100 \mathrm{KW}$ and the power generated from the $20 \mathrm{KVA}$ generator was about $18 \mathrm{KW}$. After the 20 KVA generator was isolated, the battery power increased from 0 to $18 \mathrm{KW}$. Clearly the battery inverter control system responded to the frequency error signal and increased the power discharged from the battery unit to the same amount that was generated by the lost generator. At time $\mathrm{t}=20$ seconds the first PV system was connected to the microgrid. At time $t=25$ seconds the other PV system was connected. As a result, the power generated from the $100 \mathrm{KVA}$ generator was reduced at the corresponding time instants. The microgrid frequency and frequency error were restored to the desired values $(60 \mathrm{~Hz}$ frequency and zero frequency error) at all time. Figure 5.13 shows the microgrid frequency and frequency error with and without the BSS.

Figure 5.14 shows the frequency and the frequency error more clearly when the BSS is available. Figure 5.15 shows the power injected by the PV systems into the microgrid.
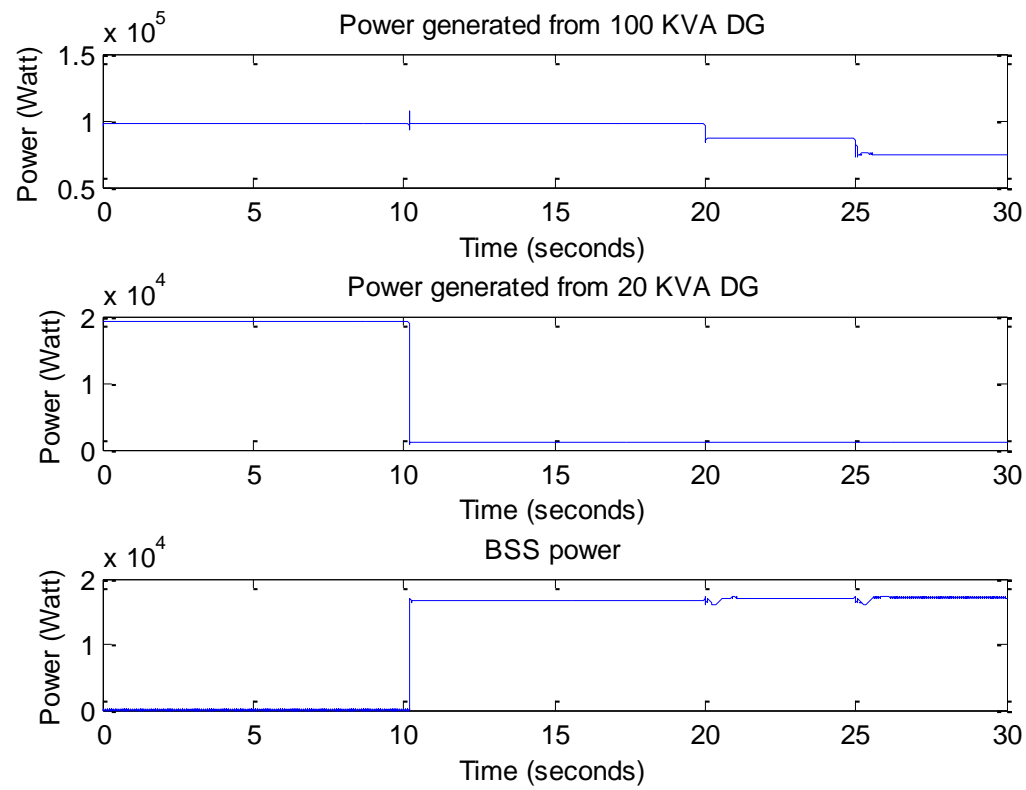

Figure 5.12: Power produced from battery system and diesel generators. 


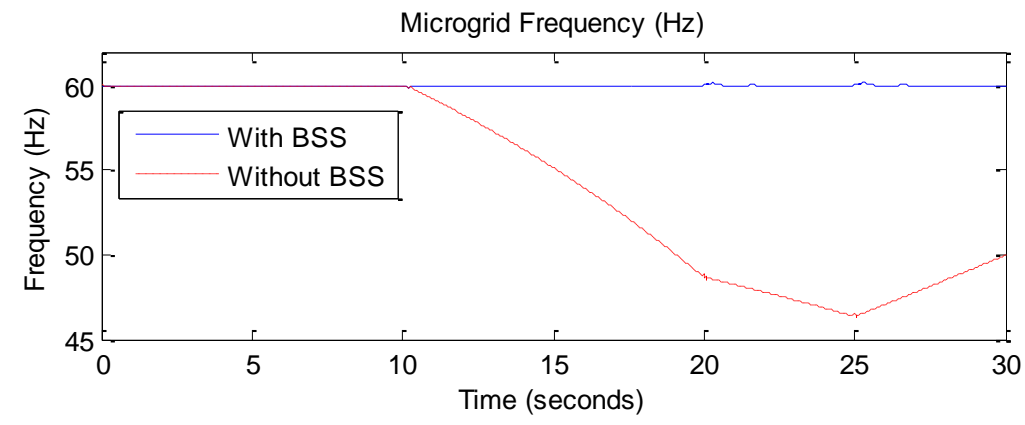

Microgrid Frequency Error df

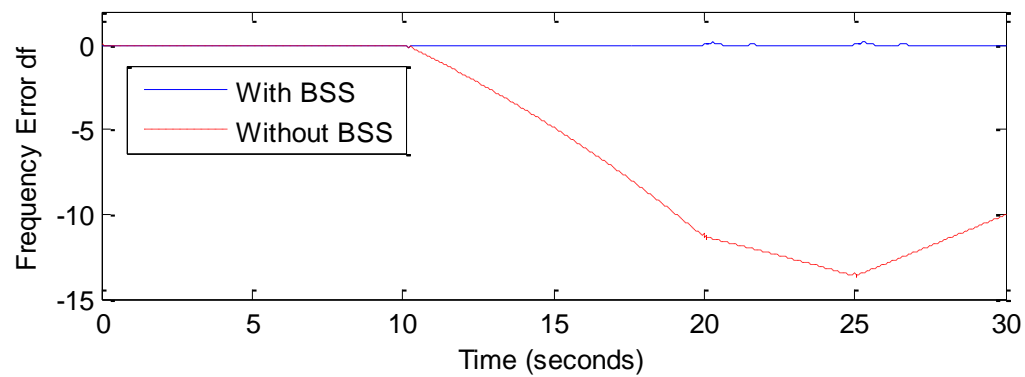

Figure 5.13: Microgrid frequency and ACE for second scenario with and without BSS

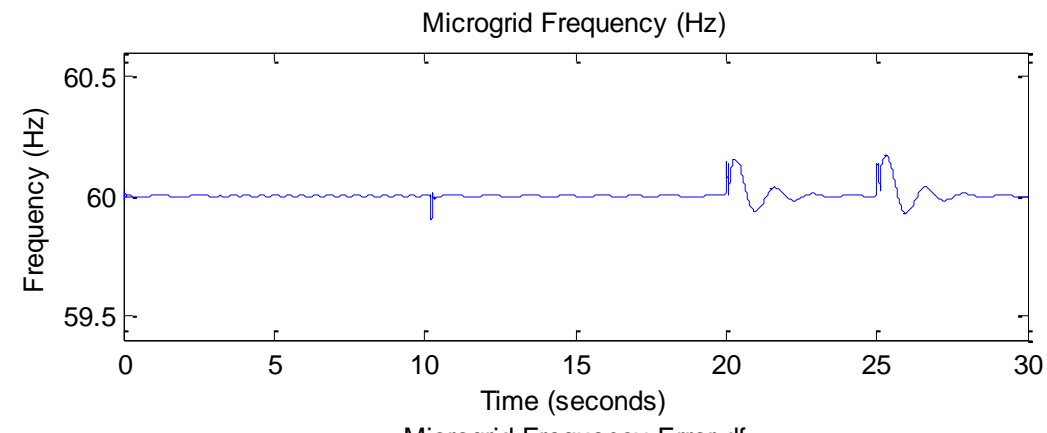

Microgrid Frequency Error df

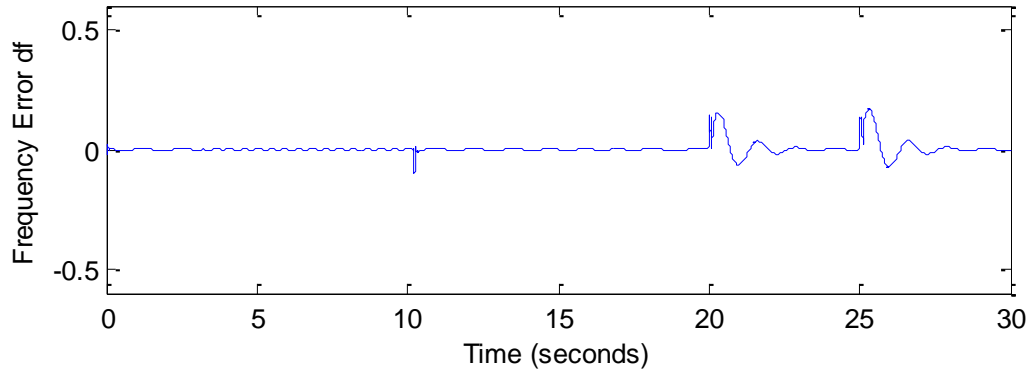

Figure 5.14: Microgrid frequency and ACE 

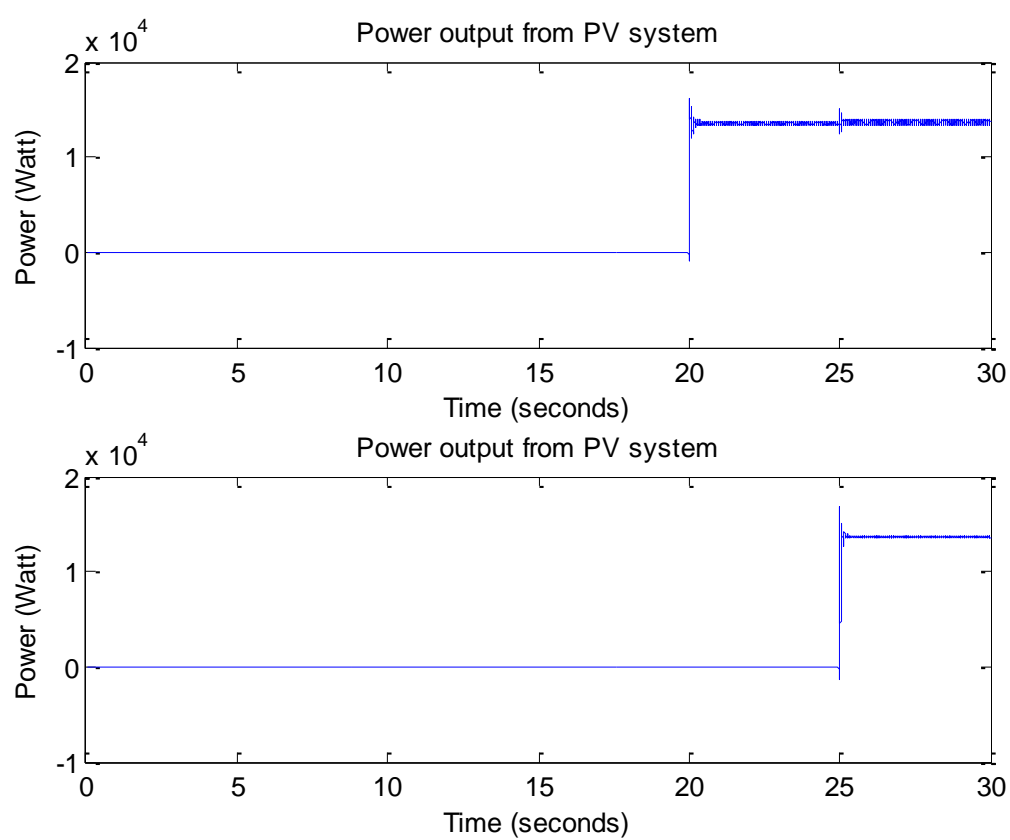

Figure 5.15: Power produced from PV systems.

\subsubsection{Loss of 100 KVA Diesel Generator}

This is considered the most severe scenario the microgrid system could experience as the system will suddenly lose its primary generation unit. In this scenario the circuit breaker connecting the generator to the microgrid system will tripp at time $t=10.2$ seconds. Also, the PV systems are initially disconnected from the grid, and they are connected to the grid each at a different time. To illustrate the significance of the contribution of the battery system in LFC, the microgrid frequency when the battery unit is available is compared with the frequency when the battery system is not available. Figure 5.16 shows the microgrid frequency and ACE when the battery unit is available. Figure 5.17 illustrates the significance of the battery unit contribution in LFC by comparing the microgrid frequency when the battery unit is available and when it is not available. Figure 5.18 shows the power produced from the battery system and the power generated from the diesel generators. 


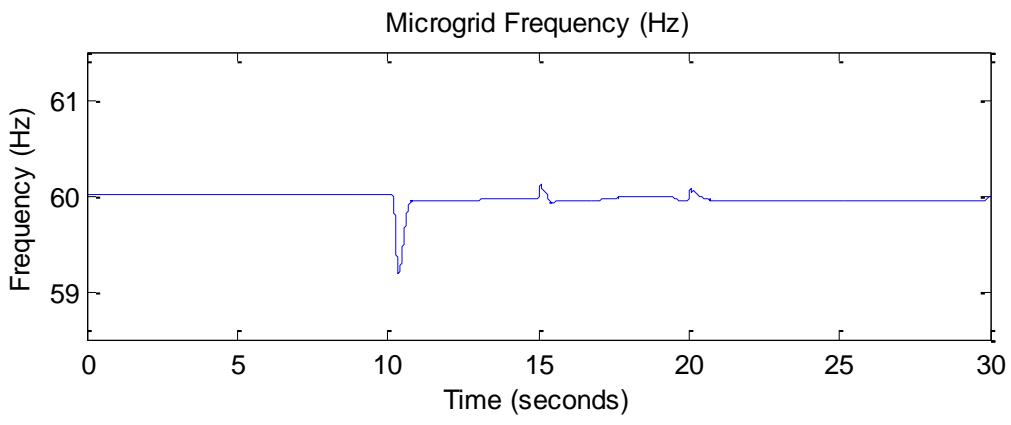

Microgrid Frequency Error df

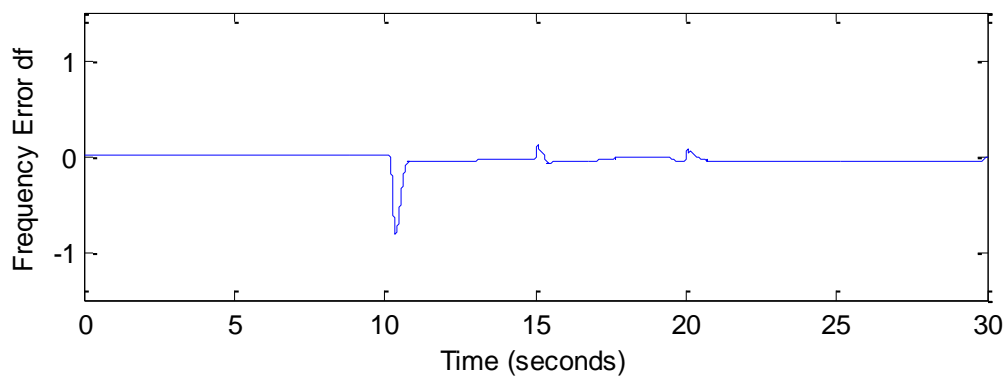

Figure 5.16: Microgrid frequency and ACE when battery unit available.

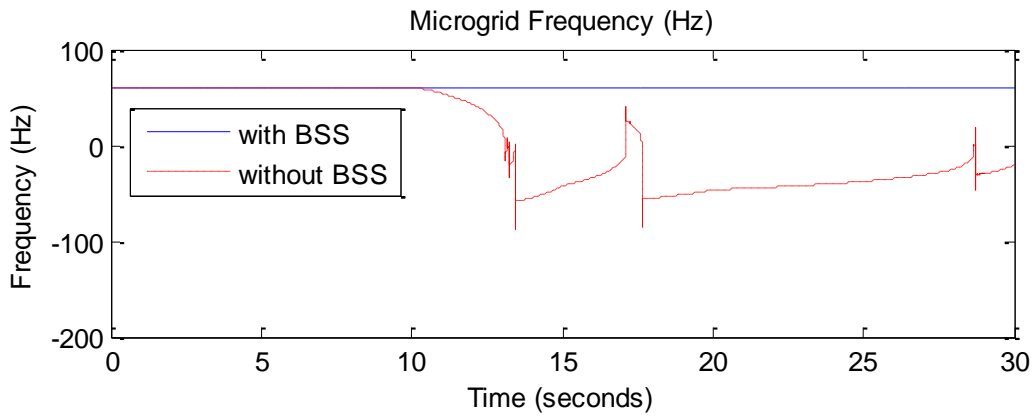

Microgrid Frequency Error df

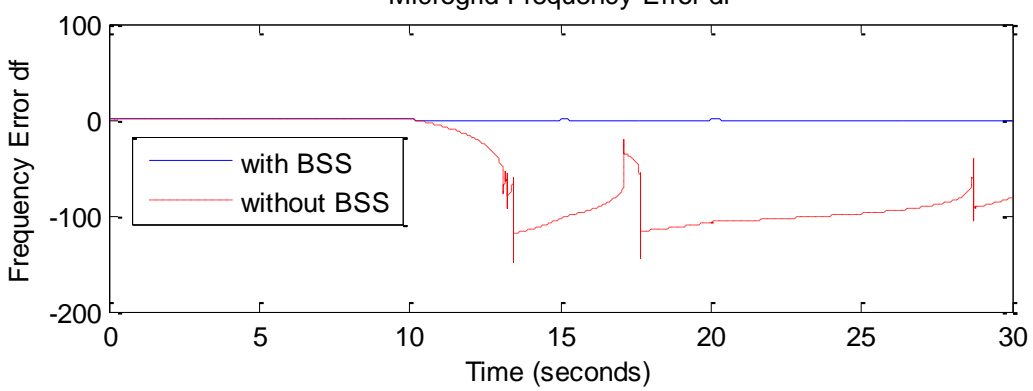

Figure 5.17: Microgrid frequency and ACE with and without the battery unit. 

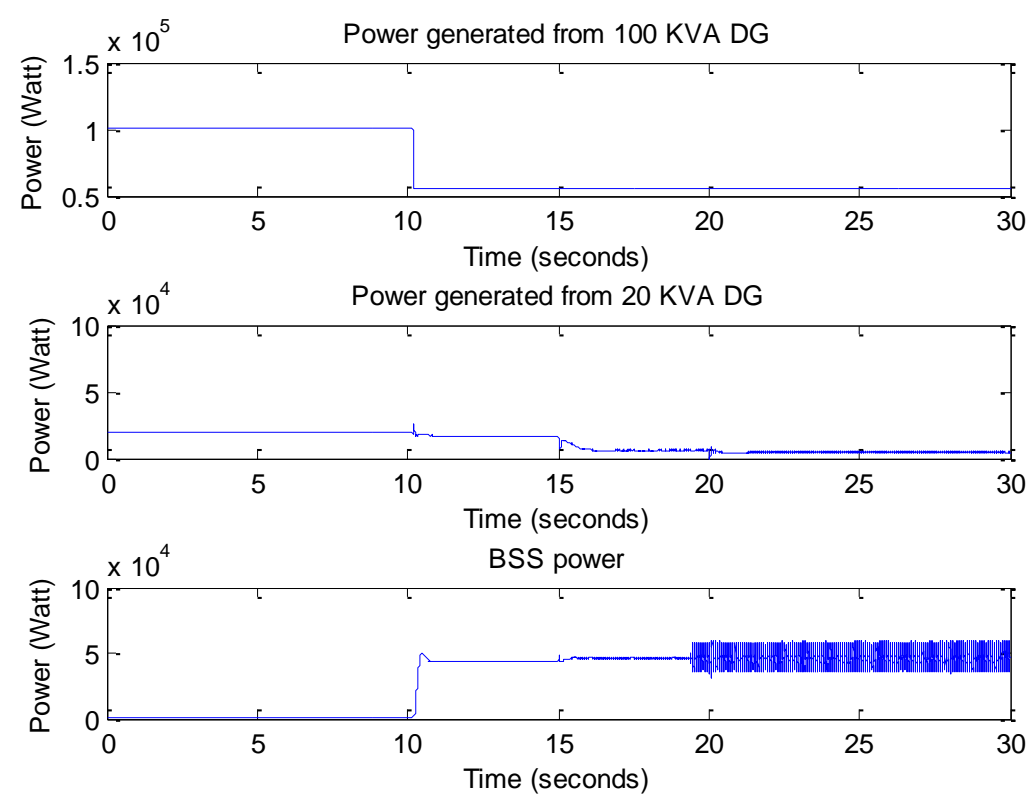

Figure 5.18: Power Generated from diesel generator, and Battery system.

From these figures, initially the $100 \mathrm{KVA}$ diesel generator is supplying its full generation capacity $(100 \mathrm{KW})$. The generator is supplying a $50 \mathrm{KW}$ load at its bus, and injecting $50 \mathrm{KW}$ into the microgrid system. At time 10.2 seconds, the $100 \mathrm{KVA}$ generator and the $50 \mathrm{KW}$ load were isolated from the system. The effect of isolating the generator on the frequency is visible in figure 5.16. At that instant, it is clear in figure 5.18 that the battery control system responded to the change in system's frequency and increased the active power injected by the battery unit to $50 \mathrm{KW}$ (i.e. to compensate for the amount of power that was injected by the $100 \mathrm{KVA}$ generator in the system), and the frequency was restored back to the scheduled value $(60 \mathrm{~Hz})$, and the frequency error was restored back to zero.

At time $\mathrm{t}=15$ seconds, the first PV system was connected to the microgrid. As a result, the power generated from the $20 \mathrm{KVA}$ generator dropped to $12 \mathrm{KW}$. At time $\mathrm{t}=$ 20 seconds, the other PV system was connected and the power from the generator dropped to $8 \mathrm{KW}$. Figure 5.19 shows the power produced by each of the PV systems injected into the microgrid. 

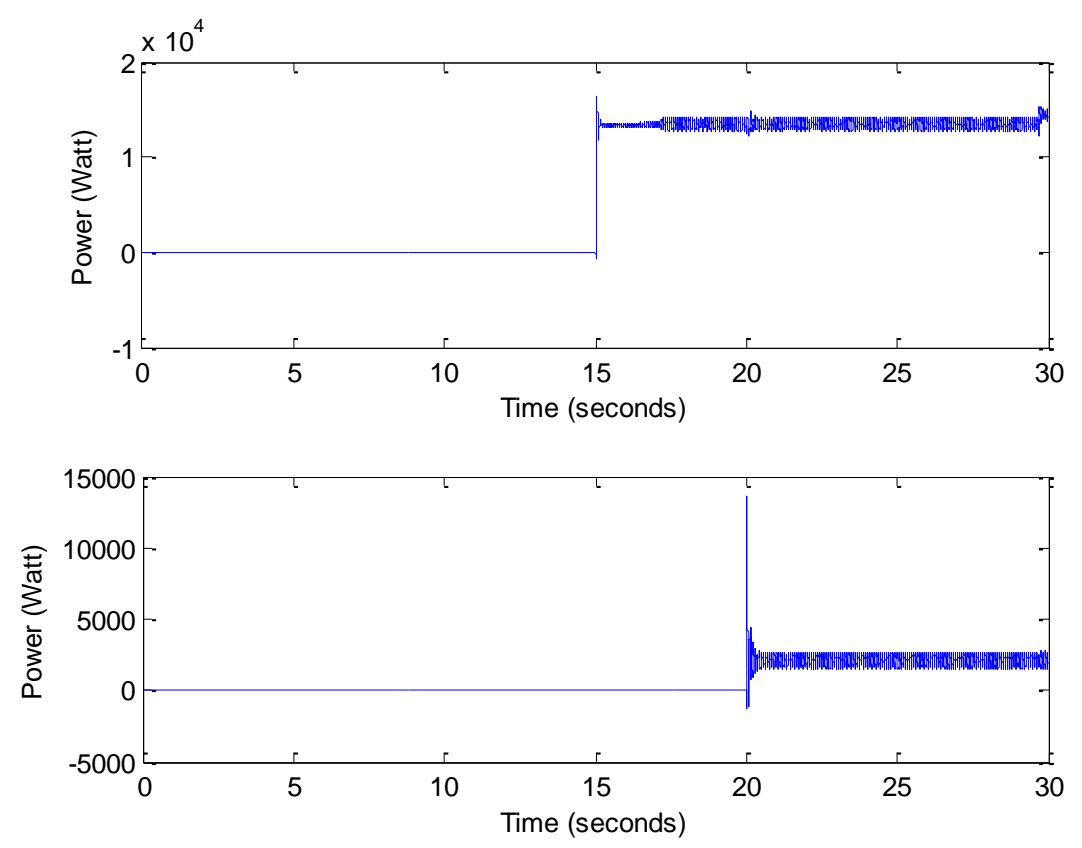

Figure 5.19: Power produced from PV systems.

From figure 5.19, the powers produced from the two PV systems are not equal. This is due the irradiance level input to the first PV system is set to $1000 \mathrm{~W} / \mathrm{m}^{2}$, while it is set to $200 \mathrm{~W} / \mathrm{m}^{2}$ to the other PV system. The reason for setting to two different values of irradiances is to investigate the effect of changing the irradiance level on the power injected into the microgrid. However, since this study focuses on LFC that is usually investigated in a time range of seconds, there is a good reason to assume constant irradiance level for both PV systems since the level of sunlight reaching the PVs usually changes on an hourly basis. 


\section{CONCLUSION}

Microgrids are small power grids. They can operate either independently or connected to larger grids. Microgrids are proliferating worldwide due to several advantages they bring such as increased system reliability, and deferring investments in transmission and distribution networks. Power systems, in general, are subject to different kinds of disturbances; fluctuating power demand, intermittent power coming from renewable energy resources such PV and wind generations, and unexpected events such as losing one of the system's generation units. Such disturbances will result in deviation of the system's frequency from its nominal value. In order to attain stable operation of a power system the system's frequency must be restored back to its nominal value or maintained within acceptable limits around the nominal value after the occurrence of a disturbance as soon as possible. The control mechanism responsible for controlling the system's frequency or maintaining a balance between generation and demand is known as Load Frequency Control (LFC) mechanism. Attaining a real-time balance between generation and demand in a small and isolated microgrid system, however, is an issue of much greater significance than in the case of large grids. Microgrids, especially the isolated from primary grids, will require new and robust LFC mechanisms to ensure stable operation under all operation circumstances.

Energy Storage Systems (ESSs) are integrated in power grids in order to provide several services such as peak-demand shifting and load leveling. Battery Storage Systems (BSSs) are amongst the very popular energy storage technologies due to their wide range of sizes, not limited by topography, and bi-directional power flow capabilities. Hence, they are an excellent candidate for LFC service.

This thesis focused on implementing a LFC mechanism in an isolated microgrid system comprised from two diesel generators (one is 100KVA, and the other is $20 \mathrm{KVA}$ ), two PV systems (14.8 KW each), and a $30 \mathrm{Kwh}$ battery storage unit. The contribution of the proposed mechanism is the development of a control system to control the power flow of the battery system inverter. The proposed control system tracks the system's frequency deviations and controls the amount of power injected or absorbed by the battery unit to regulate these deviations. The LFC mechanism also entailed two local control systems for each of the two diesel units. These are designed to regulate the generators speeds i.e. to maintain the speeds at the desired reference values. The proposed LFC mechanism is implemented in a decentralized fashion. 
The control systems were tested under three different scenarios; the first scenario represented the normal operation of a power system where the demand is continually fluctuating, the second scenario the $20 \mathrm{KVA}$ generator was lost, and the third scenario the 100 KVA generator was lost, which is considered the most severe situation as the microgrid lost it primary generation unit. Results showed that the developed controls were successful in maintaining the system's frequency within acceptable limits in the first scenario, and restoring the system's frequency back to the nominal value of $60 \mathrm{~Hz}$ in the second and third scenario. Issues like voltage regulation, and optimal economic operation were out of scope in this study. The microgrid model as well as the control systems was developed in the Simulink/SimPowerSystems environment. 


\section{REFERENCES}

[1] S. P. Chowdhury, P. Crossley, "Microgrids and Active Distribution Networks". London, United Kingdom: The Institution of Engineering and Technology, 2009.

[2] A. Niinistö, "Simulation of the Management of a Micro Grid with Wind, Solar and Gas Generators," Master's Thesis, Automation and Systems Technology, Aalto University School of Science and Technology, Faculty of Electronics, Communications and Automation, Espoo, 2009.

[3] F. Katiraei, R. Iravani, N. Hatziargyriou, and A. Dimeas, "Microgrids management," Power and Energy Magazine, IEEE, vol. 6, pp. 54-65, 2008.

[4] G. M. Cook, W. C. Spindler, and G. Grefe, "Overview of Battery Power Regulation and Storage," Power Engineering Review, IEEE, vol. 11, p. 48, 1991.

[5] H. L. A. Ralph Masiello, Frederick Butler, Richard Cowart, Roger Duncan, Robert Gramlich, Brad Roberts, Wanda Reder, Mike Weedall, Brian Wynne, and David Meyer, "Energy storage Activities in the United States Electricity Grid," 2011.

http://www.oe.energy.gov/DocumentsandMedia/FINAL_DOE_Report-

Storage_Activities_5-1-11.pdf

[6] D. Kottick, M. Blau, and D. Edelstein, "Battery energy storage for frequency regulation in an island power system," Energy Conversion, IEEE Transactions on, vol. 8, pp. 455-459, 1993.

[7] A. Oudalov, T. Buehler, and D. Chartouni, "Utility Scale Applications of Energy Storage," in Energy 2030 Conference, 2008. ENERGY 2008. IEEE, 2008, pp. 1-7.

[8] P. Mercier, R. Cherkaoui, and A. Oudalov, "Optimizing a Battery Energy Storage System for Frequency Control Application in an Isolated Power System," Power Systems, IEEE Transactions on, vol. 24, pp. 1469-1477, 2009.

[9] M. E. Robert Lasseter, "Integration of Battery-Based Energy Storage Element in the CERTS Microgrid," University of Wisconsin-MadisonOct 27, 2009.

[10] D. Sutanto, "Power management solutions for energy management, power quality and environment using battery energy storage systems," in Power Electronics and Drive Systems, 1999. PEDS '99. Proceedings of the IEEE 1999 International Conference on, 1999, p. 15 vol.1. 
[11] F. E. R. Commission, "Frequency Regulation Compensation in the Organized Wholesale Power Markets," USAFebruary 17, 20112011.

[12] L. D. Watson and J. W. Kimball, "Frequency regulation of a microgrid using solar power," in Applied Power Electronics Conference and Exposition (APEC), 2011 Twenty-Sixth Annual IEEE, 2011, pp. 321-326.

[13] V. A. K. Pappu, B. H. Chowdhury, and R. Bhatt, "Implementing frequency regulation capability in a solar photovoltaic power plant," in North American Power Symposium (NAPS), 2010, 2010, pp. 1-6.

[14] K. M. Brokish, "Adaptive load control of microgrids with non-dispatchable generation," Massachusetts Institute of Technology. Dept. of Electrical Engineering and Computer Science, Massachusetts Institute of Technology, 2009.

[15] Oudalov, A.; Chartouni, D.; Ohler, C.; , "Optimizing a Battery Energy Storage System for Primary Frequency Control," Power Systems, IEEE Transactions on, vol.22, no.3, pp.1259-1266, Aug. 2007

[16] H. J. Kunisch, K. G. Kramer, and H. Dominik, "Battery Energy Storage Another Option for Load-Frequency-Control and Instantaneous Reserve," Energy Conversion, IEEE Transactions on, vol. EC-1, pp. 41-46, 1986.

[17] Papic, I.; , "Simulation model for discharging a lead-acid battery energy storage system for load leveling," Power Engineering Society General Meeting, 2006. IEEE , vol., no., pp.1 pp., 0-0 0

[18] N. Mendis, K. M. Muttaqi, S. Sayeef, and S. Perera, "Control coordination of a wind turbine generator and a battery storage unit in a Remote Area Power Supply system," in Power and Energy Society General Meeting, 2010 IEEE, 2010, pp. 17.

[19] R. Saupe, "The power conditioning system for the +/-8,5/17 MW-energy storage plant of BEWAG," in Power Electronics and Variable-Speed Drives, Third International Conference on, 1988, pp. 218-220.

[20] T. Sasaki, T. Kadoya, and K. Enomoto, "Study on load frequency control using Redox flow batteries," in Power Engineering Society General Meeting, 2004. IEEE, 2004, p. 580 Vol.1.

[21] C. M. a. J. P. L. A. Madureira, "Secondary Load-Frequency Control for MicroGrids in Islanded Operation." Faculdade de Engenharia da UP and Power Systems Unit of INESC Rua Dr. Roberto Frias, 378, 4200-465 Porto, Portugal. Available at http://www.icrepq.com/full-paper-icrep/335-madureira.pdf 
[22] H. N. K. Faisal A. Mohamed, "System Modeling and Online Optimal Management of Microgrid with Battery Storage" presented at the icrepq, 2008. Available at http://www.icrepq.com/icrepq07/220-faisal.pdf

[23] F. A. Mohamed, "Microgrid Modelling and Online Management," Doctor of Science in Technology, Department of Automation and Systems Technology, Helsinki University of Technology, Finland, 2008. Available at http://lib.tkk.fi/Diss/2008/isbn9789512292356/isbn9789512292356.pdf

[24] R. Majumder, "MODELING, STABILITY ANALYSIS AND CONTROL OF MICROGRID," Doctor of Philosophy Dissertation, Faculty of Build and Environment Engineering, Queensland University of Technology, Queensland, Australia, 2010.

[25] A. Karlis and P. Dokopoulos, "Small power systems fed by hydro, photovoltaic, wind turbines and diesel generators," in Electronics, Circuits, and Systems, 1996. ICECS '96., Proceedings of the Third IEEE International Conference on, 1996, pp. 1013-1016 vol.2.

[26] O. Leitermann and J. L. Kirtley, "Energy storage for use in load frequency control," in Innovative Technologies for an Efficient and Reliable Electricity Supply (CITRES), 2010 IEEE Conference on, 2010, pp. 292-296.

[27] G. S. Stavrakakis and G. N. Kariniotakis, "A general simulation algorithm for the accurate assessment of isolated diesel-wind turbines systems interaction. I. A general multimachine power system model," Energy Conversion, IEEE Transactions on, vol. 10, pp. 577-583, 1995.

[28] S. Roy, O. P. Malik, and G. S. Hope, "An adaptive control scheme for speed control of diesel driven power-plants," Energy Conversion, IEEE Transactions on, vol. 6, pp. 605-611, 1991.

[29] R. Mukund. Wind and solar power systems. CRC Press, CRC Press LLC, 2000 N.W.,

Corporate Blvd., Boca Raton, Florida 33431, 1999.

[30] M. G. Molina and P. E. Mercado, "Modeling and control of grid-connected photovoltaic energy conversion system used as a dispersed generator," in Transmission and Distribution Conference and Exposition: Latin America, 2008 IEEE/PES, 2008, pp. 1-8.

[31] Mathworks. (2012). Solar Available: http://www.mathworks.com/help/toolbox/physmod/elec/ref/solarcell.html

[32] T. Esram and P. L. Chapman, "Comparison of Photovoltaic Array Maximum Power Point Tracking Techniques," Energy Conversion, IEEE Transactions on, vol. 22, pp. 439-449, 2007. 
[33] O. Erdinc, B. Vural, and M. Uzunoglu, "A dynamic lithium-ion battery model considering the effects of temperature and capacity fading," in Clean Electrical Power, 2009 International Conference on, 2009, pp. 383-386.

[34] C. Min and G. A. Rincon-Mora, "Accurate electrical battery model capable of predicting runtime and I-V performance," Energy Conversion, IEEE Transactions on, vol. 21, pp. 504-511, 2006.

[35] Mathworks. (2012). Battery. Available: http://www.mathworks.com/help/toolbox/physmod/powersys/ref/battery.html

[36] M. Morari, J.H. Lee, C.E. Garcia and D.M. Prett, "Model Predictive Control", to be published by Prentice Hall, 2003.

[37] N. z. Ati', "Model Predictive Control Design for Load Frequency Control Problem," Master of Science in Electrical Engineering, Lane Department of Computer Science and Electrical Engineering, College of Engineering and Mineral Resources at West Virginia University, Morgantown, West Virginia, 2003.

[38] Mathworks. (2009). Introduction to Model Predictive Control Toolbox. Available: http://www.mathworks.com/company/events/webinars/wbnr32784.html?id=3278 4\&p1=493937496\&p2=493937514

[39] Mathworks. (2012). R2012a Documentation - Simulink Control Design frestimate. Available: http://www.mathworks.com/help/toolbox/slcontrol/ug/frestimate.html.

[40] Mathworks. (2012). Simulink Control Design - Designing PID Controller in Simulink with Estimated Frequency Response. Available: http://www.mathworks.com/products/simcontrol/demos.html?file=/products/dem os/shipping/slcontrol/scdenginectrlpidpad.html.

[41] A. Baggini, Handbook of Power Quality: John Wiley \& Sons, 2008. The Atrium, Southern Gate, Chichester, West Sussex PO19 8SQ, England, ISBN10:0470754230, Pages: 642.

[42] A. Yasin, G. Napoli, M. Ferraro and V. Antonucci, 2011. Modelling and Control of a Residential Wind/PV/Battery Hybrid Power System with Performance Analysis. Journal of Applied Sciences, 11: 3663- 3676. 


\section{Appendix A}

\section{SIMULINK AND SIMPOWERSYSTEMS MODELS}

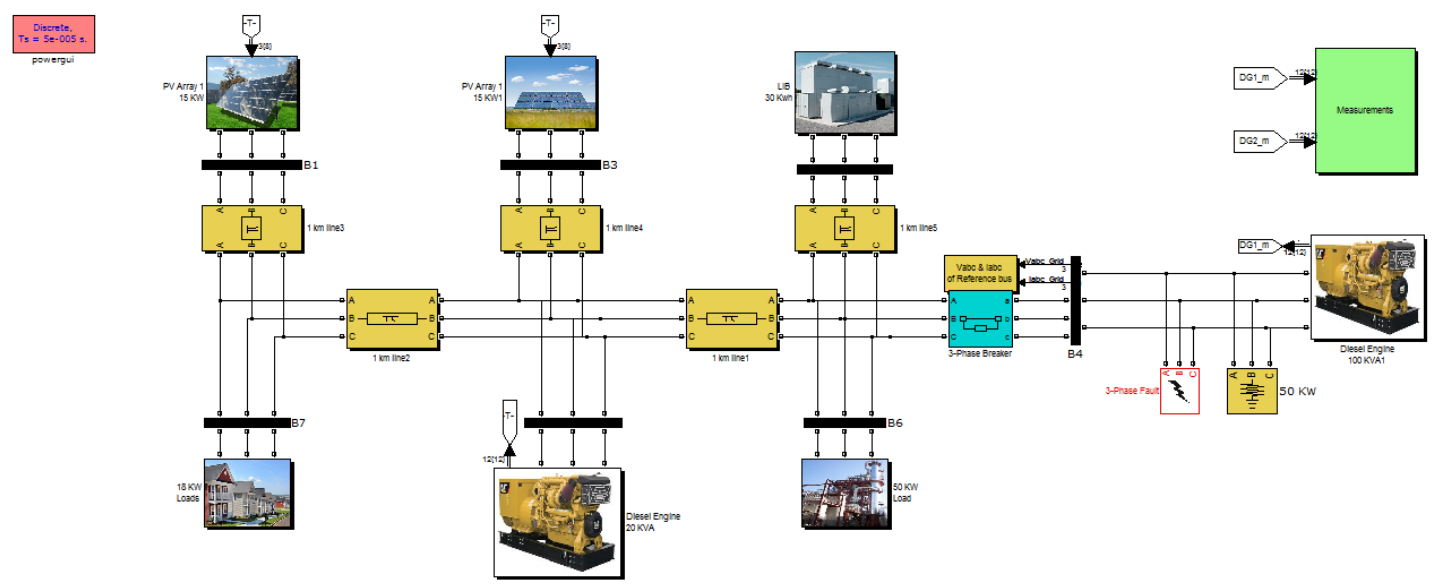

A.1: Microgrid system model.

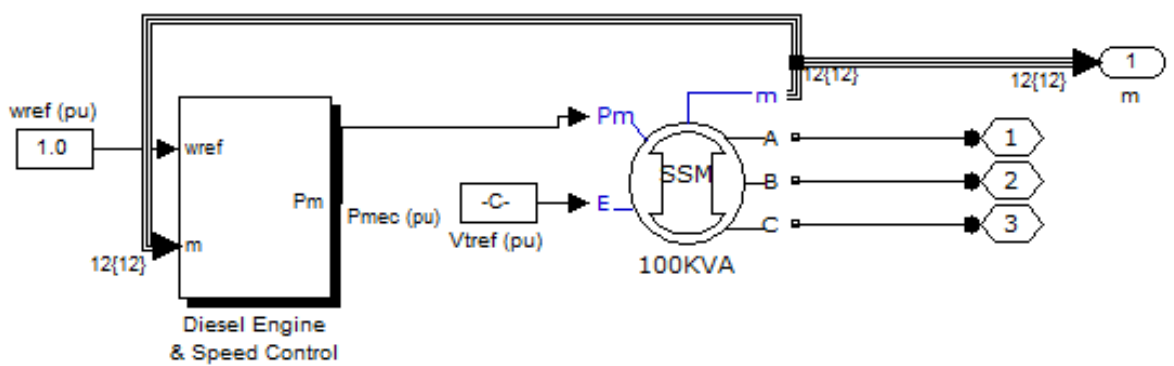

A.2: Inside the Diesel Engine block. 


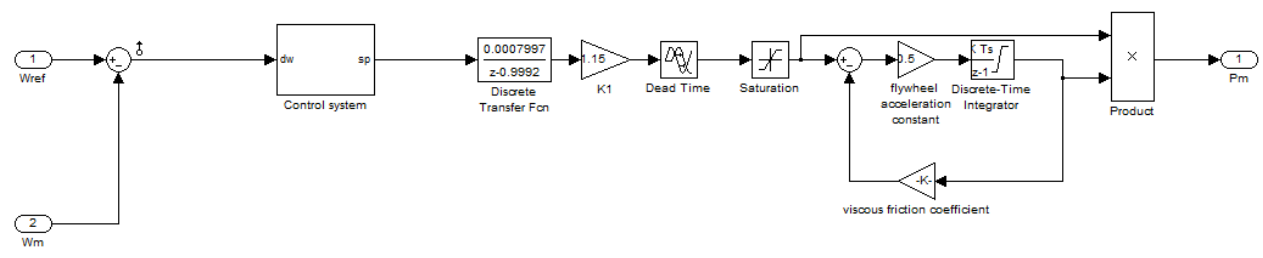

A.3: Inside Diesel Engine \& Speed Control block.

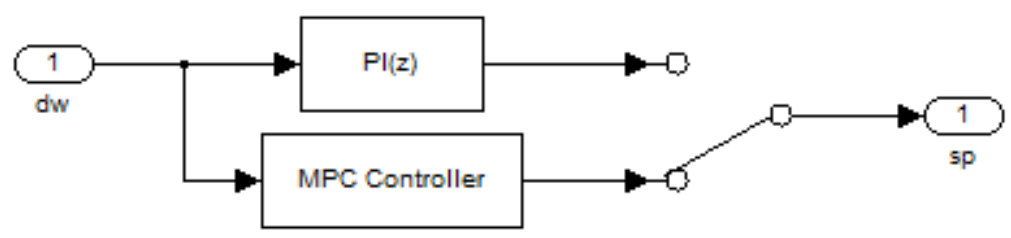

A.4: Inside Control System block.

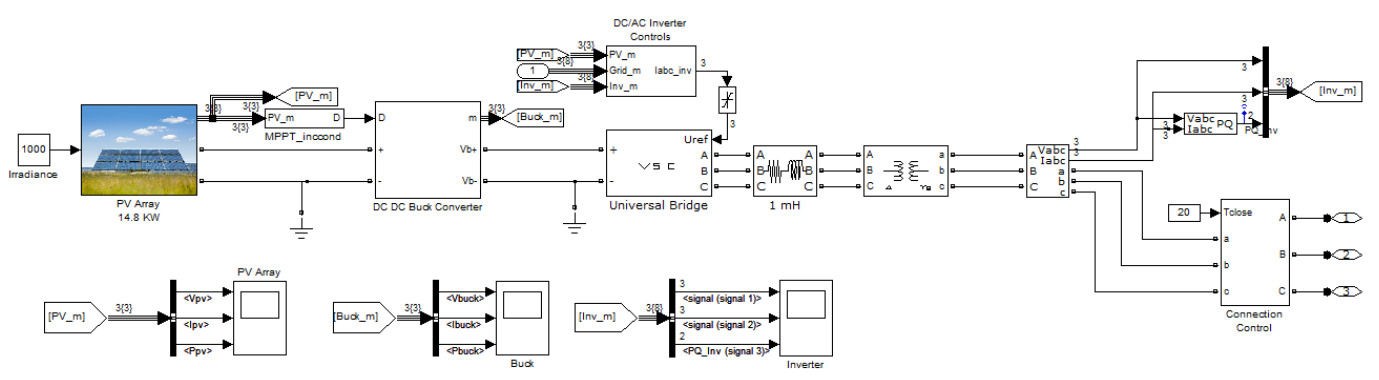

A.5: Grid-connected PV system. 


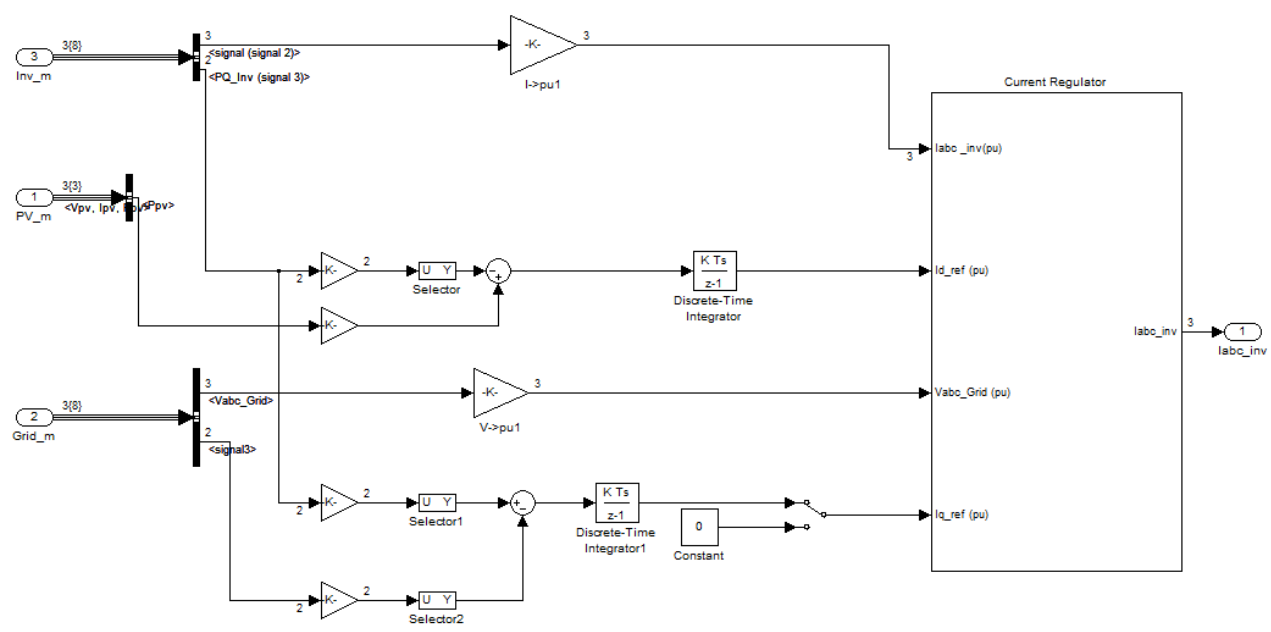

A.6: Inside DC/AC inverter controls block.

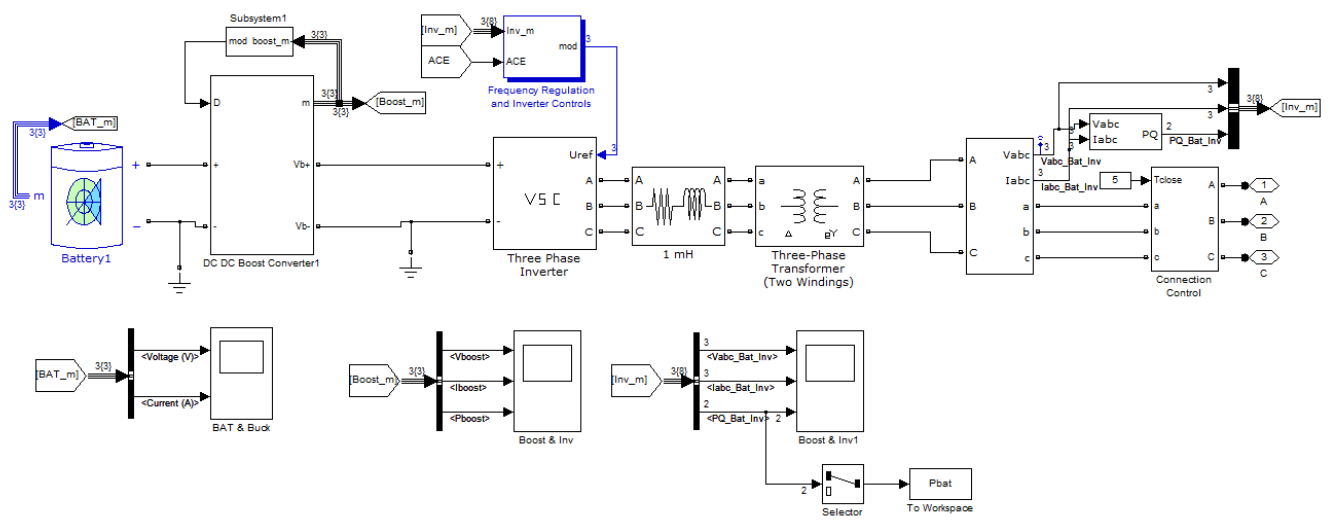

A.7: Grid-connected Battery system. 


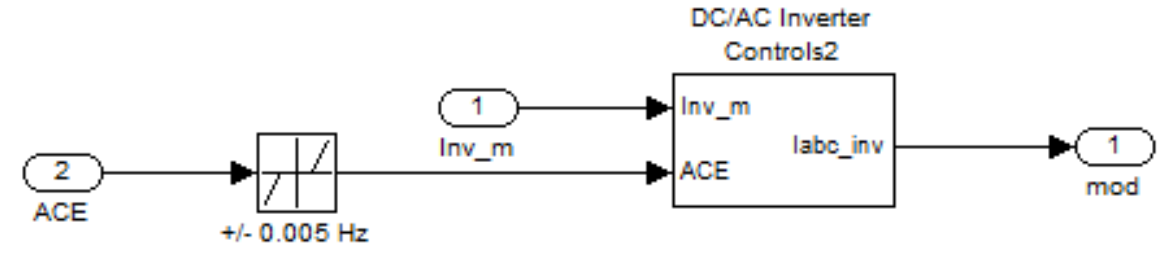

A.8: Inside the Frequency Regulation and Inverter Controls block.

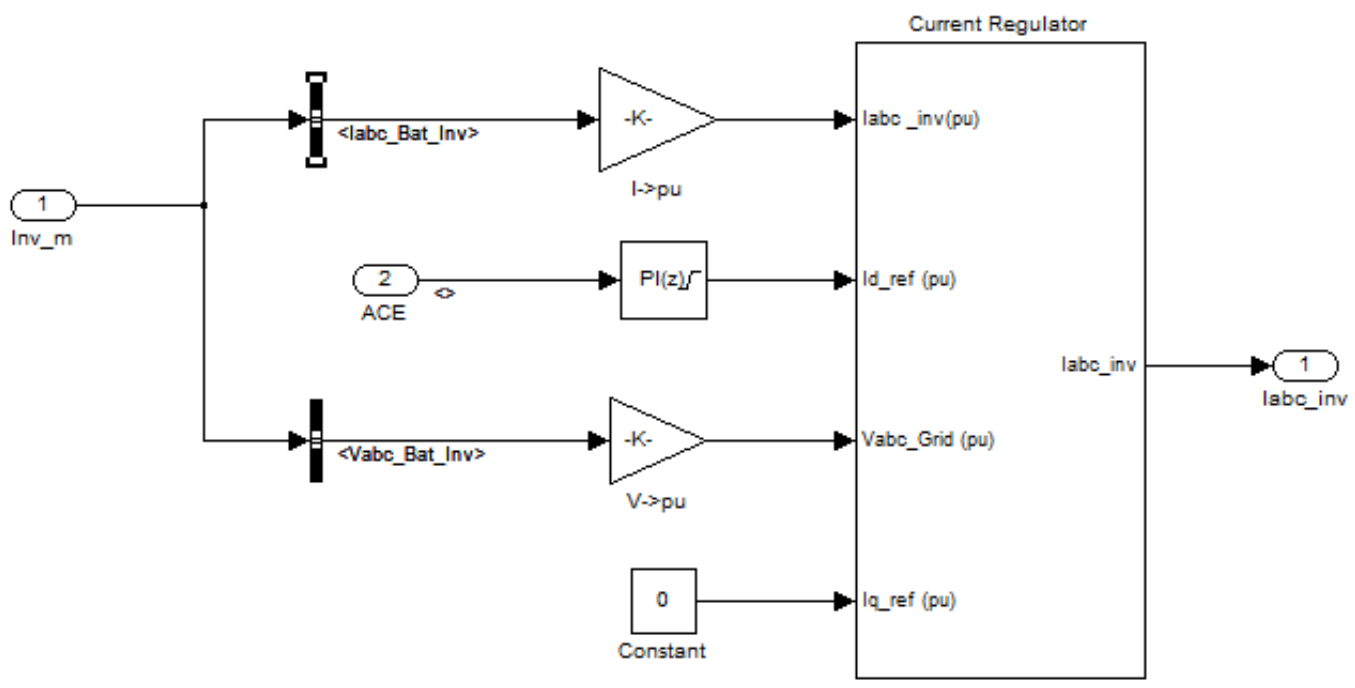

A.9: Inside the DC/AC Inverter Control2 block.

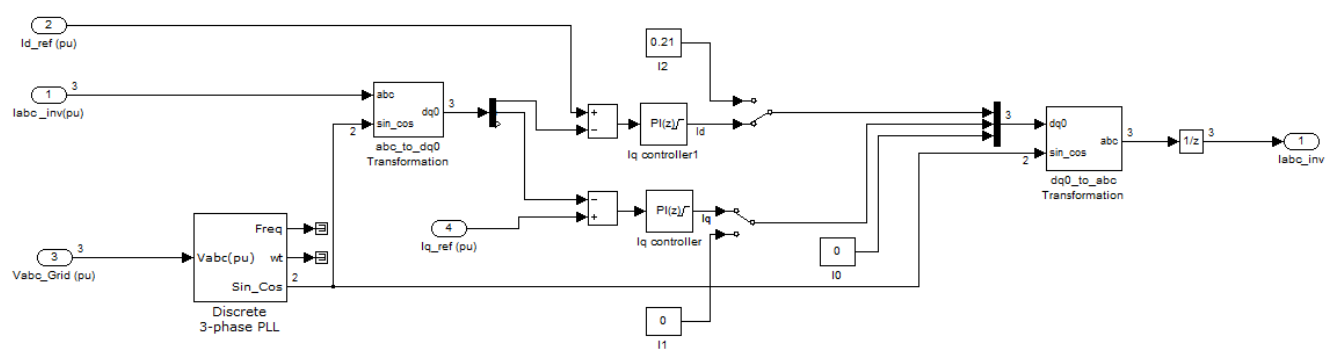

A.10: Inside Current Regulator block. 